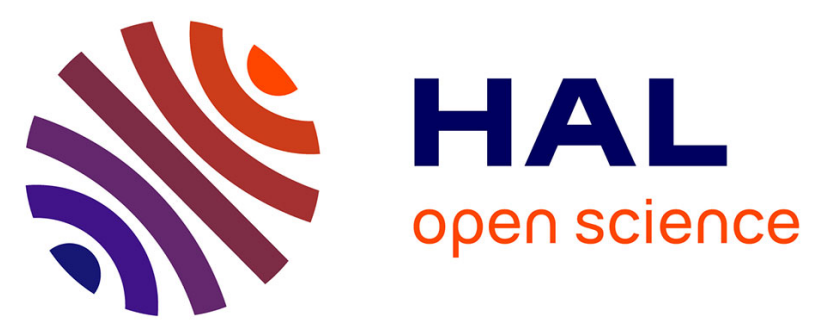

\title{
New DMAP meso-arylporphyrin Magnesium(II) complex. Spectroscopic, Cyclic voltammetry and X-ray molecular structure characterization. DFT, DOS and MEP calculations and Antioxidant and Antifungal activities
}

T. Fradi, O. Noureddine, F.B. Taheur, M. Guergueb, S. Nasri, N. Amiri, A. Almahri, Thierry Roisnel, Vincent Guerineau, N. Issoui, et al.

\section{To cite this version:}

T. Fradi, O. Noureddine, F.B. Taheur, M. Guergueb, S. Nasri, et al.. New DMAP meso-arylporphyrin Magnesium(II) complex. Spectroscopic, Cyclic voltammetry and X-ray molecular structure characterization. DFT, DOS and MEP calculations and Antioxidant and Antifungal activities. Journal of Molecular Structure, 2021, 1236, pp.130299. 10.1016/j.molstruc.2021.130299 . hal-03196135

\author{
HAL Id: hal-03196135 \\ https://hal.science/hal-03196135
}

Submitted on 21 Apr 2021

HAL is a multi-disciplinary open access archive for the deposit and dissemination of scientific research documents, whether they are published or not. The documents may come from teaching and research institutions in France or abroad, or from public or private research centers.
L'archive ouverte pluridisciplinaire HAL, est destinée au dépôt et à la diffusion de documents scientifiques de niveau recherche, publiés ou non, émanant des établissements d'enseignement et de recherche français ou étrangers, des laboratoires publics ou privés. 


\title{
New DMAP meso-arylporphyrin Magnesium(II) complex. Spectroscopic, Cyclic voltammetry and X-ray molecular structure characterization. DFT, DOS and MEP calculations and Antioxidant and Antifungal activities
}

\author{
Taissir Fradi ${ }^{a}$, Olfa Noureddine ${ }^{b}$, Fadia Ben Taheur $^{c}$, Mouhieddinne Guergueb ${ }^{a}$, Soumaya \\ Nasri $^{a}$, Nesrine Amiri ${ }^{a}$, Albandary Almahri ${ }^{d}$, Thierry Roisnel ${ }^{e}$, Vincent Guerineau ${ }^{f}$, Noureddine \\ Issoui $^{b}$, Habib Nasri ${ }^{a, *}$
}

${ }^{a}$ : University of Monastir, Laboratory of Physico-chemistry of Materials LR01ES19, Faculty of Sciences of Monastir, Avenue de l'environnement, 5019 Monastir, Tunisia.

${ }^{b}$ : University of Monastir, Laboratory of Quantum and Statistical Physics LR18ES18, Faculty of Sciences of Monastir, Monastir, 5079, Tunisia.

${ }^{c}$ : University of Monastir, Laboratoire d'Analyse, Traitement et Valorisation des Polluants de l'Environnement et des Produits, Faculté de Pharmacie, Rue Avicenne, 5000, Monastir, Tunisia

${ }^{d}$ : Faculty of Sciences and Arts, King Khalid University, Dhahran Aljanoub, Saudi Arabia.

${ }^{e}:$ Centre de Diffractométrie X, Institut des Sciences Chimiques de Rennes, UMR 6226, CNRSUniversité de Rennes 1, Campus de Beaulieu, 35042 Rennes Cedex, France.

${ }^{f}$ : Institut de Chimie des Substances Naturelles CNRS, Avenue de la Terrasse, F-91198

Gif-sur-Yvette, France.

\begin{abstract}
This study aims at first at the synthesis and the UV-visible, the infrared and the ${ }^{1} \mathrm{H}$ Nuclear Magnetic Resonance spectroscopic characterizations of the 4-(dimethylamino)pyridine)[meso-tetra(parachlorophenyl)porphyrinato]magnesium(II) with the formula $[\mathrm{Mg}(\mathrm{TCIPP})(\mathrm{DMAP})] \cdot 1 / 2 \mathrm{C}_{6} \mathrm{H}_{14}$ (I). The fluorescence and cyclic voltammetry studies have also been performed. The molecular structure of (I) was determined and described by single crystal X-ray diffraction analysis and Hirshfeld surfaces computational method. Complex (I) has a distorted square pyramidal geometry with a $\mathrm{Mg}-\mathrm{N}(\mathrm{DMAP})$ distance value of 2.130 (4) $\AA$ and the average equatorial distance between the magnesium(II) central ion and the nitrogen atoms is 2.082 (3) $\AA$. The crystal packing of our synthetic $\mathrm{Mg}(\mathrm{II})$ porphyrinic species is made by layers perpendicular to the [010] direction and the cohesion of the crystal packing is stabilized by nonconventional $\mathrm{C}-\mathrm{H} \cdots \mathrm{Cl}$ and by $\mathrm{C}-\mathrm{H} \cdots \mathrm{Cg}$ intermolecular interactions involving the pyrrole and phenyl rings of the porphyrin macrocycle. DFT calculations on (I) indicated an agreement
\end{abstract}


with both UV-visible and IR experimental data. To gain further insights into the reactivity of (I), a density of states (DOS) and a molecular electrostatic potential (MEP) theoretical calculation were carried out. Furthermore, the antifungal and the antioxidant activities of the free base $\mathrm{H}_{2} \mathrm{TClPP}$ porphyrin, the $[\mathrm{Mg}(\mathrm{TClPP})]$ starting material and $[\mathrm{Mg}(\mathrm{TClPP})(\mathrm{DMAP})](\mathrm{I})$ were also tested.

\footnotetext{
* Corresponding author. Fax: +216 73500278.

E-mail address: hnasri1@gmail.com and habib.nasri@fsm.rnu.tn (Habib Nasri).
}

Keywords: Magnesium(II) porphyrin complex; X-ray molecular structure; UV-visible, Cyclic voltammetry, Antifungal and antioxidant activities.

\section{Introduction}

Since the 1960s, research investigations involving porphyrins and metalloporphyrins has been increasing, especially after the use of the Aller et Longo method, since 1967 [1] for the preparation of meso-arylporhyrines with yields close to $20 \%$. In 1975, Colman et al., [2] described a rather simple method to prepare the famous staked porphyrin and in 1987, Lindsey et al.,[3] used a new method for the synthesis of meso-arylporhyrins with a better yield close to $30 \%$ and especially which allows the use of aldehydes that do not withstand the high synthesis temperatures ( $\left.140{ }^{\circ} \mathrm{C}\right)$ required by the Adler et Longo method. This eagerness in the use of porphyrins and metalloporphyrins is due to the wide range of uses of these aromatic compounds. Until the early 1980s, porphyrin derivatives were mainly used as synthetic models for hemoproteins such as myoglobin, hemoglobin, cytochromes c and cytochromes P450 [4-7]. Beginning in the early 1980s, metalloporphyrins, especially iron(III), began to be used as catalysts in oxidation reactions of a number of organic compounds, including the pioneering work of Groves et al. [8]. Over the last three decades, the field of use of porphyrin compounds has spanned disciplines ranging from chemistry, biology, physics, electronics, pharmacy, and medicine. Currently, porphyrins and metalloporphyrins are used in many technical applications 
including, catalysts [9], solar cells [10], sensors [11], supramolecular chemistry [12], photosensitizers in photodynamic therapy (PDT) [13], photocatalysts[14], semiconductors, [15] and nonlinear optics [16]. Moreover, the past decade has witnessed intense research devoted to the antioxidant, antibacterial and antifungal activities of porphyrin species [17-22]. It should also be noted that our research group has published in recent years a number of works on the use of magnesium(II) porphyrin complexes as antibacterial agents $[23,24]$.

As a continuation of our investigation of magnesium porphyrin complexes, a new coordination compound has been synthesized entitled: (4-(dimethylamino)pyridine)[meso-tetra(parachlorophenyl)porphyrinato]magnesium(II) with formula [Mg(TCIPP)(DMAP)] (I) where TClPP is the meso-tetra(para-chlorophenyl)porphyrinato and DMAP is the 4-(dimethylamino)pyridine axial ligand. This $\mathrm{Mg}(\mathrm{II})$ porphyrin derivative was characterized by Infrared, UV-visible, ${ }^{1} \mathrm{H}$ Nucleus Magnetic Resonance and fluorescence spectroscopy. Complex (I) was further investigated by MALDI-TOF mass spectrometry and cyclic voltammetry. Furthermore, single crystal X-ray investigation followed by Hirshfeld surfaces analysis on complex (I) are reported. In order to better understand the molecular structure of the complex (I), theoretical structural analysis was performed, and the chemical reactivity behaviors were investigated. The antioxidant and antifungal activities of $[\mathrm{Mg}(\mathrm{TClPP})(\mathrm{DMAP})]$ were also performed.

\section{Experimental Section}

\section{1. Materials and methods}

Fourier-transformed IR spectra were recorded on a PerkinElmer Spectrum Two FT-IR spectrometer. UV-visible spectra were recorded with a WinASPECT PLUS (validation for SPECORD PLUS version 4.2). ${ }^{1} \mathrm{H}$ NMR spectra were obtained at room temperature on a Bruker 300 Ultrashield spectrometer. Chemical shifts are reported in ppm downfield from internal tetramethylsilane (TMS).

MALDI-TOF MS: A PerSeptive Voyager DE-STR MALDI-TOF mass spectrometer (PerSeptive Biosystems, Framingham, MA, USA), equipped with a $337 \mathrm{~nm}$ pulsed nitrogen laser $(20 \mathrm{~Hz})$ and an Acqiris $2 \mathrm{GHz}$ digitizer board, was used for all experiments. Mass spectra were obtained in the positive ion mode with the following settings: accelerating voltage $20 \mathrm{kV}$, grid voltage $62 \%$ of accelerating voltage, extraction delay time of $100 \mathrm{~ns}$. The laser intensity was set just above the ion generation threshold to obtain peaks with the highest possible signal-to-noise $(\mathrm{S} / \mathrm{N})$ ratio without 
significant peak broadening. All data were processed using the Data Explorer software package (Applied Biosystems). Trans-2-[3-(4-tert-Butylphenyl)-2-methyl-2propenylidene] malonitrile (DCTB), used as the matrix for MALDI-TOF MS, was of the highest grade available and used without further purification. It was purchased from Sigma Aldrich Co. The samples were made as $3.10^{-3} \mathrm{M}$ in tetrahydrofuran (THF).

Emission spectra were recorded in dichloromethane at room temperature on a Horiba Scientic Fluoromax-4 spectrofluorometer. Samples were placed in $1 \mathrm{~cm}$ path length quartz cuvettes. Luminescence lifetime measurements were performed after irradiation at $\lambda=420 \mathrm{~nm}$ obtained by the second harmonic of a titanium: Sapphire laser (picosecond Tsunami laser spectra physics 3950-M1BB +39868-03 pulse picker doubler) at an $800 \mathrm{kHz}$ rate of repetition. For the decay acquisition, Fluotime 200 (AMS technologies) was utilized consisting of a GaAsmicro channel plate photomultiplier tube (Hamamatsu model R3809U-50) followed by a time-correlated single photon counting system from Picoquant (PicoHarp300). The ultimate time resolution of the system is close to $30 \mathrm{ps.} \mathrm{Luminescence}$ decays were analyzed with FLUOFIT software available from Picoquant. Emission quantum yields were determined at room temperature in dichloromethane solutions using the optically dilute method. $[\mathrm{Zn}(\mathrm{TPP})]$ in air-equilibrated dichloromethane solution was used as quantum yield standard $\left(\phi_{\mathrm{f}}=\right.$ 0.031) [25]. The instrumental uncertainties are as follows: absorption maxima, $2 \mathrm{~nm}$; molar absorption, 20\%; emission maxima, $5 \mathrm{~nm}$; emission lifetimes, 10\%; emission quantum yields, 20\%. The fluorescence quantum yield $\left(\phi_{\mathrm{f}}\right)$ was measured using the following equation (Eq. 1) [26]:

$$
Q_{f}=\emptyset_{f(s t d)} \frac{F \cdot A_{s t d} \cdot n^{2}}{F_{s d t} \cdot A \cdot n_{s t d}^{2}}
$$

Where $\phi_{f(s t d)}$ is the fluorescence quantum standard (in dichloromethane) $\left(\phi_{f(s t d)}=0.03\right)$, the reference used is $[\mathrm{Zn}(\mathrm{TPP})]$ as mentioned above. $F$ and $F_{\text {std }}$ are the areas of the fluorescence emission plots for both the sample and the standard. $A, n, A_{s t d}$ and $n_{\text {std }}^{2}$ are the relative absorbance of the sample and the refractive indices of the solvents for the sample and standard at the excitation wavelength.

Cyclic voltammetry (CV) experiments were conducted with a $\mathrm{CH}-660 \mathrm{~B}$ potentiostat (CH Instruments). All analytical experiments were performed at room temperature under an argon atmosphere (argon flux) in a standard single compartment, three-electrode electrochemical cell. Th e electrolyte used was tetra-n-butylammonium perchlorate (TBAP) $(0.2 \mathrm{M})$ in dichloromethane. 
Hirshfeld surfaces (HSs) and 2D fingerprint plots (FPs) were generated using Crystal Explorer 3.15 $[27,28]$ based on results of single crystal X-ray diffraction studies. The function $d_{\text {norm }}$ is a ratio encompassing the distances of any surface point to the nearest interior $\left(\mathrm{d}_{\mathrm{i}}\right)$ and exterior $\left(\mathrm{d}_{\mathrm{e}}\right)$ atom and the van der Waals radii of the atoms $[29,30]$.

\subsection{Antifungal activity}

Yeasts Strains: three yeasts strains, C. krusei ATCC6258, C. albicans ATCC90028 and C.neoformans ATCC14116 were cultured on Sabouraud agar at $37{ }^{\circ} \mathrm{C}$ for $48 \mathrm{~h}$. Then, pure colonies were suspended in $10 \mathrm{~mL}$ of physiological medium, mixed well for $5 \mathrm{~min}$ and suspensions were adjusted to 0.5 McFarland standard turbidity. $1 \mathrm{~mL}$ of yeast suspension was spread over Sabouraud agar medium plates and incubated for $30 \mathrm{~min}$ at $37^{\circ} \mathrm{C}$. After that, $6 \mathrm{~mm}$ diameters wells were dug in agar medium using sterile glassy borer. The compounds were prepared in DMSO $(1 \mathrm{mg} / \mathrm{mL})$ and introduced into the respective wells, one of the wells was supplemented with DMSO as control. The plates were placed in a $37{ }^{\circ} \mathrm{C}$ incubator for $48 \mathrm{~h}$ to allow yeast growth. After $48 \mathrm{~h}$, the diameters of the clear zone of inhibition surrounding the sample were measured in millimetres by digital caliper.

Fungal Strains: two fungi strains, A brasiliensis ATCC16404 and A. fumigatus ATCC204305 were cultured on inclined Sabouraud agar in Falcon tube $15 \mathrm{~mL}$ at $25{ }^{\circ} \mathrm{C}$ for 7 days. The spore of fungal strain was suspended in peptone water and counted to have 106 spores $/ \mathrm{mL}$. Then, $1 \mathrm{~mL}$ of fungal suspension was spread over Sabouraud agar medium plates and incubated for $30 \mathrm{~min}$ at $25{ }^{\circ} \mathrm{C}$. After that, $6 \mathrm{~mm}$ diameters wells were dug in agar medium using sterile glassy borer. The compounds were prepared in DMSO (1 $\mathrm{mg} / \mathrm{mL})$ and introduced into the respective wells, one of the wells was supplemented with DMSO as control. The plates were placed in a $25{ }^{\circ} \mathrm{C}$ incubator for five days to allow fungal growth. The diameters of the clear zone of inhibition surrounding the sample were measured in millimetres by digital

caliper.

\subsection{Antioxidant activity}

The antioxidant activity of the free porphyrin and their magnesium complexes were evaluated using, DPPH (2,2-diphenyl-1-picrylhydrazyl) radical scavenging method. Different concentrations (25, 50, 75 and $100 \mu \mathrm{g} / \mathrm{mL}$ ) of our compounds were taken. $2 \mathrm{~mL}$ of the sample was mixed with $2 \mathrm{~mL}$ of $0.1 \mathrm{M}$ sodium acetate buffer $(\mathrm{pH}=5.5)$. Then, $1 \mathrm{~mL}$ of $0.5 \mathrm{M}$ methanol DPPH (2,2-diphenyl-1- 
picrylhydrazyl) solution was added. The reaction mixture was shaken vigorously and kept in completely dark for $30 \mathrm{~min}$. Then the absorbance was measured at $517 \mathrm{~nm}$ in a spectrophotometer. The percentage of Radical Scavenging Activity (RSA \%) was calculated according to the following equation (Eq. 2):

$$
R S A \%=[(A C-A S) / A C] \times 100 \quad \text { (Eq. 2) }
$$

where, $\mathrm{AC}$ is the absorbance of control and AS is the absorbance of sample.

\subsection{Synthetic methods}

Solvents were appropriately distilled and dried before use and the reagents employed were commercially available and were used as received without further purification. The meso-tetra(parachlorophenyl)porphyrin ( $\left.\mathrm{H}_{2} \mathrm{TClPP}\right)$ and the $\mathrm{Mg}(\mathrm{II})$-metallated porphyrin $[\mathrm{Mg}(\mathrm{TClPP})]$ starting materials were prepared as described in the literature [1,31]. The ${ }^{1} \mathrm{H}$ NMR spectra of $\mathrm{H}_{2} \mathrm{TClPP}$ and $[\mathrm{Mg}(\mathrm{TClPP})]$ starting materials are reported in the supplementary information (Figures S2 and S3 ).

\subsection{Synthesis of $[\mathrm{Mg}(\mathrm{TClPP})(\mathrm{DMAP})] \cdot 3 / 2\left(\mathrm{C}_{6} \mathrm{H}_{14}\right)(\mathrm{I})$}

A mixture of $[\mathrm{Mg}(\mathrm{TClPP})]$ (100 $\mathrm{mg}, 0.213 \mathrm{mmol})$, 4-(dimethylamino)pyridine (DMAP) (200 mg, $1.637 \mathrm{mmol})$ and dichloromethane $(10 \mathrm{~mL})$ was stirred at room temperature for 4 hours. The reaction was monitored by UV-visible spectra. The solvent was removed under reduced pressure and the $\mathrm{Mg}(\mathrm{II})$ - DMAP porphyrin derivative (I) crystalizes by slow diffusion of n-hexane into a dichloromethane solution of this complex with a yield of $\sim 80 \%$. $\mathrm{C}_{60} \mathrm{H}_{55} \mathrm{Cl}_{4} \mathrm{~N}_{6} \mathrm{Mg}$ (1026.25): calcd. C 70.22, H 5.40, N 8.19; found: C 70.61, H 5.29 a, N 8.34; MALDI-TOF (+, \{(2E)-2-Methyl-3-[4-(2methyl-2-propanyl)phenyl]-2-propen-1-ylidene]malononitrile known as trans-2-[3-(4-tertButylphenyl)-2-methyl-2-propenylidene]malononitrile matrix (DCTB), $\mathrm{THF}$ ): $\mathrm{m} / \mathrm{z}=774.80$ $[\mathrm{Mg}(\mathrm{TCPP})+2 \mathrm{H}]^{+}$found $\mathrm{m} / \mathrm{z}=774.50$ (Figure S1) ; UV-visible : $\left[\lambda_{\max }(\mathrm{nm})\right.$ in $\mathrm{CH}_{2} \mathrm{Cl}_{2},(\log \varepsilon \mathrm{x}]: 432$ (5.70), 570 (4.69), 609 (4.61) ; ${ }^{1} \mathrm{H}$ NMR (300 MHz, $\mathrm{CDCl}_{3}$ ): $\delta$ (ppm) 8.88 (Hß-pyrrol), $8.21-7.73$ 8.42 (H-phenyl protons), 7.21 ( $\mathrm{H}_{\mathrm{Lo}}$ DMAP), 6.49 ( $\mathrm{H}_{\mathrm{Lm}}$ DMAP), 2.35 ( $\mathrm{H}_{\mathrm{a}}$ DMAP). FTR-IR [solid, $\bar{v}$ $\left.\left(\mathrm{cm}^{-1}\right)\right]: 3041$ (vCH DMAP)

2960-2860 (vCH porphyrin), 1087 (vCN, DMAP ligand), 995 ( $\delta \mathrm{CCH}$ porphyrin).

\section{6. $X$-ray structure determination}


A dark purple block shaped single crystal of dimensions $0.52 \times 0.44 \times 0.24 \mathrm{~mm}$ of complex (I) was chosen for an X-ray diffraction study. The data were collected at $150 \mathrm{~K}$ on a D8 VENTURE Bruker AXS CCDC diffractometer using MoK $\alpha$ radiation of wavelength $0.71073 \AA$. The reflections were scaled and corrected for absorption effects by using SADABS program (Bruker AXS 2008) [32]. The structure was solved by direct methods by using SIR-2004 [33] and refined by full-matrix least-squares techniques on $\mathrm{F}^{2}$ by using the SHELXL-2014 program [34]. Two disorder problems were encountered during the refinement of the structure (I): (i) the $\mathrm{N}\left(\mathrm{CH}_{2}\right)$ - group of the DMAP axial ligand presents two positions : (C50-N6-C51 and C50A-N6-C51A) where the refined occupancy coefficients of the major position converged to 0.874 (13) and (ii) one phenyl group with a chlorine atom of the TCIPP moiety is disordered in two positions (C334-C34A-C35A-C36A-C37A-C38A-CL3A and C33B-C34BC35B-C36B-C37B-C38B-CL3B) with position occupancies of 0.816(5) and 0.184 (5), respectively. The anisotropic displacement ellipsoids of some atoms of the porphyrin molecule and the DMAP axial ligand in complex (I) were very elongated which indicates static disorder. For fragments involving these atoms, the DFIX and SIMU/ISOR restraints commands in the SHELXL-2014 software were used [35] (Table 1).

A n-hexane solvent molecule found to be badly disordered was removed using the PLATON SQUEEZE procedure [36]. Therefore, the given chemical formula of (I) and other crystal data of this complex do not take into account the removed solvent molecule. The $\mathrm{H}$ atoms were placed in calculated positions and treated as riding on their parent atoms. The geometrical calculations were carried out using the program PLATON [37]. The molecular and packing diagrams were generated using the software MERCURY [38]. The crystallographic data and structural refinement details of (I) is shown in Table 1. Selected bond lengths and angles for the compound are listed in Table 2.

Table 1. Crystal data and structural refinement for $[\mathrm{Mg}(\mathrm{TClPP})(\mathrm{DMAP})] \cdot 1 / 2 \mathrm{C}_{6} \mathrm{H}_{14}{ }^{*}$ (I).

$\begin{array}{ll}\text { Formula } & \mathrm{C}_{54} \mathrm{H}_{41} \mathrm{Cl}_{4} \mathrm{~N}_{6} \mathrm{Mg} \\ \text { Crystal System } & \text { monoclinic } \\ \text { Crystal } & P{ }_{1} / n \\ \text { a }(\AA) & 13.9355(8) \\ \text { b }(\AA) & 22.0512(13) \\ \mathrm{c}(\AA) & 17.6318(10) \\ \beta\left({ }^{\circ}\right) & 101.941(2) \\ \mathrm{V}\left(\AA^{3}\right) & 5300.9(5) \\ \mathrm{Z} & 4 \\ \rho_{\text {calc }} . / \mathrm{g} \mathrm{cm}^{-3} & 1.178\end{array}$




$\begin{array}{ll}\mu / \mathrm{mm}^{-1} & 0.275 \\ F(000) & 1948 \\ \text { Crystal size }\left(\mathrm{mm}^{3}\right) & 0.520 \times 0.440 \times 0.224 \\ \text { Crystal Color } & \text { dark purple } \\ \text { Crystal Shape } & \text { block } \\ \mathrm{T}(\mathrm{K}) & 150(2) \\ \theta_{\text {min }}-\theta_{\text {max }}\left(^{\circ}\right) & 2.192-24.999 \\ \text { Limiting indices } & -16 \leq \mathrm{h} \leq 16,-23 \leq \mathrm{k} \leq 26,-20 \leq 1 \leq 20 \\ \mathrm{R}(\text { int }) & 0.0352 \\ \text { Reflections collected/unique } & 35520 / 9263 \\ \text { Observed data }\left[I_{o}>2 \sigma\left(F_{o}\right)\right] & 7427 \\ \text { Parameters/Rest } & 62 / 90 \\ S[\text { Goodness of fit }] & 1.046 \\ R_{l}{ }^{a}, w R_{2}{ }^{b}\left[F_{o}>4 \sigma\left(F_{o}\right)\right] & R_{1}=0.0789, w R_{2}=0.1797 \\ \left.w R_{2}{ }^{b} \text { [all data }\right] & R_{1}=0.0940, w R_{2}=0.1897 \\ \text { Min./max. res. }\left(\mathrm{e} \AA^{-3}\right) & 0.657 /-0.633 \\ \text { CCDC } & 1997737\end{array}$

*: The given chemical formula of (I) and other crystal data of this complex do not take into account the removed n-hexane solvent molecule, using PLATON-Squeeze procedure (see details in the text).

${ }^{\mathrm{a}}: R 1=\left.\Sigma|| F_{\mathrm{O}}|-| F_{\mathrm{C}}|/ \Sigma| F_{\mathrm{O}}\right|^{\mathrm{b}}, w R_{2}=\left\{\Sigma\left[w\left(\left|F_{\mathrm{O}}\right|^{2}-\left|F_{\mathrm{C}}\right|^{2}\right)^{2}\right] / \Sigma\left[w\left(\left|F_{\mathrm{O}}\right|^{2}\right)^{2}\right]\right\}^{1 / 2}$.

Table 2. Selected bond lengths $(\AA)$ and angles $\left({ }^{\circ}\right)$ of $(\mathbf{I})$.

\section{Magnesium coordination polyhedron}

$\begin{array}{llllll}\mathrm{Mg}-\mathrm{N} 1 & 2.084(3) & \mathrm{N} 1-\mathrm{Mg}-\mathrm{N} 2 & 88.53(11) & \mathrm{N} 3-\mathrm{Mg}-\mathrm{N} 4 & 88.27(11) \\ \mathrm{Mg}-\mathrm{N} 2 & 2.083(3) & \mathrm{N} 1-\mathrm{Mg}-\mathrm{N} 3 & 160.58(14) & \mathrm{N} 1-\mathrm{Mg}-\mathrm{N} 5 & 98.34(12) \\ \mathrm{Mg}-\mathrm{N} 3 & 2.08(3) & \mathrm{N} 1-\mathrm{Mg}-\mathrm{N} 4 & 88.59(11) & \mathrm{N} 2-\mathrm{Mg}-\mathrm{N} 5 & 101.45(12) \\ \mathrm{Mg}-\mathrm{N} 4 & 2.079(3) & \mathrm{N} 2-\mathrm{Mg}-\mathrm{N} 3 & 87.88(11) & \mathrm{N} 3-\mathrm{Mg}-\mathrm{N} 5 & 101.08(12) \\ \mathrm{Mg}-\mathrm{N} 5 & 2.130(4) & \mathrm{N} 2-\mathrm{Mg}-\mathrm{N} 4 & 159.92(13) & \mathrm{N} 4-\mathrm{Mg}-\mathrm{N} 5 & 98.64(12)\end{array}$

DMAP Axial ligand

$\begin{array}{llll}\text { N5-C45 } & 1.345(5) & \mathrm{Mg}-\mathrm{N} 5-\mathrm{C} 48 & 120.9(3) \\ \mathrm{C} 45-\mathrm{C} 46 & 1.359(6) & \mathrm{C} 45-\mathrm{N} 5-\mathrm{C} 48 & 114.5(3) \\ \mathrm{C} 46-\mathrm{C} 49 & 1.397(6) & \mathrm{N} 5-\mathrm{C} 45-\mathrm{C} 46 & 125.1(4) \\ \mathrm{C} 49-\mathrm{C} 47 & 1.397(5) & \mathrm{C} 45-\mathrm{C} 46-\mathrm{C} 49 & 119.8(3) \\ \mathrm{C} 47-\mathrm{C} 48 & 1.363(6) & \mathrm{C} 47-\mathrm{C} 49-\mathrm{C} 46 & 115.7(4) \\ \mathrm{C} 48-\mathrm{N} 5 & 1.337(5) & \mathrm{C} 48-\mathrm{C} 47-\mathrm{C} 49 & 119.9(4) \\ \mathrm{C} 49-\mathrm{N} 6 & 1.357(6) & \mathrm{C} 47-\mathrm{C} 48-\mathrm{N} 5 & 125.0(4) \\ \text { N6-C50 } & 1.463(4) & \mathrm{C} 47-\mathrm{C} 49-\mathrm{N} 6 & 121.8(4) \\ \text { N6-C51 } & 1.466(4) & \mathrm{C} 46-\mathrm{C} 49-\mathrm{N} 6 & 122.6(4) \\ \text { N6-C50A } & 1.460(2) & \mathrm{C} 50-\mathrm{N} 6-\mathrm{C} 51 & 118.0(5) \\ \text { N6-C51A } & 1.462(5) & \mathrm{C} 50 \mathrm{~A}-\mathrm{N} 6-\mathrm{C} 51 \mathrm{~A} & 121(5) \\ \text { Mg-N5-C45 } & 124.6(3) & & \end{array}$




\section{Results and Discussion}

\section{1. ${ }^{1} \mathrm{H}$ NMR spectroscopy}

The ${ }^{1} \mathrm{H}$ NMR spectrum of the $\mathrm{H}_{2} \mathrm{ClPP}$ free base porphyrin presents $\mathrm{NH}$ pyrrole protons very shielded and appear at $-2.83 \mathrm{ppm}$ as low intensity (Figure S2). The disappearance of this H-pyrrole signal is an indication of the metalation of the porphyrin by $\mathrm{Mg}$ (II) (Figures S3 and S4). For the $\mathrm{H}_{2} \mathrm{TCIPP}$ and the corresponding metaleted porphyrins $[\mathrm{Mg}(\mathrm{TClPP})]$ and $\left[\mathrm{Mg}(\mathrm{TClPP})(\mathrm{DMAP})_{2}\right]$ complexes, the $\beta$ pyrrolic protons and the aromatic protons of the meso-phenyl rings of the TCIPP moiety resonate in the range $8.89-8.14 \mathrm{ppm}$ indicating a diamagnetic character for all three species. Notably, the chemical shift values of our three synthetic species are very close to the related porphyrin species reported in Table 3. Furthermore, the chemical shift values of the $\mathrm{N}\left(\mathrm{CH}_{3}\right)_{2}$ protons $(\mathrm{Ha}$,$) , the ortho (\mathrm{HL}, \mathrm{o})$ and the meta (HL,m) protons of the DMAP axial ligand of complex (I) are 7.21, 6.49 and $2.35 \mathrm{pm}$, respectively. These values are smaller than those of the free DABCO molecule with values of 8.44, 6.64 and $2.47 \mathrm{ppm}$ indicating the coordination of DMAP for complex (I). For the two non-porphyrinc DMAP complexes reported in Table 3, the chemical shift values of the protons corresponding to this molecule are also smaller than those of the free DMAP which confirms the coordination of DMAP in the case of complex (I).

Table 3. Chemical shift values for selected free base meso-arylporphyrins and magnesium(II) meso-arylporphyrin complexes and several non-porphyrinic DMAP complexes from ${ }^{1} \mathrm{H}$ NMR spectra. Spectra recorded in $\mathrm{CDCl}_{3}$, exception is indicated*.

\begin{tabular}{|c|c|c|c|c|c|}
\hline Compound & $\mathrm{H} \beta$-pyrrolic & H-phenyl & H-pyrrole & $\mathrm{H}_{\mathrm{L}, \mathrm{o}} ; \mathrm{H}_{\mathrm{L}, \mathrm{m}} ; \mathrm{H}_{\mathrm{a}}^{\mathrm{a}}$ & Ref. \\
\hline
\end{tabular}

Meso-arylporphyrins

$\begin{array}{llllll}\mathrm{H}_{2} \mathrm{TPP}^{\mathrm{b}} & 8.84 & 8.23 ; 7.91 ; 7.67 ; 7.26 & -2.87 & - & {[39]} \\ \mathrm{H}_{2} \mathrm{TpivPP}^{\mathrm{c}} & 8.82 & 8.70 ; 7.88 ; 7.50 & -2.86 & - & {[39]}\end{array}$




$\begin{array}{llll}\mathrm{H}_{2} \mathrm{TMPP}^{\mathrm{d}} & 8.86 & 8.08 ; 7.27 ; & -2.89 \\ \mathrm{H}_{2} \mathrm{TBrPP}^{\mathrm{e}} & 8.85 & 8.05 ; 7.91 & -2.86 \\ \mathrm{H}_{2} \mathrm{TClPP} & 8.89 & 8.18 ; 7.74 & -2.83 \\ \mathrm{H}_{2} \mathrm{TPBP}^{\mathrm{f}} & 8.94 & 8.42 ; 8.33 ; 7.60 & -2.80\end{array}$

[40]

Tetracoordinated Mg(II)-meso-arylporphyrins

$\begin{array}{ll}8.88 & 8.35 ; 8.08 ; 7.94 \\ 8.96 & 8.67 ; 8.36 ; 7.62 \\ 8.85 & 8.14 ; 7.72\end{array}$

Mg(II)-meso-arylporphyrins this work

$\begin{array}{lll}{[\mathrm{K}(222)]\left[\mathrm{Mg}(\mathrm{TPP})\left(\mathrm{N}_{3}\right)\right]^{\mathrm{b}, \mathrm{g}}} & 8.72 & 8.10 ; 7,68 \\ {[\mathrm{Mg}(\mathrm{TBrPP})(\mathrm{Him})]^{\mathrm{e}}} & 8.86 & 8.38 ; 8.07 ; 7.90 \\ {\left[\mathrm{Mg}(\mathrm{TPBP})(\mathrm{HTMA})_{2}\right]^{\mathrm{f}, \mathrm{i}}} & 9.01 & 8.42 ; 8.30 ; 7.73 \\ {\left[\mathrm{Mg}(\mathrm{TPBP})(\mathrm{DABCO})_{2}\right]^{\mathrm{f}, \mathrm{j}}} & 9.00 & 8.45 ; 8.30 ; 7.75 \\ {[\mathrm{Mg}(\mathrm{TClPP})(\mathrm{DMAP})]^{-1}} & 8.88 & 8.21 ; 8.21 ; 7.73\end{array}$

Non-porphyrinic DMAP complexes
(BDI)

[Mg(OCMe $\left.\mathrm{OOOEt}_{2}(\mathrm{DMAP})\right]^{\mathrm{k}, *}$

$\left[\mathrm{Mg}(\mathrm{L})(\mathrm{DMAP})_{2}(1,2 \text {-dadhp })\right]^{1, \mathrm{~m}}$ -
$8.76 ; 5.99 ; 2.22$

$7.71 ; 4.75 ; 2.93$
$7.21 ; 6.49 ; 2.35 \quad$ this work

\footnotetext{
${ }^{a}: \mathrm{H}_{\mathrm{L}, \mathrm{o}} ; \mathrm{H}_{\mathrm{L}, \mathrm{m}} ; \mathrm{H}_{\mathrm{a}}=$ otho, meta and the $\mathrm{CH}_{2}$ protons of the $\mathrm{N}\left(\mathrm{CH}_{2}\right)_{2}$ - protons of the DMAP axial ligand (see Figure $\mathrm{S} 4$ ),

${ }^{b}: \mathrm{H}_{2} \mathrm{TPP}=$ meso-tetraphenylporphyrin, ${ }^{\mathrm{c}}: \mathrm{H}_{2}$ TpivPP $=$ meso $-[\alpha, \alpha, \alpha, \alpha$-tetrakis $(o$-pivalamidophenyl $)]$ porphyrin,

d: $\mathrm{H}_{2}$ TMPP = meso-tetra(para-methoxyphenyl)porphyrin, ${ }^{\mathrm{e}}: \mathrm{H}_{2} \mathrm{TBrPP}=$ meso-tetrakis(4-bromophenyl)porphyrin,

f: $\mathrm{H}_{2}$ TPBP $=$ meso-tetrakis[4(benzoyloxy)phenyl]porphinato, ${ }^{\mathrm{g}}:[\mathrm{K}(222)]^{+}=($cryptand-222)potassium $(+)$cation,

${ }^{\mathrm{i}}:$ HTMA $=$ Hexamethylenetetramine, ${ }^{\mathrm{j}}$ : DABCO $=$,4-diazabicyclo[2.2.2]octane, ${ }^{\mathrm{k}}$ : $(\mathrm{BDI})=2-[(2,6-$ diisopropylphenyl)amino]-4-[(2,6-diisopropylphenyl)imino]pent-2-ene, ${ }^{1}: \mathrm{L}=(\mathrm{Ph} 2 \mathrm{PNDip})-$ and $\mathrm{Dip}=2,6-$ $\left.{ }_{i P r} \mathrm{C}_{6} \mathrm{H}_{3}\right),{ }^{\mathrm{m}}:$ 1,2-dadhp = 4-dimethylamino-1,2-dihydropyridide, $*$ : spectrum recorded in toluene.
}

\section{2. $U V$-visible and IR spectroscopy}

Figure 1 illustrates the UV-visible spectra of the free base $\mathrm{H}_{2} \mathrm{TClPP}$, the $[\mathrm{Mg}(\mathrm{TClPP})]$ starting material and the $\mathrm{Mg}(\mathrm{II})$-DMAP derivative $[\mathrm{Mg}(\mathrm{TClPP})(\mathrm{DMAP})]$ (I). $\mathrm{H}_{2}$ TClPP exhibits a strong absorbance band in the near-UV called the Soret (or B) band located at $418 \mathrm{~nm}$ corresponding to the allowed transition between the $S_{0}$ ground state.to the second excited state $S_{2}\left(S_{0} \rightarrow S_{2}\right)$. In the visible region, four weaker absorption bands known as the Q bands are located at 515, 550, 549 and $64 \mathrm{~nm}$ corresponding to the

$\mathrm{S}_{0} \rightarrow \mathrm{S}_{1}$ transition where $\mathrm{S}_{1}$ is the first excited state. The metallated $[\mathrm{Mg}(\mathrm{TClPP})]$ and $[\mathrm{Mg}(\mathrm{TClPP})(\mathrm{DMAP})]$ (I) present a Soret bands redshifted compared to the $\mathrm{H}_{2} \mathrm{TClPP}$ free base 
porphyrin with values of 429 and $423 \mathrm{~nm}$, respectively. The change in the symmetry from $\mathrm{D}_{2 \mathrm{~h}}$ in free base porphyrin to $\mathrm{D}_{4 \mathrm{~h}}$ in the two corresponding magnesium metalloporphyrins $[\mathrm{Mg}(\mathrm{TClPP})]$ and complex (I) leads to only two absorptions of $\mathrm{Q}(0,0)$ and $\mathrm{Q}(1,0)$ instead of four bands in the case of the corresponding free base porphyrin (Table 4). The values of the $\lambda_{\max }$ of the two $\mathrm{Q}(0,0)$ and $\mathrm{Q}(1,0)$ bands are 567 and 607 for [Mg(TClPP)] and 570 and $609 \mathrm{~nm}$ for complex (I). From Table 4, we noticed that the Soret and the $\mathrm{Q}$ bands $\lambda_{\max }$ values of our $\mathrm{Mg}(\mathrm{II})$ derivative are very close to those of the related $\left[\mathrm{Mg}(\mathrm{Porph})(\mathrm{L})_{2}\right]$ (Porph = meso-arylporphyrinato and $\mathrm{L}$ is a $\mathrm{N}$-donor neutral axial ligand). Therefore, the UV-visible study indicates that for meso-arylporphyrins type $\left[\mathrm{Mg}(\mathrm{Porph})(\mathrm{L})_{\mathrm{x}}\right](\mathrm{x}=1$ or 2), neither the donor-withdrawing character of the substituent at the para positions of the mesoarylporphyrin nor the type of the N-donor neutral axial ligand have an important role in the absorption proprieties of these $\mathrm{Mg}(\mathrm{II})$ metalloporphyrins.

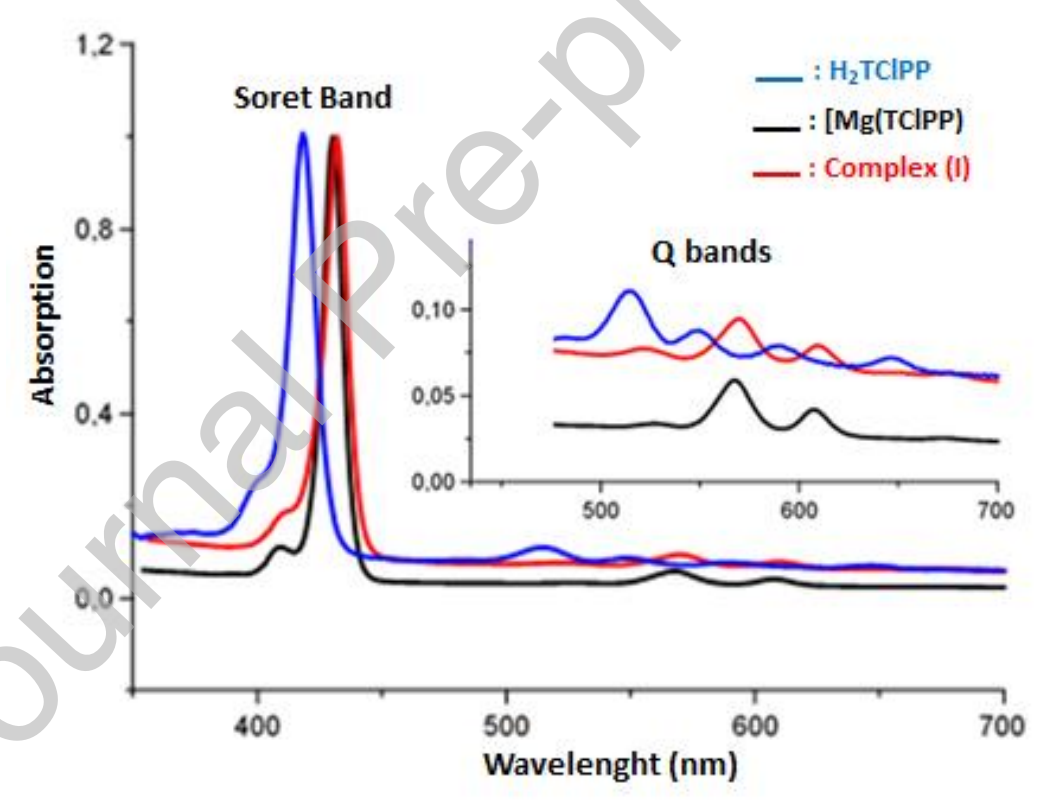

Figure 1. Electronic absorption spectra of free base $\mathrm{H}_{2} \mathrm{TClPP}$, the starting material $[\mathrm{Mg}(\mathrm{TClPP})]$ and complex (I) at ca. $10^{-6} \mathrm{M}$ in dichloromethane. The inset shows enlarged views.

The UV-visible spectrum of (I) was simulated at TD-DFT approach with CAM-B3LYP/6-31G(d) level of theory taking into account the chloroform solvent.

The theoretical spectrum of $[\mathrm{Mg}(\mathrm{TClPP})(\mathrm{DMAP})]$ (I) presents an intense absorption band with $\lambda_{\max }$ value of $405 \mathrm{~nm}$ corresponding to the Soret band, but the Q bands in the visible region de not appear in the spectrum due to their low intensities (Figure 2). 


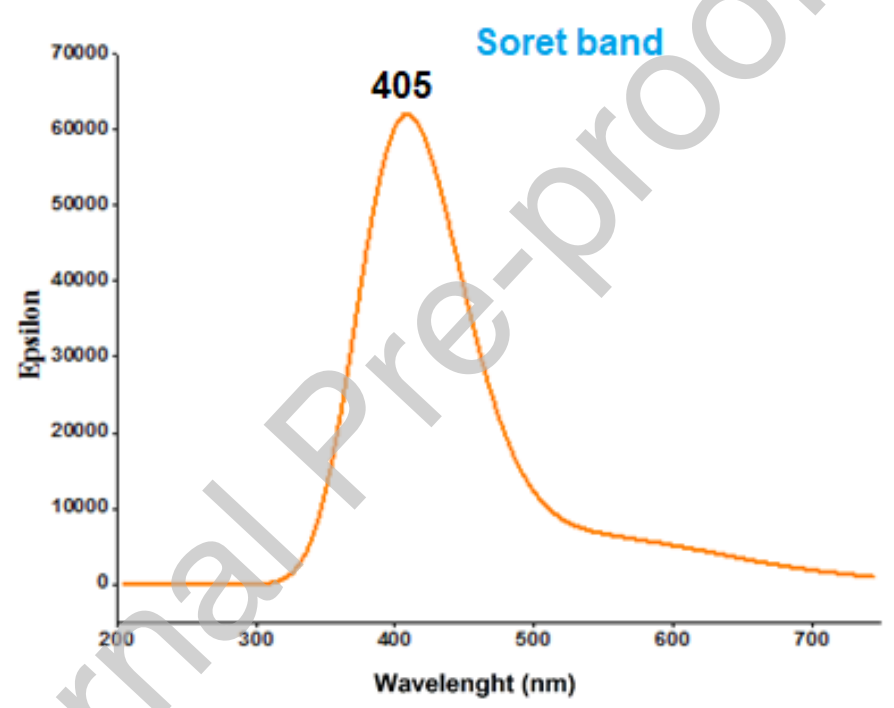

Figure 2. Theoretical UV-visible spectrum of [Mg(TCPP)(DMAP)] (I) TD/DFT method in chloroform solvent.

Table 4. UV-visible ${ }^{\text {a }}$. data of complex (I) and a selection of meso-arylporphyrin compounds.

\begin{tabular}{|c|c|c|c|}
\hline \multirow[t]{2}{*}{ Compound } & Soret band & Q bands & \multirow[t]{2}{*}{ Ref. } \\
\hline & & n) $(\log \varepsilon)$ & \\
\hline
\end{tabular}

Meso-arylporphyrins

$\begin{array}{llll}\mathrm{H}_{2} \text { TPP }^{\mathrm{b}} & 418(7.96) & 515(6.60) 549(6.30) 591(6.27) 647(6.27) & {[45]} \\ \mathrm{H}_{2} \text { TBrPP }^{\mathrm{c}} & 419(6.58) & 515(5.24) 549(4.93) 590(4.77) 648(4.68) & {[23]} \\ \mathrm{H}_{2} \text { TPBP }^{\mathrm{d}} & 419(5.90) & 514(4.46) 551(4.13) 590(3.94) 646(3.84) & {[41]} \\ \mathrm{H}_{2} \mathrm{TClPP} & 418(5.49) & 515(4.20) 550(4.27) 549(3.78) 647(3.45) & \text { this work }\end{array}$


Manganese(II) tetracoordinated meso-arylporphyrins

$\begin{array}{lllll}{[\mathrm{Mg}(\mathrm{TPP})]^{\mathrm{b}}} & 424(5.87) & 563(4.52) & 603(4.39) & {[46]} \\ {[\mathrm{Mg}(\mathrm{TBP})]^{\mathrm{c}}} & 426(6.63) & 563(5.23) & 603(5.06) & {[23]} \\ {[\mathrm{Mg}(\mathrm{TPBP})]^{\mathrm{d}}} & 427(5.86) & 565(4.42) & 605(4.16) & {[41]} \\ {[\mathrm{Mg}(\mathrm{TClPP})]} & 429(5.77) & 567(4.60) & 607(4.52) & \text { this work }\end{array}$

Manganese(II) hexacoordinate meso-arylporphyrins

\begin{tabular}{|c|c|c|c|}
\hline$[\mathrm{Mg}(\mathrm{TClPP})(\mathrm{DMAP})] \quad 432(5.70)$ & $570(4.69)$ & $609(4.61)$ & this work \\
\hline$\left[\mathrm{Mg}(\mathrm{TPBP})(\mathrm{HTMA})_{2}\right]^{\mathrm{d}, \mathrm{e}} 435(5.88)$ & $576(4.33)$ & $617(4.40)$ & [41] \\
\hline$\left[\mathrm{Mg}(\mathrm{TPBP})\left(4,4^{\prime}-\mathrm{bpy}\right)_{2}\right]^{\mathrm{f}} 430(6.04)$ & $571(5.08)$ & $614(5.00)$ & [47] \\
\hline
\end{tabular}

${ }^{\mathrm{a}}$ : All data are from spectra recorded in dichloromethane, ${ }^{\mathrm{b}}: \mathrm{H}_{2} \mathrm{TPP}=$ meso-tetraphenylporphyrin, $,{ }^{\mathrm{c}}: \mathrm{H}_{2} \mathrm{TBrPP}=$ meso-tetrakis(4-bromophenyl)porphyrin, ${ }^{\mathrm{d}}: \mathrm{H}_{2} \mathrm{TPBP}=$ meso-tetrakis[4(benzoyloxy)phenyl]porphinato, ${ }^{\mathrm{e}}:$ HTMA = Hexamethylenetetramine, ${ }^{\mathrm{f}}:$ 4,4'-bpy $=4,4^{\prime}$ '-bipyridine.

The IR spectra of the $\mathrm{H}_{2}$ TClPP free base porphyrin and the [Mg(TClPP)] starting material are depicted in Tables S5 and S6 while the spectrum of our Mg(II)-TClPP-DMAP complex (I) is illustrated by Figure 3. The disappearance of the absorption band attributed to the $v(\mathrm{NH})$ stretching of the pyrrole groups $\left(\bar{v}=3314 \mathrm{~cm}^{-1}\right)$ (Figures S5 and S6) indicates the metalation of the porphyrin. By the other hand, the absorption bands, attributed to the $\delta(\mathrm{CCH})$ bending mode of the TCIPP moiety, of the metallated porphyrins $[\mathrm{Mg}(\mathrm{TClPP})]$ and (I) (with values of 998 and $995 \mathrm{~cm}^{-1}$ respectively) are shifted toward the high frequencies compared to that of the $\mathrm{H}_{2}$ TClPP free base porphyrin $\left(\bar{v}=965 \mathrm{~cm}^{-1}\right)$. The values of the $\mathrm{CH}$ ) stretching frequencies of $\mathrm{H}_{2} \mathrm{TClPP},[\mathrm{Mg}(\mathrm{TClPP})]$ and $[\mathrm{Mg}(\mathrm{TClPP})(\mathrm{DMAP})]$ (I) are in the [2997 - 2850] $\mathrm{cm}^{-1}$ domain. Complex (I) exhibits an absorption band at $3041 \mathrm{~cm}^{-1}$ attributed to the $\mathrm{CH}$ stretching frequency of the pyridyl group of the DMAP axial ligand. The other absorption bands of this axial ligand are superposed with those of the TCIPP porphyrinate. 


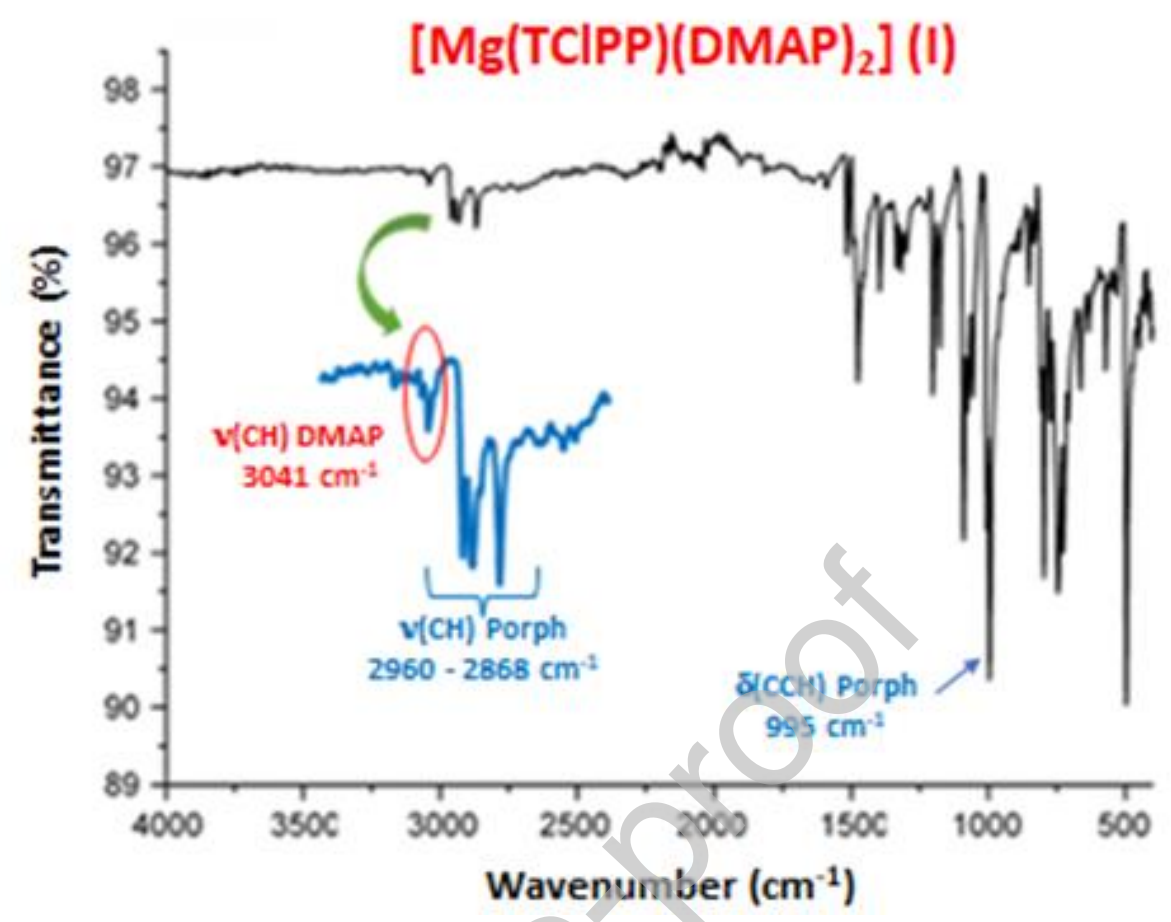

Figure 3. Solid IR spectrum of $[\mathrm{Mg}(\mathrm{TCIPP})(\mathrm{DMAP})]$ (I).

The theoretical FT-IR spectrum of (I) was simulated using the B3LYP/LanL2DZ method (Figure 4). Comparison of the theoretical and the experimental spectra of (I) reveals a quite hypochromic shift of the absorption bands of the theoretical spectrum compared to the experimental spectrum. Nevertheless, the characteristic absorption bands of (I) such as the $v(\mathrm{C}-\mathrm{H})$ of the porphyrin and the DMAP axial ligand and the $\delta(\mathrm{CCH})$ of the porphyrin ring are present.

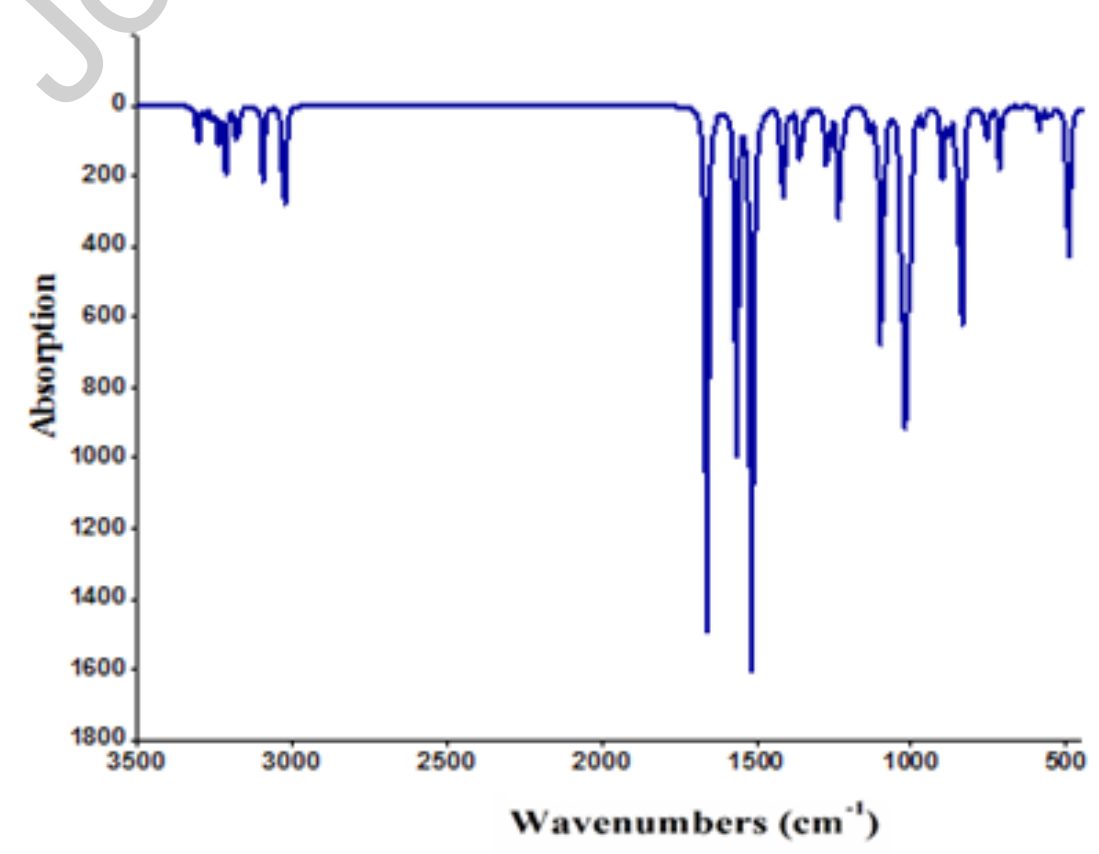


Figure 4. Calculated IR spectra (gas phase) of [Mg (TCPP)(DMAP)] (I) using the B3LYP/LanL2DZ method.

\subsection{Steady-state emission spectroscopy}

Porphyrins and metallopophyrins emission spectra show the two emission transitions: $S_{1} \rightarrow S_{0}$ and $S_{2} \rightarrow S_{1}$. The first one is between the first excited state $S_{1}$ and the $S_{0}$ ground state, concerns the $Q$ bands. The second emission transition which is between the second excited state $S_{2}$ and the ground state concerns the Soret band. We usually neglect the $S_{2} \rightarrow S_{0}$ transition because for it's very weak intensity compared to that of the $S_{1} \rightarrow S_{0}$ transition. The fluorescence spectra of the $\mathrm{H}_{2} \mathrm{TClPP}$, the $[\mathrm{Mg}(\mathrm{TClPP})]$ and complex (I) are depicted in Figure 5 and the photoluminescence data of our $\mathrm{Mg}(\mathrm{II})$ species and a selection of related compounds are reported in Table 5. A close investigation of Table 5 indicates that: (i) the $\lambda_{\max }$ values of the $\mathrm{Q}(0,0)$ and $\mathrm{Q}(0,1)$ emission bands of the free bases mesoarylporphyrins are $\sim 652 \mathrm{~nm}$ and $718 \mathrm{~nm}$, respectively and the fluorescence quantum yields $\phi_{\mathrm{f}}$ and the lifetime of singlet excited state $\tau_{\mathrm{f}}$ values of these non-metallated porphyrin species are in the range $[0.055-0.12]$ for $\phi_{\mathrm{f}}$ and in the range [7.2 - 9.6] ns for the lifetime $\tau_{\mathrm{f}}$, (ii) the $\mathrm{Q}(0,0)$ and $\mathrm{Q}(0,1)$ emission bands of the $[\mathrm{Mg}(\mathrm{Porph})]$ (Porph = meso-arylporphyrins) starting materials are remarkably hypochromic shifts of about $40 \mathrm{~nm}$ compared to those of the corresponding free base porphyrins which is due to the metalation of the porphyrin, (iii) this is also the case of the pentacoordinated and hexacoordinated manganese(II) metalloporphyrins, (iv) the fluorescence quantum yields and the lifetime of the singlet excited state values of the manganese(II) meso-arylporphyrins are slightly smaller than those of the corresponding free base porphyrins and (v) even though the $\mathrm{Q}$ bands values of the related diamagnetic zinc(II) meso-arylporphyrins are very close to those of the $\mathrm{Mg}$ (II)-mesoarylporphyrins, the $\phi_{\mathrm{f}}$ and the $\tau_{\mathrm{f}}$ values of the later species are quite higher than those of the $\mathrm{Zn}$ (II) meso-arylporphyrins which is also the case of the $\mathrm{Q}$ bands values. Representative fluorescence decay for complex (I) is shown in Figure S7. 
Table 5. Emission parameter values of several meso-porphyrins and a selection of Magnesium(II) mesometalloporphyrins.

\begin{tabular}{lllllll}
\hline Compound & $\lambda_{\text {exci }}$ & $Q(0,0)$ & $Q(0,1)$ & $\Phi_{\mathrm{f}}$ & $\tau_{\mathrm{f}}^{\mathrm{c}}$ (in ns) & Ref.
\end{tabular}

Free base meso-arylporphyrin

$\begin{array}{lllllll}\mathrm{H}_{2} \text { TClPP } & 418 & 651 & 714 & 0.089 & 7.42 & {[40]} \\ \mathrm{H}_{2} \text { TClPP } & 420 & 652 & 714 & 0.082 & 7.20 & \text { this work } \\ \mathrm{H}_{2} \text { TMPP }^{\mathrm{a}} & 424 & 656 & 719 & 0.082 & 7.20 & {[40]} \\ \mathrm{H}_{2} \mathrm{TPP}^{\mathrm{b}} & - & 653 & 722 & 0.12 & 9.60 & {[48]} \\ \mathrm{H}_{2} \mathrm{TBrPP}^{\mathrm{c}} & 420 & 654 & 720 & 0.055 & - & {[23]} \\ \mathrm{H}_{2} \mathrm{TPBP}^{\mathrm{d}} & - & 652 & 719 & - & - & {[41]}\end{array}$

Tetracoordinated Magnesium(II) meso-arylmetalloporhyrins

$\begin{array}{lllllll}{[\mathrm{Mg}(\mathrm{TClPP})]} & 420 & 628 & 679 & 0.18 & 6.3 & \text { this work } \\ {[\mathrm{Mg}(\mathrm{TPP})]^{\mathrm{b}}} & - & 608 & 665 & 0.15 & 9.2 & {[49]} \\ {[\mathrm{Mg}(\mathrm{TPBP})]^{\mathrm{d}}} & - & 611 & 665 & - & - & {[23]} \\ {\left[\mathrm{Mg}^{\mathrm{II}}(\mathrm{TClPP})\right]} & 420 & 615 & 670 & 0.18 & 6.3 & \text { this work }\end{array}$

Pentacoordinated and hexacoordinated Magnesium(II)meso-arylporphyrins

\begin{tabular}{|c|c|c|c|c|c|c|}
\hline$[\mathrm{Mg}(\mathrm{TClPP})(\mathrm{DMAP})]$ & 420 & 608 & 659 & 0.16 & 5.0 & this work \\
\hline$\left[\mathrm{Mg}(\mathrm{TPP})(\mathrm{THF})_{2}\right]^{\mathrm{b}}$ & - & & 660 & 0.16 & - & {$[50]$} \\
\hline$[\mathrm{Mg}(\mathrm{TPP})(\mathrm{NCO})]^{-\mathrm{b}}$ & 560 & 609 & 664 & 0.18 & 3.8 & [42] \\
\hline$[\mathrm{Mg}(\mathrm{TPP})(\mathrm{NCS})]^{-\mathrm{b}}$ & 560 & 608 & 662 & 0.19 & 6.1 & [42] \\
\hline$\left[\mathrm{Mg}(\mathrm{TPBP})(\mathrm{HTMA})_{2}\right]^{\mathrm{d}}$ & & 611 & 666 & 0.055 & - & [41] \\
\hline$\left[\mathrm{Mg}(\mathrm{TPBP})(\mathrm{DABCO})_{2}\right.$ & & 612 & 666 & 0.065 & - & [41] \\
\hline$\left[\mathrm{Mg}(\mathrm{TPBP})\left(4,4^{\prime}-\mathrm{bpy}\right)_{2}\right]$ & & 611 & 665 & 0.060 & - & [51] \\
\hline
\end{tabular}

Pentacoordinated and hexacoordinated Zinc(II)meso-arylporphyrins

$\begin{array}{lllllll}{\left[\mathrm{Zn}(\mathrm{TPP})\left(\mathrm{N}_{3}\right)\right]^{-\mathrm{b}}} & 560 & 594 & 643 & 0.036 & 1.7 & {[\mathbf{5 2}]} \\ {[\mathrm{Zn}(\mathrm{TPP})(\mathrm{CN})]^{-\mathrm{b}}} & 560 & 594 & 643 & 0.055 & 1.7 & {[\mathbf{5 2}]} \\ {[\mathrm{Zn}(\mathrm{TPBP})(\mathrm{DABCO})]^{\mathrm{d}}} & 540 & 612 & 660 & 0.039 & 1.3 & {[\mathbf{5 3}]} \\ {\left[\mathrm{Zn}(\mathrm{TPBP})(\mathrm{pyz})_{2}\right]^{\mathrm{d}, \mathrm{i}}} & 540 & 596 & 644 & 0.049 & 1.6 & {[\mathbf{5 3}]} \\ {[\mathrm{Zn}(\mathrm{TPBP})(4-\mathrm{CNpy})]^{\mathrm{d}, \mathrm{j}}} & 540 & 596 & 645 & 0.041 & 1.5 & {[\mathbf{5 3}]}\end{array}$

\footnotetext{
${ }^{\mathrm{a}}: \mathrm{H}_{2} \mathrm{TMPP}=$ meso-tetra(para-methoxyphenyl)porphyrin, ${ }^{\mathrm{b}}: \mathrm{H}_{2} \mathrm{TPP}=$ meso-tetraphenylporphyrin, ${ }^{\mathrm{c}}: \mathrm{H}_{2} \mathrm{TBrPP}=$ mesotetrakis(4-bromophenyl)porphyrin, ${ }^{\mathrm{d}}: \mathrm{H}_{2} \mathrm{TPBP}=$ meso-tetrakis[4(benzoyloxy)phenyl]porphinato, ${ }^{\mathrm{e}}: \mathrm{HTMA}=$ Hexamethylenetetramine, ${ }^{\mathrm{f}}:$ DABCO $=, 4$-diazabicyclo[2.2.2] octane, ${ }^{\mathrm{g}}:{ }^{\prime}$ 4,4'-bpy $=4,4^{\prime}$ '-bipyridine. ${ }^{\mathrm{i}}:$ pyz $=$ pyrazine, ${ }^{\mathrm{j}}$ : 4-CNpy = 4-cyanopyridine.
} 


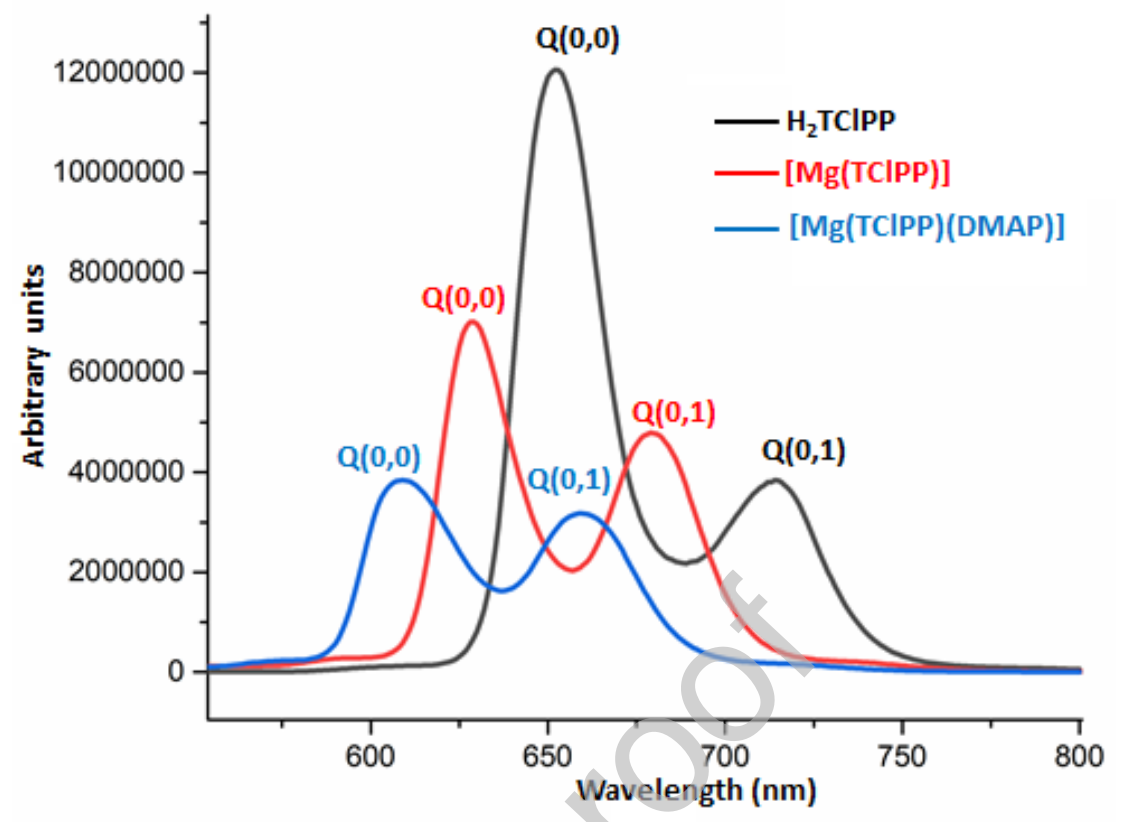

Figure 5. Emission spectrum of $\mathrm{H}_{2} \mathrm{TClPP},[\mathrm{Mg}(\mathrm{TClPP})]$ and $[\mathrm{Mg}(\mathrm{TClPP})(\mathrm{DMAP})]$ (I). Concentrations $\sim 10^{-6} \mathrm{M}$ in dichloromethane solutions.

\section{4. $\mathrm{X}$-ray Structures of $[\mathrm{Mg}(\mathrm{TClPP})(\mathrm{DMAP})] \cdot 1 / 2 \mathrm{C}_{6} \mathrm{H}_{14}(\mathrm{I})$}

Figure 6 represents the ORTEP view of the $[\mathrm{Mg}(\mathrm{TClPP})(\mathrm{DMAP})]$ coordination compound with thermal ellipsoids drawn at $30 \%$ probability. The asymmetric unit of (I) is made by one $[\mathrm{Mg}(\mathrm{TClPP})(\mathrm{DMAP})]$ molecule and a half of $\mathrm{n}$-hexane solvent molecule. Another disordered $\mathrm{n}$-hexane solvent molecule was removed using the PLATON SQUEEZE method [37].

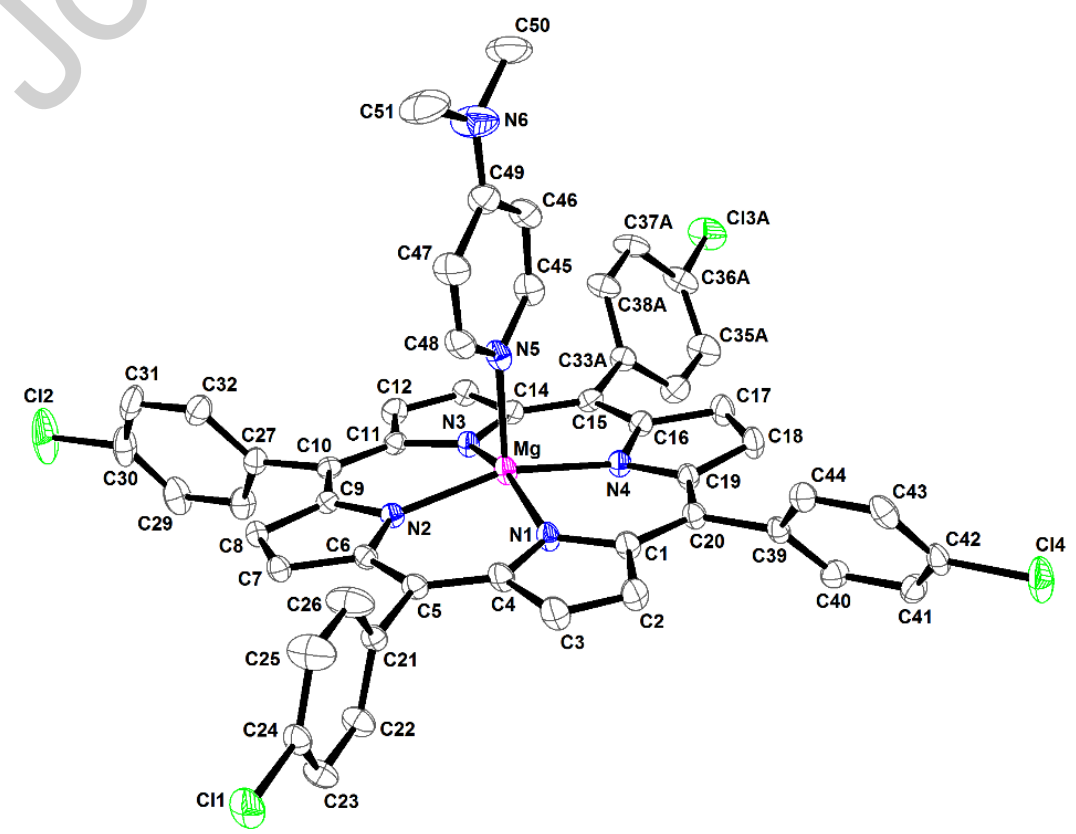


Figure 6. Ortep drawing of [Mg(TCIPP)(DMAP)] (I) with thermal ellipsoids drawn at $30 \%$ probability. The hydrogen atoms are removed for clarity. Only the major positions of (i) the disordered phenyl group of the porphyrin is shown and (ii) the $\mathrm{N}\left(\mathrm{CH}_{2}\right)$ - group of the DMAP axial ligand are represented.

The coordination geometry around the $\mathrm{Mg}$ (II) center metal ion in (I) is square pyramidal, where the four nitrogens of the pyrrole rings of the TCIPP moiety occupy the equatorial positions and the $\mathrm{N}$ atom of the pyridyl group of the DMAP axial ligand occupies the apical position (Figures 6 and 7). 
Figure 7. Ortep diagram of $[\mathrm{Mg}(\mathrm{TClPP})(\mathrm{DMAP})]$ viewed perpendicular to the mean plane of the porphyrinato core showing the $\phi$ dihedral angle. The hydrogen atoms are removed for clarity and only the major positions of the disordered fragments are represented.

It is noteworthy that the reported magnesium(II) metalloporphyrins (Table 6) with an ionic axial ligand are pentacoordinated species type $[\mathrm{Mg}(\mathrm{Porph})(\mathrm{X})]^{-}$(Porph $=$meso-arylporphyrinato, $\mathrm{X}=$ ionic axial ligand) e.g. $[\mathrm{Mg}(\mathrm{TPP})(\mathrm{OCN})]^{-[42]}$. The reaction of the $[\mathrm{Mg}(\mathrm{Porph})]$ starting material with axial neutral ligand (L) leads either to a pentacoordinated complexes type $[\mathrm{Mg}(\mathrm{Porph})(\mathrm{L})]$ or a hexacoordinated species type $\left[\mathrm{Mg}(\mathrm{Porph})(\mathrm{L})_{2}\right]$. Thus, as shown in Table 6, both $\left[\mathrm{Mg}(\mathrm{TPP})\left(\mathrm{H}_{2} \mathrm{O}\right)\right][54]$ and $\left[\mathrm{Mg}(\mathrm{TPP})\left(\mathrm{H}_{2} \mathrm{O}\right)_{2}\right]$ [55] structures are reported. Furthermore, the magnesium porphyrin complexes with N-donor neutral cyclic axial ligands such as DABCO (1,4-diazabicyclo[2.2.2]octane), pyridine, 4Picoline-N (4-Methylpyridine), 4,4'-bipy (4,4'-bipyridine), pipz (piperazine) are hexacoordinated which is not the case for our Mg-DMAP-porphyrin derivative (I) which is pentacoordinated as determined by X-ray molecular structure.

The $\mathrm{Mg}-\mathrm{N}(\mathrm{DMAP})$ distance value of (I) is 2.130 (4) $\AA$ is in the range [2.096 - 2156] $\AA$ of the related $\mathrm{Mg}(\mathrm{II})-\mathrm{DMAP}$ non-porphyrinic complexes reported in Table 6.

A formal diagram of the porphyrinato core of $[\mathrm{Mg}(\mathrm{TClPP})](\mathrm{DMAP})]$ showing the displacements of each atom from the mean plane of the porphyrin macrocycle $\left(\mathrm{P}_{\mathrm{C}}\right)$ in units of $0.01 \AA$ is depicted by Figure 8. This figure shows (i) that (I) exhibits a moderate domed deformation of the $\mathrm{C}_{20} \mathrm{~N}_{4}$ least squares plane as indicated by the values of the displacements of the nitrogens toward the DMAP axial ligand, (ii) a moderate saddle $S 4$ distortion of the porphyrin mean plane indicated by the displacement of the pyrrole rings alternately above and below the mean porphyrin macrocycle and (iii) a weak ruffling as shown by the small displacements of the meso-carbon atoms above and below the porphyrin mean plane [56].

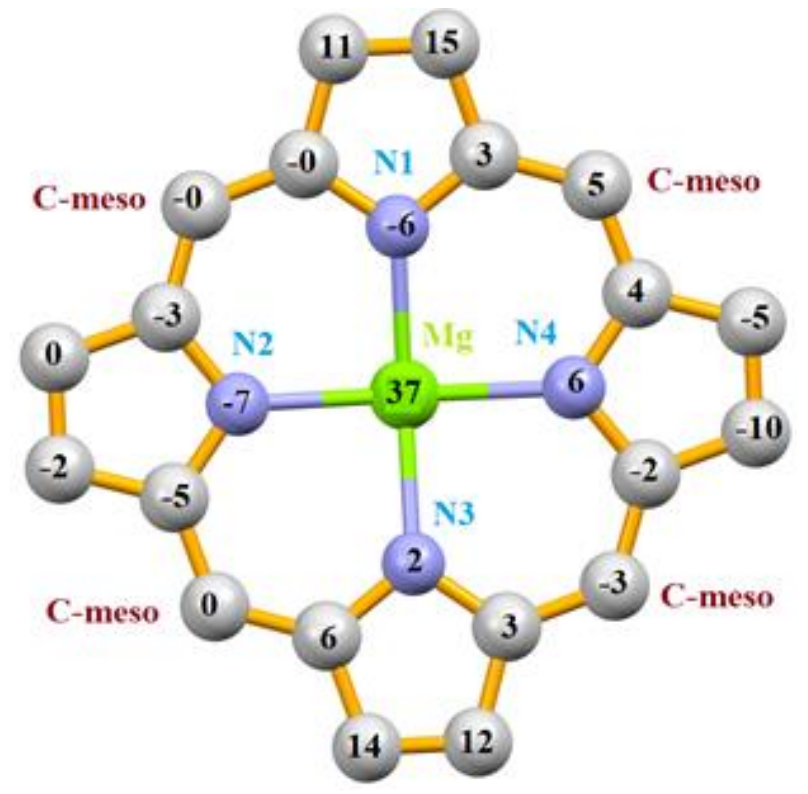


Figure 8. Formal diagram of the mean plane of the 24-atom porphyrin core. Positive values of the displacements are toward the axial DMAP ligand.

The displacement of the metal atom out of the mean-plan porphyrin core $\left(\mathrm{Mg}-\mathrm{P}_{\mathrm{C}}\right)$ of our $\mathrm{Mg}$ (II)DMAP derivative (I) with a value of 0.3709 (14) is the smallest among all five-coordinated magnesium(II) meso-arylporphyrines reported in Table 6. This may indicates a strong affinity between the $\operatorname{Mg}(\mathrm{II})$ center ion and the DMAP ligand. The values of the dihedral angles $(\phi)$ between the DMAP plane and the closest $\mathrm{N}$ (pyrrole)-Mg-N(DMAP) plane is $30.41^{\circ}$ (Figure 7). This value is quite close to the value $45^{\circ}$ which leads to a minimum nonbonded interaction between the porphyrin core atoms and the planar axial ligand hydrogen atoms [57]. The average equatorial distance between the manganese(II) central ion and the nitrogen atoms of the porphyrin ring $(\mathrm{Mg}-\mathrm{Np})$ of complex (I) is 2.082 (3) $\AA$ which in the [2.066 - 2.094 (2)] A range of neutral pentacoordinated and hexacoordinated $\mathrm{Mg}(\mathrm{II})$ complex type $\left[\mathrm{Mg}(\mathrm{Porph})(\mathrm{L})_{\mathrm{x}}\right]$ (Porph = meso-arylporphyrinato, $\mathrm{L}=$ neutral axial ligand and $\mathrm{x}$ $=1$ or 2 ) (Table 6$)$ but smaller that ion complexes type $[\mathrm{Mg}(\mathrm{Porph}) \mathrm{X}]^{-}$where is $\mathrm{X}$ a anionic axial ligand such as $\mathrm{N}_{3}{ }^{-}$(Table 6).

The crystal packing of (I) is made by layers perpendicular to the [010] direction (Figure 9). Within each layer the $[\mathrm{Mg}(\mathrm{TCIPP})(\mathrm{DMAP})]$ molecules are located up-side-down. The cohesion of the crystal packing of (I) is stabilized by nonconventional $\mathrm{C}-\mathrm{H} \cdots \mathrm{Cl}$ and by $\mathrm{C}-\mathrm{H} \cdots \mathrm{Cg}$ intermolecular interactions involving the pyrrole and phenyl rings of the porphyrins (Table $\mathrm{S} 1)(\mathrm{Cg}=$ the centroid of a pyrrole a phenyl ring). Indeed, as shown by Figure 10, the chloride $\mathrm{Cl} 3$ of one TClPP moiety is weakly $\mathrm{H}$ bonded to the carbon $\mathrm{C} 28$ of a nearby $[\mathrm{Mg}(\mathrm{TClPP})(\mathrm{DMAP})]$ molecule with a $\mathrm{C} 28-\mathrm{H} 28{ }^{\cdots} \mathrm{Cl} 3$ distance value of 3.875 (5) $\AA$. The carbon $\mathrm{C} 37$ of a phenyl ring of one [Mg(TClPP)(DMAP)] complex is weakly linked to the centroid $\mathrm{Cg} 2$ of the N2/C6-C9 pyrrole ring of a neighboring $[\mathrm{Mg}(\mathrm{TClPP})(\mathrm{DMAP})]$ molecule with a $\mathrm{C} 3-\mathrm{HC} 7{ }^{\cdots} \mathrm{Cg} 2$ distance value of 3.875 (5) $\AA$. The n-hexane solvent molecule is weakly linked to the centroid $\mathrm{Cg} 7$ of the pyridyl cycle (of the DMAP axial ligand) 
of a nearby $[\mathrm{Mg}(\mathrm{TClPP})(\mathrm{DMAP})]$ molecule via le carbon C52 with a C52-H52A ${ }^{\cdots} \mathrm{Cg} 7$ distance of 3.843 (7) ^.

Table 6. Selected bond lengths $[\AA]$ and angles $\left[{ }^{\circ}\right]$ for $[\mathrm{Mg}(\mathrm{TClPP})(\mathrm{DMAP})] \cdot 1 / 2 \mathrm{C}_{6} \mathrm{H}_{14}(\mathrm{I})$ and several related complexes.

Complex $\quad \mathrm{M}^{-} \mathrm{N}_{\mathrm{p}}{ }^{\mathrm{a}} \quad \mathrm{M}^{-} \mathrm{X}_{\mathrm{L}}^{\mathrm{b}} \quad \mathrm{M}-\mathrm{P}_{\mathrm{C}}{ }^{\mathrm{c}} \quad$ Ref.

\begin{tabular}{lllll}
\hline \multicolumn{5}{c}{ Pentacoodinayed Magnesium(II) Metalloporphyrins } \\
\\
{$[\mathrm{Mg}(\mathrm{TBrPP})(\mathrm{HIm})]^{\mathrm{d}, \mathrm{e}}$} & $2.094(2)$ & $2.120(3)$ & 0.52 & \\
{$\left[\mathrm{Bu}{ }_{4} \mathrm{~N}\right]\left[\mathrm{Mg}(\mathrm{TPP})\left(\mathrm{HCO}_{3}\right)\right]^{\mathrm{f}}$} & $2.101(3)$ & $1.959(2)$ & 0.478 & {$[\mathbf{2 3}]$} \\
{$[\mathrm{K}(222)]\left[\mathrm{Mg}(\mathrm{TPP})\left(\mathrm{N}_{3}\right)\right]^{\mathrm{f,g}}$} & $2.1187(16)$ & $1.997(2)$ & $0.6629(7)$ & {$[\mathbf{5 8}]$} \\
{$[\mathrm{K}(222)][\mathrm{Mg}(\mathrm{TPP})(\mathrm{NCS})]^{\mathrm{f}, \mathrm{g}}$} & $2.0962(13)$ & $2.0817(15)$ & $0.5797(6)$ & {$[42]$} \\
{$\left[\mathrm{Mg}(\mathrm{TPP})\left(\mathrm{H}_{2} \mathrm{O}\right)\right]^{\mathrm{f}}$} & $2.092(7)$ & $2.012(6)$ & 0.460 & {$[42]$} \\
{$[\mathrm{Mg}(\mathrm{TClPP})(\mathrm{DMAP})]$} & $2.082(3)$ & $2.130(4)$ & $0.3709(14)$ & {$[\mathbf{5 4}]$} \\
& & & this work
\end{tabular}

Pentacoodinayed Magnesium(II) Metalloporphyrins

Hexacoordinnated Magnesium(II) Metalloporphyrins

\begin{tabular}{|c|c|c|c|c|}
\hline$\left[\mathrm{Mg}(\mathrm{TPP})(\text { 4-picoline- } \mathrm{N})_{2}\right]^{\mathrm{f}, \mathrm{i}}$ & 2.070 & 2.385 & 0.000 & \\
\hline$\left\{\left[\mathrm{Mg}(\mathrm{TPBP})\left(4,4^{\prime}-\mathrm{bpy}\right)_{2}\right]\right\}_{\mathrm{n}}^{\mathrm{j}, \mathrm{k}}$ & 2.066 & 2.320 & 0.000 & [51] \\
\hline$\left[\mathrm{Mg}(\mathrm{TBrPP})\left(\mathrm{H}_{2} \mathrm{O}\right)_{2}\right]^{\mathrm{j}}$ & 2.069 & 2.221 & 0.000 & [59] \\
\hline$\left[\mathrm{Mg}(\mathrm{TPP})\left(\mathrm{H}_{2} \mathrm{O}\right)_{2}\right]^{\mathrm{f}}$ & 2.071 & 2.213 & 0.000 & [55] \\
\hline$\left[\mathrm{Mg}(\mathrm{TPP})(\mathrm{HTMA})_{2}\right]^{\mathrm{f}, \mathrm{m}}$ & $2.067(5)$ & $2.473(2)$ & 0.000 & [60] \\
\hline$\left[\mathrm{Mg}(\mathrm{TPP})(1-\mathrm{MeIm})_{2}\right]^{\mathrm{f}, \mathrm{n}}$ & 2.079 & 2.297 & 0.000 & [61] \\
\hline$\left[\mathrm{Mg}(\mathrm{TPP})(\mathrm{pipz})_{2}\right]^{\mathrm{f}, \mathrm{o}}$ & 2.073 & 2.423 & 0.000 & [61] \\
\hline$\left[\mathrm{Mg}(\mathrm{TPP})(\mathrm{py})_{2}\right]^{\mathrm{f}, \mathrm{p}}$ & 2.072 & 2.376 & 0.000 & [62] \\
\hline$\left[\mathrm{Mg}(\mathrm{TPBP})(\mathrm{HTMA})_{2}\right]^{\mathrm{j}, \mathrm{n}}$ & 2.074 & 2.439 & 0.000 & [24] \\
\hline$\left[\mathrm{Mg}(\mathrm{TPBP})(\mathrm{DABCO})_{2}\right]$ & 2.066 & 2.487 & 0.000 & [63] \\
\hline
\end{tabular}

DMAP-Mg(II) non-porphyrinic complexes

\begin{tabular}{|c|c|c|c|c|}
\hline$\left[\mathrm{Mg}(\mathrm{DMAP})_{2}\left(\mathrm{~L}_{1}\right)_{2}\right]^{\mathrm{s}}$ & - & $2.156(1) / 2.154(2)$ & - & [64] \\
\hline$\left[\mathrm{Mg}(\mathrm{I})(\mathrm{DMAP})\left(\mathrm{L}_{2}\right)\right]^{\mathrm{t}}$ & - & $2.112(3)$ & - & [65] \\
\hline$\left[\mathrm{Mg}(\mathrm{DMAP})\left(\mathrm{L}_{3}\right)\left(\mathrm{L}_{4}\right)\right]^{\mathrm{u}, \mathrm{v}}$ & - & 2.096 & - & [66] \\
\hline$\left[\operatorname{Mg}(\mathrm{DMAP})\left(\mathrm{L}_{5}\right)\left(\mathrm{L}_{6}\right)\right]^{\mathrm{x}, \mathrm{y}}$ & - & 2.142 & - & [67] \\
\hline
\end{tabular}

\footnotetext{
${ }^{a}: \mathrm{M}-\mathrm{Np}=$ average equatorial cobalt-nitrogen pyrrole distance, ${ }^{\mathrm{b}}: \mathrm{M}-\mathrm{X}_{\mathrm{L}}=$ metal-axial ligand distance, ${ }^{c}: \mathrm{M}-\mathrm{P}_{\mathrm{C}}=$ distance between the metal atom and the mean plane made by the 24 -atom core of the porphyrin $\left(\mathrm{P}_{\mathrm{C}}\right) .{ }^{\mathrm{d}}: \mathrm{TBrPP}=$ meso-tetrakis(4-bromophenyl)porphyrinato, e: Him = imidazole, ${ }^{\mathrm{f}}:$ meso-tetraphenylporphyrin, ${ }^{\mathrm{g}}:[\mathrm{K}(222)]^{+}=$ (cryptand-222)potassium $(+)$ cation, ${ }^{\mathrm{i}}:$ 4-picoline $=4$-Methylpyridine, ${ }^{\mathrm{j}}:$ TPBP $=m e s o-\{$ tetrakis-[4(benzoyloxy)phenyl]porphyrinato, ${ }^{\mathrm{m}}:$ HTMA $=$ hexamethylenetetramine, ${ }^{\mathrm{n}}: 1$-MeIm $=1$-methylimidazole, ${ }^{\circ}:$ pipz $=$ piperazine, ${ }^{\mathrm{p}}:$ py $=$ pyridine, ${ }^{\mathrm{r}}:$ DABCO $=4$-diazabicyclo[2.2.2] octane, $^{\mathrm{s}}: \mathrm{L}_{1}=$ Isopropyl(trimethylsilyl $)$ amido, ${ }^{\mathrm{t}}: \mathrm{L}_{2}=$
} 
N,N'-bis(2,6-Di-isopropylphenyl)-2,2,6,6-tetramethylheptane-3,5-di-iminato-N,N', ${ }^{\prime}: \mathrm{L}_{3}=$ Benzophenone radical-O, ${ }^{\mathrm{V}}$ : $\mathrm{L}_{4}=\mathrm{N}, \mathrm{N}$-bis(2,6-di-isopropylphenyl)-2,4-diiminopropane, ${ }^{\mathrm{X}}: \mathrm{L}_{5}=$ (4,4,5,5-tetramethyl-1,3,2-dioxborolan-2yl)diphenylmethoxy, ${ }^{\mathrm{y}}: \mathrm{L}_{6}=\mathrm{N}, \mathrm{N}^{\prime}$-bis(2,6-di-isopropylphenyl)pentane-2,4-di-iminato.

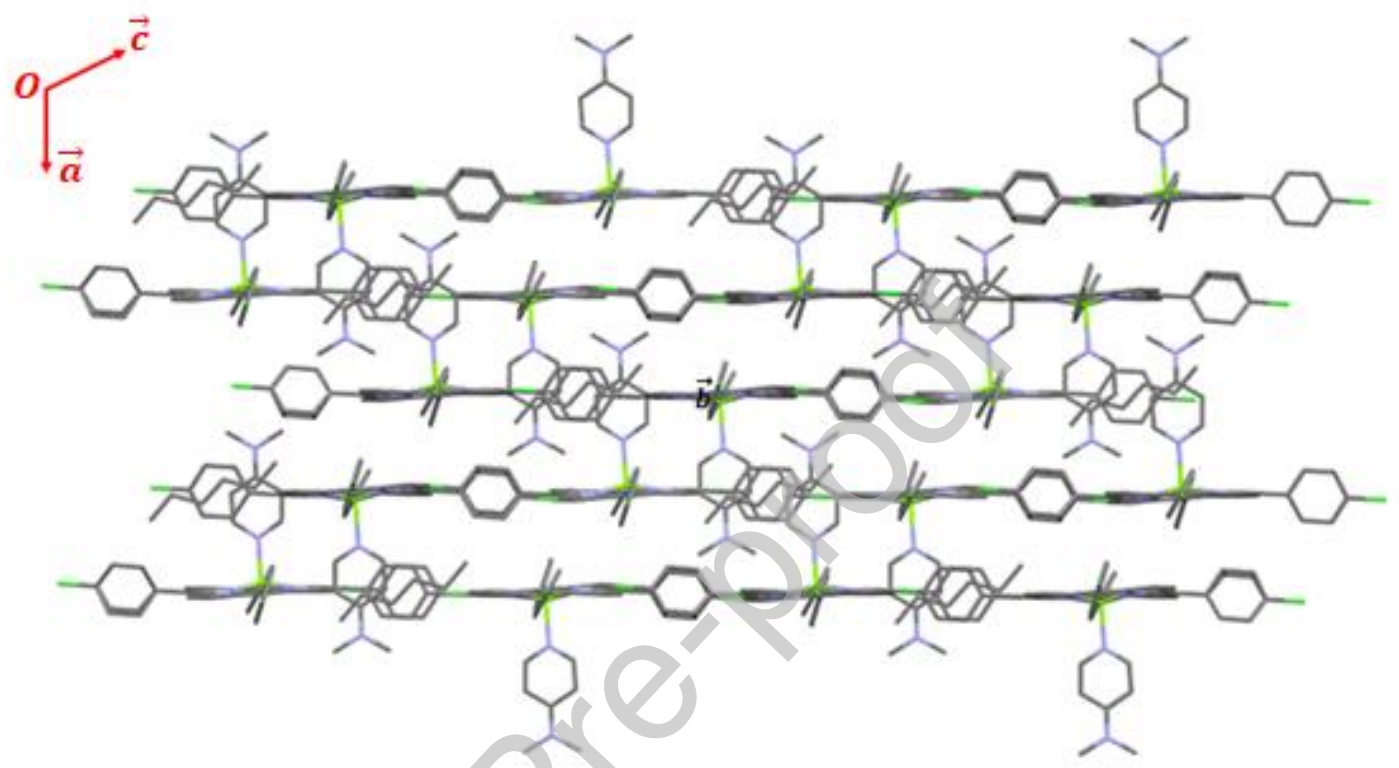

Figure 9. Projection down the [010] direction showing the parallel layers. 


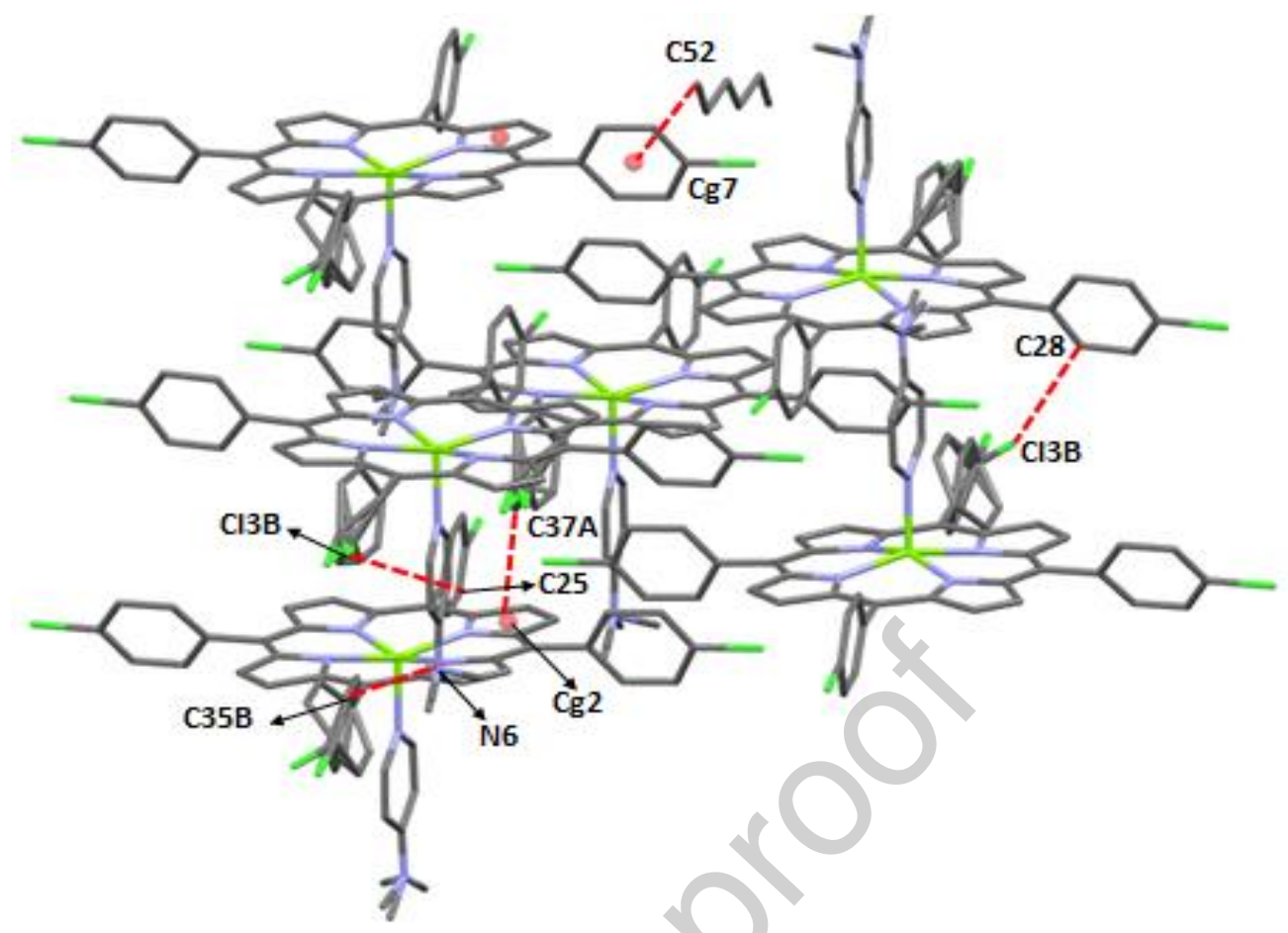

Figure 10. Packing diagram of (I) showing the three dimensional arrangement of the $[\mathrm{Mg}(\mathrm{TClPP})(\mathrm{DMAP})]$ and the n-hexane molecules.

\subsection{Hirshfeld Surface Analysis}

The supramolecular interactions in the title structure have been further investigated and visualized by Hirshfeld surface analysis [27,68,69] performed with CrystalExplorer17 [70]. The different normalized contact distances " $d_{\text {norm }}$ " were calculated using the following equation (Eq. 3) [30]:

$$
d_{n o r m}=\frac{d_{i}-r_{i}^{v d W}}{r_{i}^{v d W}}+\frac{d_{e}-r_{e}^{v d W}}{r_{e}^{v d W}}
$$

where " $\mathrm{d}_{\mathrm{e}}$ " is the distance from the point to the nearest nucleus external to the surface, " $\mathrm{d}_{\mathrm{i}}$ " is the distance to the nearest nucleus internal to the surface and "vdW" is the van der Waals radii of the atom. The $d_{\text {norm }}$ surface is mapped on the Hirshfeld surface with blue, white, or red colors. The $d_{\text {norm }}$ value is negative (red) when intermolecular contacts are shorter than the van der Waals radii, and the $d_{\text {norm }}$ value is positive (blue) when longer. The $d_{\text {norm }}$ value of the white zones is zero and represents contacts equal to the van der Waals radius.

The Hirshfeld surfaces of synthetic $\mathrm{Mg}$ (II)-DMAP species (I), which are shown as transparent to allow visualization of the asymmetric unit of the given crystal structure, are illustrated in Figure 11-a. These Hirshfeld surfaces have been mapped over a « $\mathrm{d}_{\text {norm }} »$ range of -0.7287 to $1.5763 \AA$ 
(a)

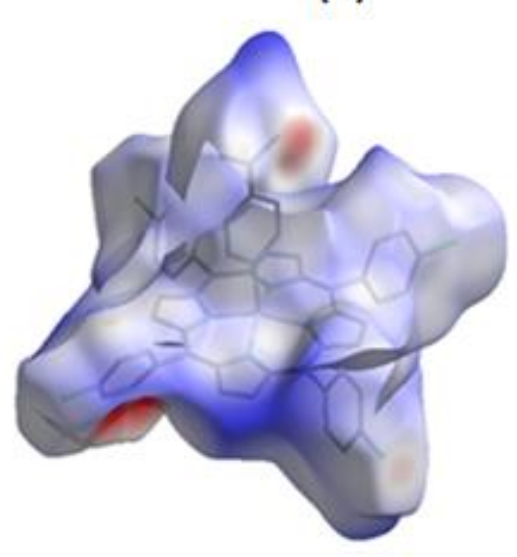

(b)

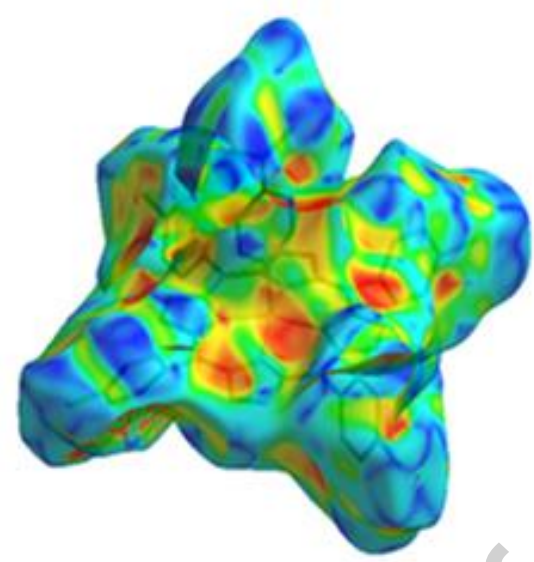

(c)

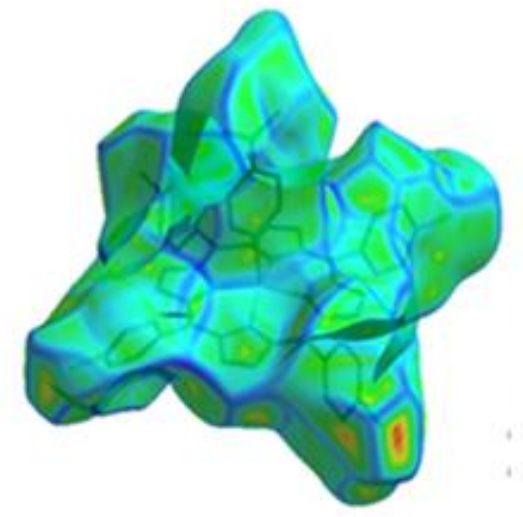

Figure 11. Hirshfeld surfaces mapped with $\mathrm{d}_{\text {norm }}(\mathbf{a})$, shape Index surface (b) and curvedness surfaces(c) for (I).

The shape index that is the most sensitive to very little changes in surface, give the information about each donor-acceptor pair. The $\mathrm{C}-\mathrm{H}^{\cdots} \mathrm{Cg} \pi$ contacts in the compound represented by the concave red triangles above the plane of the $[\mathrm{Mg}(\mathrm{TClPP})(\mathrm{DMAP})]$ molecule and the contacts by ring atoms of molecule inside these surfaces represent by convex blue triangles (Figure II-b).

The curvedness is a measure of 'how much shape', which usually tend to divide the surface into patches, which indicating interactions between neighboring molecules. So, sharp curvature regions of the surface correspond to high curvedness values, while the flat regions correspond to low curvedness values. The relatively large green regions, observed as flat patches in the curvedness mapped surfaces, indicate the presence of $\pi-\pi$ interactions between molecules (Figure 11-c) which is confirmed by the PLATON calculations (see crystallographic section) [71].

The 2D fingerprint plots $\left(d_{i}\right.$ versus $d_{e}$ ) (Figure 12) present contacts between two atoms interactions and indicate percentage of contributions from different interaction types. Practically all interactions occur between two chemically and crystallographically equal molecules. The $\mathrm{H} \cdots \mathrm{H}$ and $\mathrm{C} \cdots \mathrm{H}$ contacts have the most important contribution to the total Hirshfeld surface with $49.9 \%$ and $12.7 \%$, respectively. The proportions of $\mathrm{H}^{\cdots \cdot} \mathrm{Cl}$ and $\mathrm{H}^{\cdots \cdots} \mathrm{N}$ contacts comprise $11 \%$ and $2.9 \%$ of the total map, respectively. 


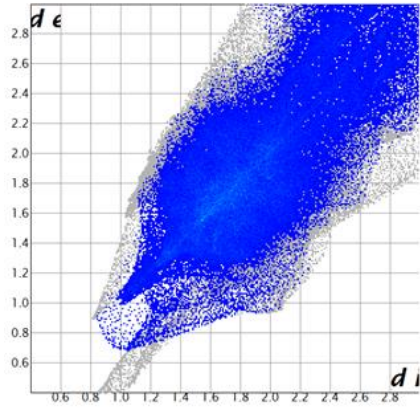

H'*H (49.9\%)

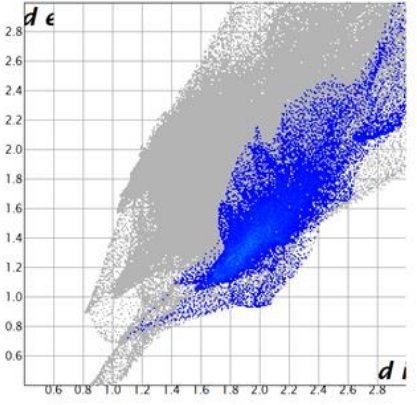

H...C/C...H (12.7\%)

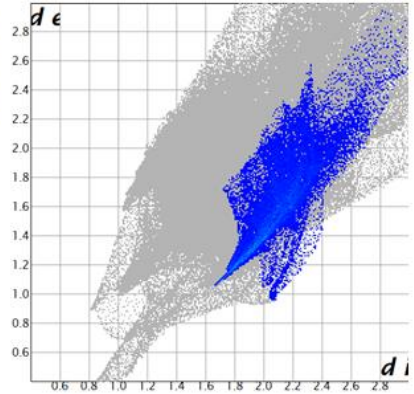

H...Cl /Cl...H (11\%)

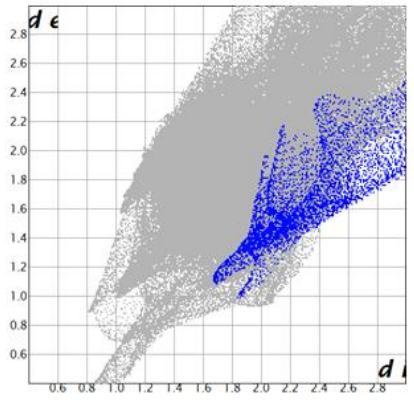

H...N/N...H (2.9\%)

Figure 12. Two-dimensional fingerprint plots for (I).

\subsection{Theoretical Structural study}

Theoretical studies of [Mg(TCPP)(DMAP)] compound have been determined using DFT (Density Functional Theory) method implanted in the Gaussian 09 program [72] and their interface Gauss view [73]. All the physical or chemical properties of a system can only be determined for stable structures. The geometric optimization allows to find the most stable structure associated with the lowest energy. Subsequently, this geometry was used as an input file for other calculations such as the calculation of the infrared spectrum. It is for this reason that the first step we have taken is the geometric optimization.

The stable structure of [Mg(TCPP)(DMAP)] (I) has been optimized in the ground state at B3LYP (Becke's three parameter hybrid functional [74] with Lee-Yang-Parr correlation functional LYP [75]) theory with LanL2DZ basis sets (as shown in Figure 13). The optimized structure represents the most stable structure since it does not contain imaginary frequencies in the vibration frequency calculations. In gas phase, the optimized molecular structure has an energy worth -2352.8169 a.u and a dipolar moment equal to 9.0255 Debye. While, in the chloroform solvent, the optimized geometry has an energy equal to -2352.8346 a.u and a dipole moment equal to 10.6344 Debye (Table 7). Figure S8 is the optimized molecular structure of $[\mathrm{Mg}(\mathrm{TCPP})(\mathrm{DMAP})]$ shown the label scheme used. The experimental and theoretical geometrical parameters such as the bond lengths and the bond angles of $[\mathrm{Mg}(\mathrm{TCPP})(\mathrm{DMAP})]$ molecule are given in Table $\mathrm{S} 2$ in the gas phase and in chloroform solvent. These geometrical parameters are discussed in terms of RMSD (Root-Mean-Square Deviation) values, which consists in comparing the calculated with the observed values. The calculated values of the RMSD are given in Table 7. As clearly seen, the bond lengths and the bond angles values are very similar in both phase (in gas and in chloroform solvent). For the bond lengths, the value of the RMSD 
in the gas phase is equal to 0.0645 , while in the chloroform is equal to 0.0649 . For the bond angles, $\operatorname{RMSD}_{\text {(gas) }}=0.6351 ; \operatorname{RMSD}_{\text {(Chloroform) }}=0.6399$. From these RMSD values, we can conclude that the geometrical molecular parameters are found to be in good agreement with the experimental values.

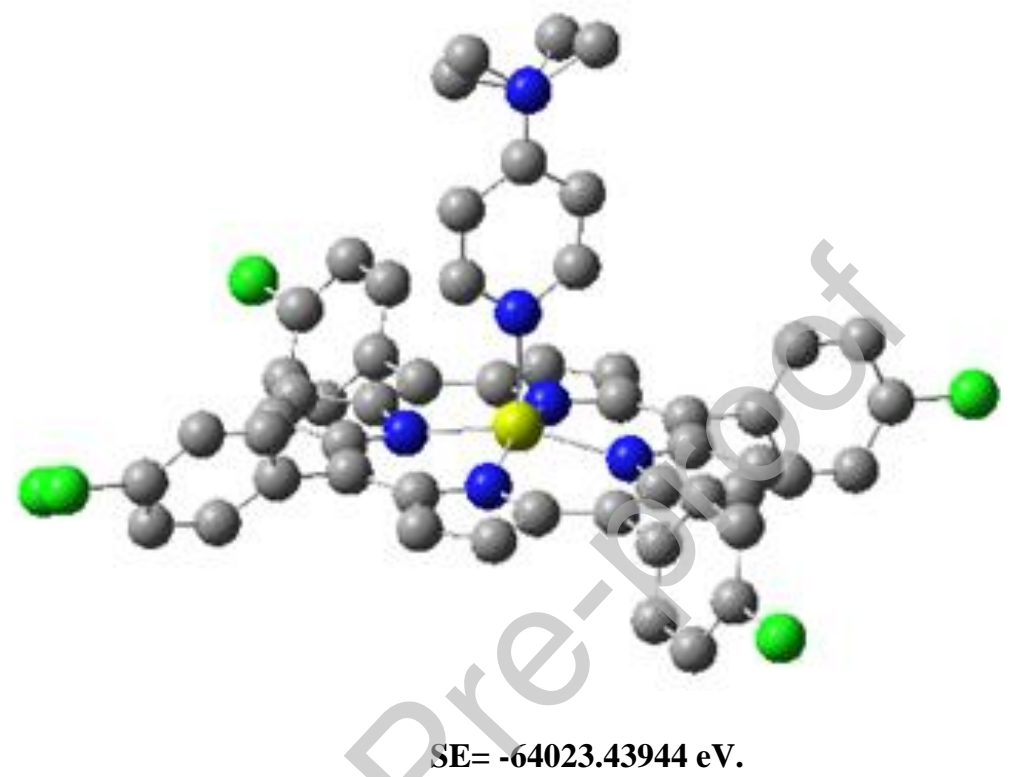

Figure 13. Optimized molecular structure of [Mg(TCPP)(DMAP)] using DFT/B3LYP/LanL2DZ method in gas phase.

Table 7. Maximum force, RMS force, RMS Gradient Norm and point group of $[\mathrm{Mg}(\mathrm{TCPP})(\mathrm{DMAP})]$ calculated at B3LYP/ LanL2DZ levels of theory.

B3LYP / LanL2DZ

Parameters

Gaz Chloroform

Energy (a.u.)

Dipole moment (Debye)

Maximum force

RMS force

RMS Gradient Norm (a.u.)

Point group
$-2353.9201$

9.0341

0.1680

0.0734

$3.01 .10^{-6}$

$\mathrm{C}_{1}$

-2353.9355
10.7891
0.1680
0.0733
$1.75 .10^{-6}$
$C_{1}$

$-2353.9355$

0.0733

$\mathrm{C}_{1}$ 


\subsection{Frontier Molecular Orbital study}

TD-DFT (Time-Dependent Density-Functional Theory) calculation is used to determine the electronic parameters, such as the excitation energies, absorption wavelength, oscillator strengths and major contributions. The calculations are carried out using the B3LYP functional and LanL2DZ basis set. The frontier molecular orbitals (FMOs) of $[\mathrm{Mg}(\mathrm{TCPP})(\mathrm{DMAP})]$ (I) molecule are illustrated in Figure 14. These orbitals have the advantage of analysing the reaction and the selectivity of the reaction. Among these frontier orbitals, we can cite the highest occupied molecular orbital "HOMO" and the lowest unoccupied molecular orbital "LUMO". The molecular reactions are permitted if the HOMO orbital and the LUMO orbital are placed in such a way that the lobes of the same sign overlap [76]. These two orbitals have the same role as chemical valence orbitals [76].

Figure 14 shows that for the HOMO molecular orbital of (I), the charge density is mostly localized on the meso-carbons and the nitrogens of the TCIPP porphyrinate while for the LUMO molecular orbital of (I), the charge density is mostly distributed over the meso, $\alpha$-pyrrole and $\beta$-pyrrole carbons as well as the nitrogen atoms of the macrocycle of the TCIPP moiety.

We define, the Gap energy (E-Gap), the ionization potential $(I)$, the electron affinity $(A)$, the chemical potential $(\mu)$, the chemical hardness $(\eta)$, the global softness $(S)$ and the global electrophilicity $(\Psi)$ by equations (Eq. 4-10):

$$
\begin{aligned}
& E-G a p=E_{\text {HомO }}-E_{\text {LUMO }} \\
& I=-E_{\text {HомO }} \\
& A=-E_{\text {LUMO }} \\
& \mu=-1 / 2(I+A)) \\
& \eta=1 / 2(I-A) \\
& S=\frac{1}{2 \eta} \\
& \psi=\frac{\mu^{2}}{2 \eta}
\end{aligned}
$$

These parameters were determined via TD-DFT approach with LanL2DZ basis set. The theoretical gap energy (E-Gap) define by equation (Eq. 4) is $2.630 \mathrm{eV}$. One can deduce whether a complex is hard or soft based on the values of the energies of the HOMO and the LUMO molecular orbitals. In general, a molecule with low gap energy is more polarizable, this is associated with high chemical reactivity and 
low kinetic stability. The increase in Gap energy implies high stability in the sense of its lower reactivity in chemical reactions. The global electrophilicity $(\Psi)$ parameter gives us an estimation on the lowering of the Gap energy to the maximal electron flow between the donor and the acceptor and therefore the chemical hardness and softness is a good indicator of the chemical stability of our complex (I) (Table 8). We notice that the theoretical Gap energy value (E-Gap) is close to that of the experimental optical Gap energy which is $2.11 \mathrm{eV}$ (Figure S9). Furthermore, it is known that free base porphyrins present energy Gap values $\sim 1.80 \mathrm{eV}$ which are smaller than those of metalloporphyrins [53] indicating that free bases meso-arylporphyrins are must more polarizable and therefore more reactive than the metallated meso-arylporphyrins.

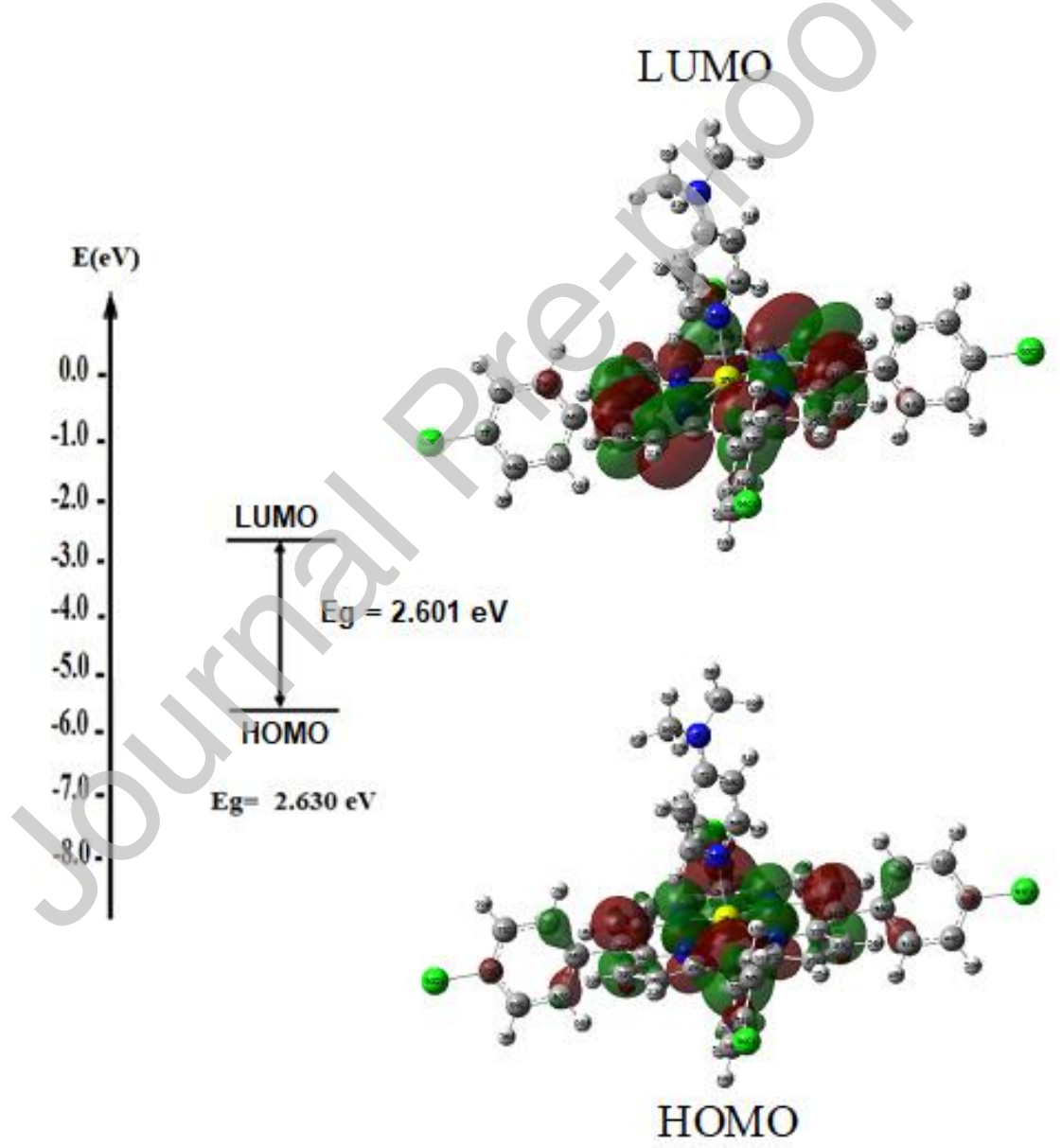

Figure 14. Plot of the frontier molecular orbitals of $[\mathrm{Mg}(\mathrm{TCPP})(\mathrm{DMAP}]$ in gas phase by using TD-DFT calculations. 
Table 8. Difference of energies between the frontier molecular orbital, the chemical potential, the global hardness, the softness and the electrophilicity in the gas phase of complex (I).

\section{DET / B3LYP / Lan2DZ}

Gas phase

\section{$\mathrm{E}_{\text {Hомо }}(\mathrm{eV})$}

$-5.101$

$\mathrm{E}_{\text {LUMO }}(\mathrm{eV})$

$-2.500$

$\left.\Delta \mathrm{E}\left[\mathrm{E}_{\mathrm{HOMO}}-\mathrm{E}_{\mathrm{LUMO}}\right)\right]:$ E-Gap $(\mathrm{eV})$

2.601

$I$ (ionization potential) $(\mathrm{eV})$

5.101

$A$ (electron affinity) $(\mathrm{eV})$

Chemical potential $\mu(\mathrm{eV})$

Global hardness $\eta(\mathrm{eV})$

1.300

Softness $S(\mathrm{eV})^{-1}$

0.384

Electrophilicity $\psi(\mathrm{eV})$

5.553

\subsection{DOS analysis}

The density of states (DOS) characterizes the energy levels per unit energy increment and its composing in energy. The corresponding plots can provide the description of a whole orbitals system [77]. For our synthetic $\mathrm{Mg}$ (II) derivative (I), the density of states (DOS) plots was obtained by using TD-DFT Gaussian output via Gauss-Sum software. The green color of the frontier molecular orbitals represents the negative phase and the red color corresponds to the positive phase which is well clarified in the density of states (DOS) spectrum (Figure 15). As expected, the energy difference between HOMO and LUMO is compatible with the values determined by the DFT calculations. 


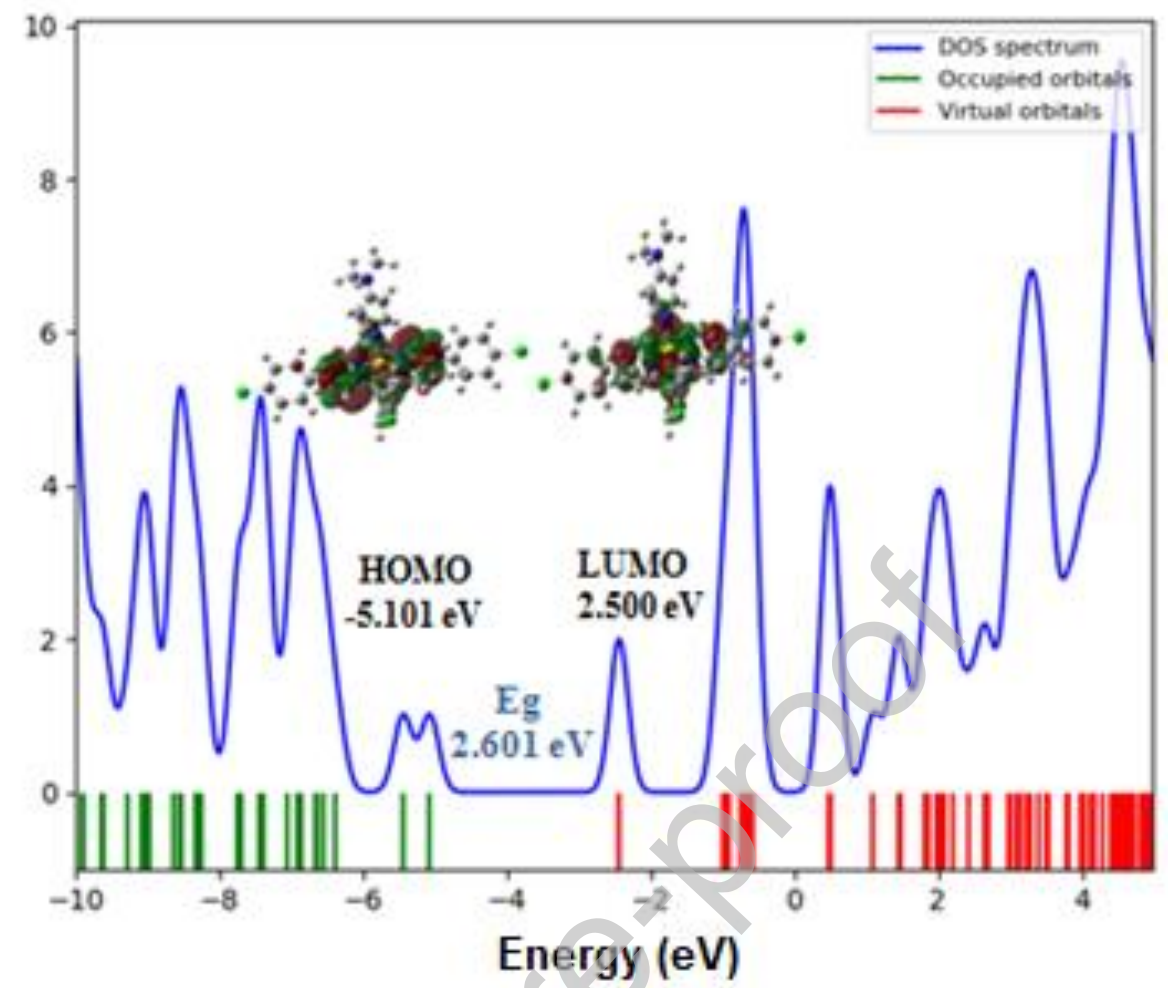

Figure 15. The density of states plots (DOS) of [Mg(TCPP)(DMAP)] using Gauss Sum program.

\subsection{Molecular electronic potential analysis}

The molecular electrostatic potential (MEP) technique is usually used to get more insights of chemical reactivity of the molecule which related the positive and the negative potential sites in harmony with the total electron density surface of this molecule. The MEP contour maps of the electrostatic potential of complex (I) was determined using DFT/B3LYP/LanL2DZ process. For a MEP map, the color code used is indicative of the potential increase in the order: red < orange < yellow < blue. The red color refers to the potential negative values while the blue color refers to the potential positive values. In Figure 16, the MEP maps were acquired by mapping electrostatic potential to the total electron density using the just mentioned color code. For the this figure, , the color code of the maps is between $-1.2 .10^{-}$ ${ }^{2}$ u.a. (red color) and $1 \cdot 2 \cdot 10^{-2}$ u.a. (blue color). It has been reported that the molecular electrostatic potential and the electronic density are related which is a good means for the determination of the nucleophilic and electrophilic sites [78]. The nucleophilic reactivity of a molecule which indicates the 
strongest repulsion of electrons, is represents in red color in a MEP map while the blue regions of MEP are related to the electrophilic reactivity; they indicate the strongest attraction. Zero potential corresponds to the green color of MEP.

The mapping potentials are produced in the space around a molecule by its nuclei and electrons.

Figure 16 illustrates three MEP maps for our Mg(II)-(DMAP)-porphyrin species. It is clear from this figure that the acidic strength (strength in blue color) is important around the magnesium atom and the DMAP axial ligand. Therefore, based on the MEP of (I), we can deduce that a nucleophile axial ligand such as an $\mathrm{N}$-donor or an $\mathrm{O}$-donor molecule can easily substitute the DMAP axial ligand of complex (I).

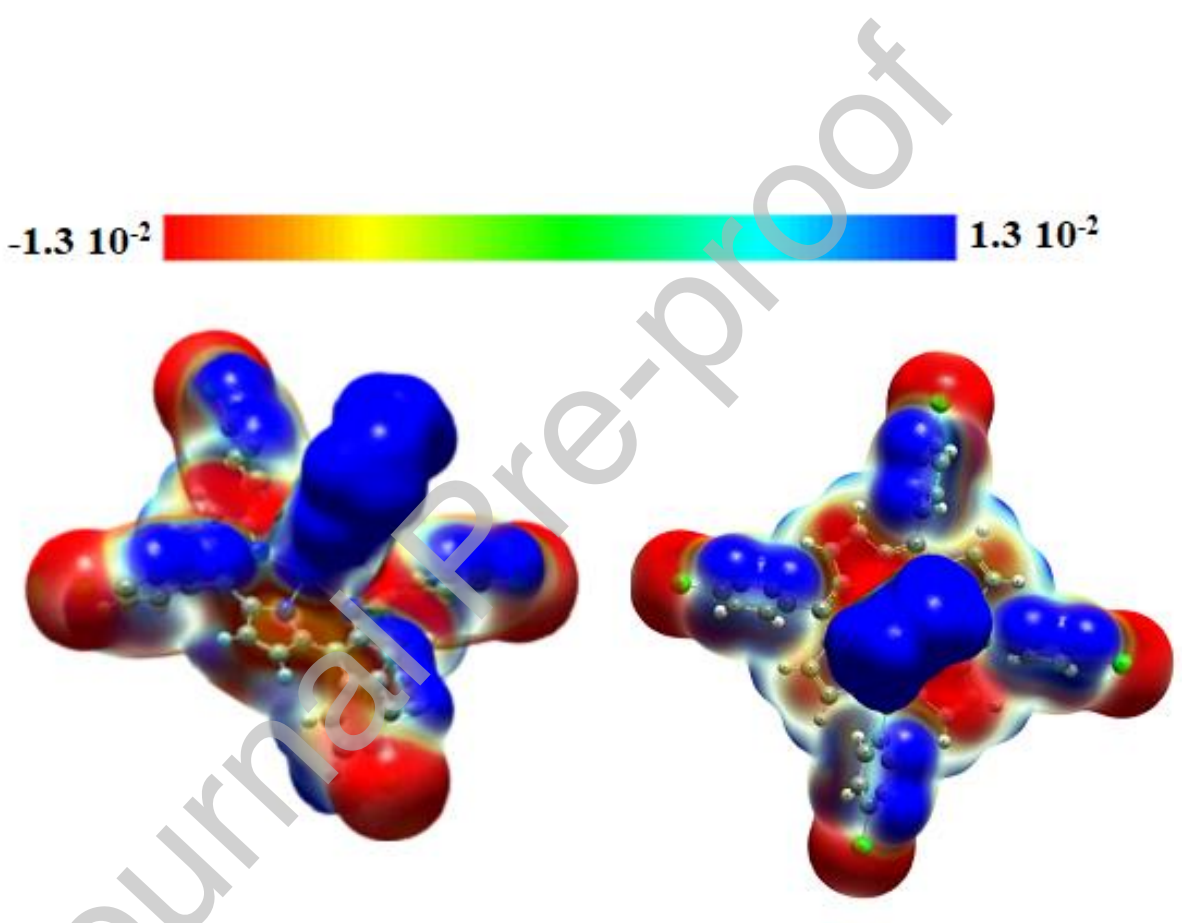

Figure 16. Molecular Electrostatic Potential (MEP) maps of the [Mg(TClPP)(DMAP)] molecule.

\subsection{Cyclic voltammetry}

Figure 17 displays the cyclic voltammogram (CV) of our $\mathrm{Mg}(\mathrm{II})$-DMAP species (I) with tetra- $n$ butylammonium perchlorate (TBAP) as the supporting electrolyte $(0.2 \mathrm{M})$ in the non-coordinating solvent dichloromethane under an argon atmosphere. The electrochemical data for [Mg(TClPP)(DMAP)] (I) along with those for other related species are given in Table 9. 


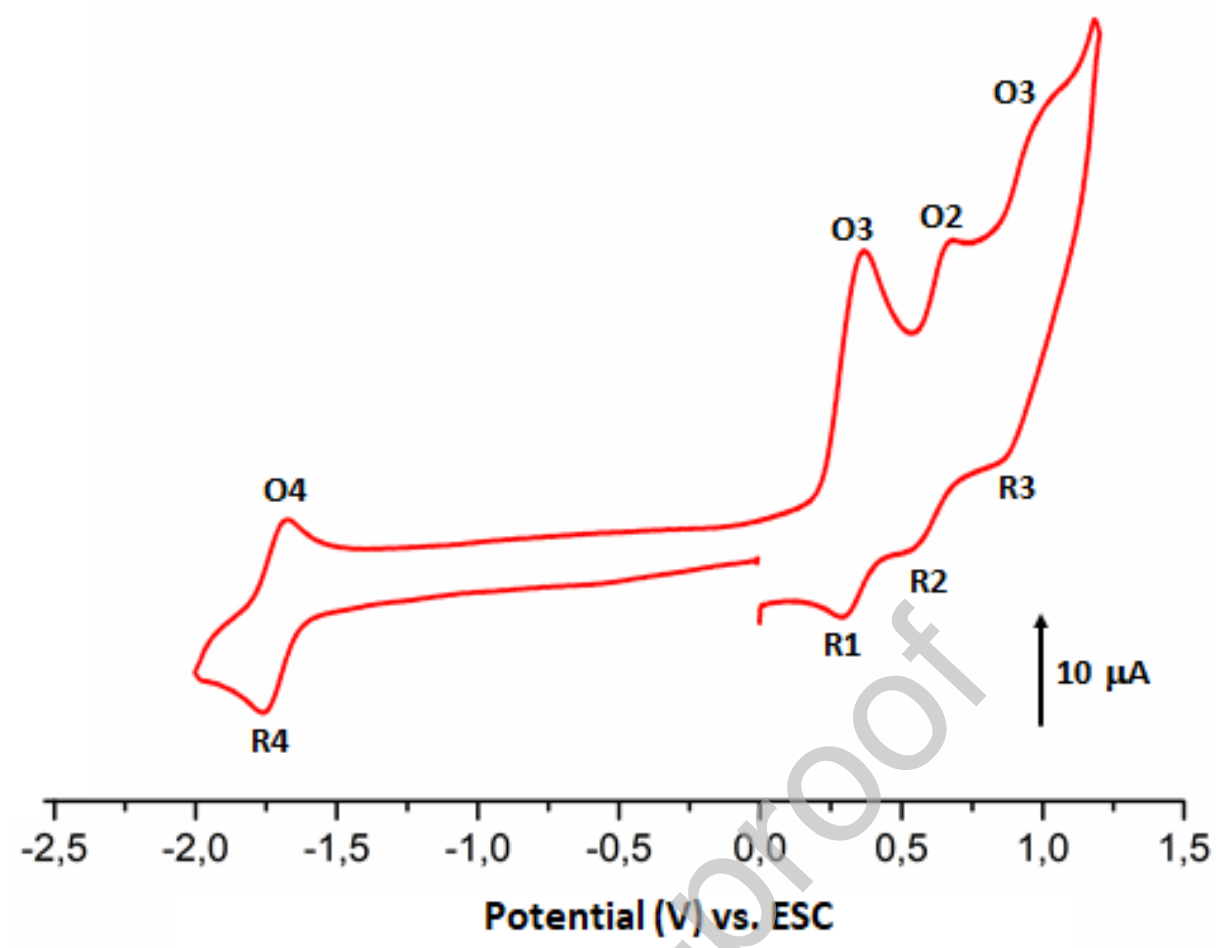

Figure 17. Cyclic voltammogram of (I). The solvent is $\mathrm{CH}_{2} \mathrm{Cl}_{2}$, and the concentration is ca. $10^{-3} \mathrm{M}$ in $0.2 \mathrm{M}$ TBAP, $50 \mathrm{mV} / \mathrm{s}$, vitreous carbon working electrode $(\varnothing=3 \mathrm{~mm})$.

Table 9. Cyclic voltammetry data ${ }^{a}$ for complex (I) and a selection of meso-arylphenylporphyrin species.

\begin{tabular}{llllll}
\hline Compound & \multicolumn{2}{l}{ Ring oxidation } & & Ring reduction & Ref. \\
\cline { 2 - 5 } & First Oxid. & Second Oxid. & Third oxid. & First Red. \\
$(\mathrm{O} 1, \mathrm{R} 1)$ & $(\mathrm{O} 2, \mathrm{R} 2)$ & $(\mathrm{O} 3, \mathrm{R} 3)$ & $(\mathrm{R} 4, \mathrm{O} 4)$ \\
\hline$-\mathrm{E}_{1 / 2}$ & $\mathrm{E}_{1 / 2}$ & $\mathrm{E}_{1 / 2}$ & $\mathrm{E}_{1 / 2}$ \\
\end{tabular}

Meso-arylporphyrins

\begin{tabular}{|c|c|c|c|c|c|}
\hline $\mathrm{H}_{2} \mathrm{TPP}^{\mathrm{c}}$ & 1.02 & 1.26 & - & -1.20 & [79] \\
\hline $\mathrm{H}_{2} \mathrm{TPBP}^{\mathrm{d}}$ & 0.95 & 1.36 & 1.48 & -1.12 & [53] \\
\hline $\mathrm{H}_{2} \mathrm{TMPP}^{\mathrm{e}}$ & 1.02 & 1.19 & 1.67 & -1.19 & [40] \\
\hline $\mathrm{H}_{2} \mathrm{TClPP}$ & 1.00 & 1.23 & 1.53 & -1.09 & [40] \\
\hline
\end{tabular}

Magnesium(II)-meso-arylporphyrins 


$\begin{array}{llllll}{\left[\mathrm{Mg}(\mathrm{TThP})(\mathrm{THF})_{2}\right]^{\mathrm{g}, \mathrm{f}}} & 0.78 & 0.98 & - & -1.42 & {[50]} \\ {\left[\mathrm{Mg}(\mathrm{TFP})(\mathrm{THF})_{2}\right]^{\mathrm{i}, \mathrm{f}}} & 0.68 & - & - & -1.40 & {[80]} \\ {\left[\mathrm{Mg}(\mathrm{TPP})(\mathrm{HMTA})_{2}\right]^{\mathrm{c}, \mathrm{j}}} & 0.73 & 0.99 & - & -1.45 & {[26]} \\ {[\mathrm{Mg}(\mathrm{TPP})(\mathrm{pyz})]_{\mathrm{n}}^{\mathrm{c}, \mathrm{k}}} & 0.65 & 0.95 & - & -1.65 & {[81]} \\ {[\mathrm{Mg}(\mathrm{TPP})(\mathrm{SCN})]^{-\mathrm{c}}} & 0.59 & 0.93 & 1.14 & -1.50 & {[42]} \\ {[\mathrm{Mg}(\mathrm{TPP})(\mathrm{OCN})]^{-\mathrm{c}}} & 0.58 & 0.90 & 1.16 & -1.50 & {[42]} \\ {\left[\mathrm{Mg}(\mathrm{TPP})\left(\mathrm{N}_{3}\right)\right]^{-\mathrm{c}}} & 0.57 & 0.89 & 1.15 & -152 & {[42]} \\ {[\mathrm{Mg}(\mathrm{TClPP})(\mathrm{DMAP})](\mathbf{I})} & 0.63 & 0.91 & 1.22 & -1.42 & \text { this work }\end{array}$

Zinc(II)-meso-arylporphyrins

$\begin{array}{llllll}{\left[\mathrm{Zn}(\mathrm{TPP})\left(\mathrm{N}_{3}\right)\right]^{-\mathrm{c}}} & 0.71 & 1.15 & 1.40 & -1.53 & {[\mathbf{5 2}]} \\ {[\mathrm{Zn}(\mathrm{TPBP})(\mathrm{DABCO})]^{\mathrm{d}, 1}} & 0.84 & 1.12 & - & -1.33 & {[\mathbf{5 3}]} \\ {[\mathrm{Zn}(\mathrm{TPBP})(\mathrm{pyz})]^{\mathrm{d}, \mathrm{k}}} & 0.82 & 1.12 & 1.38 & -1.34 & {[53]} \\ {\left[\mathrm{Zn}(\mathrm{TPBP})\left(4,4^{\prime}-\text { diam }\right)\right]^{\mathrm{d}, \mathrm{m}}} & 0.81 & 1.28 & - & -1.31 & {[53]} \\ {[\mathrm{Zn}(\mathrm{TPBP})(4-\mathrm{CNpy})]^{\mathrm{d}, \mathrm{n}}} & 0.81 & 1.10 & 1.36 & -1.52 & {[53]}\end{array}$

Cobalt(II)-meso-arylporphyrins

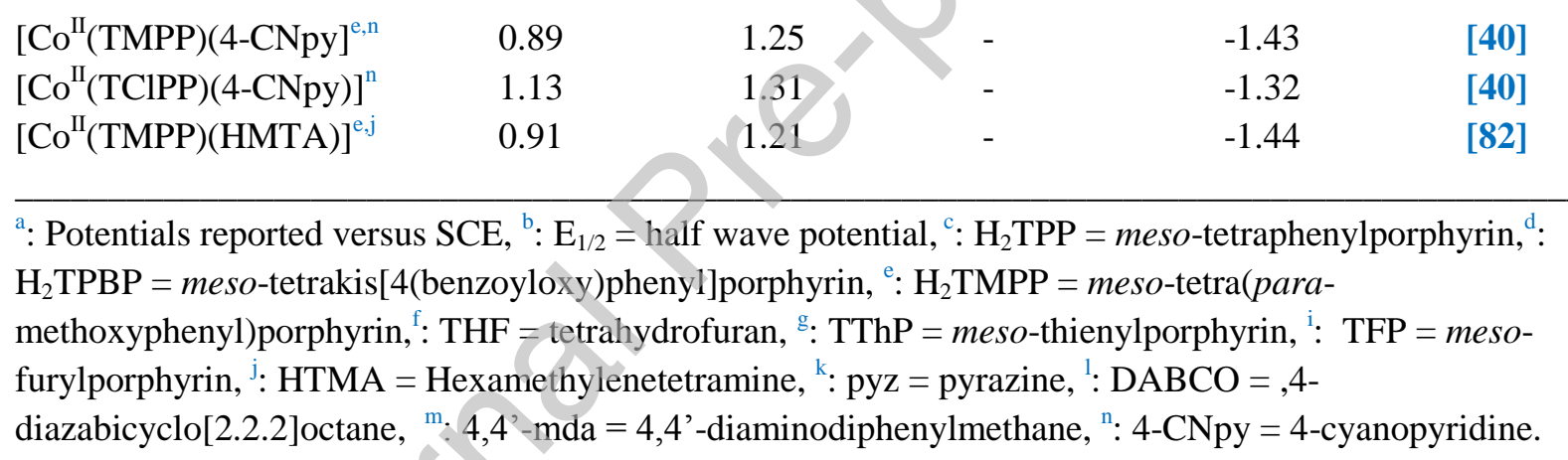

It is noteworthy that metalloporphyrins with non-electroactive divalent metal ions such as $\mathrm{Zn}$ (II), $\mathrm{Cd}(\mathrm{II})$ and $\mathrm{Mg}$ (II) undergoes usually two or three reversible one electron oxidations and one or two electron reductions of the porphyrin macrocycle [42,54,83]. For electroactive metal ions, such as Fe(II) and $\mathrm{Co}(\mathrm{II})$ metalloporphyrins, the corresponding cyclic voltammograms exhibit usually, two oneelectron oxidation waves and one one-electron reductive wave of the porphyrin macrocycle in addition to the $\mathrm{M}(\mathrm{II}) / \mathrm{M}(\mathrm{III})$ oxidation wave and the $\mathrm{M}(\mathrm{II}) / \mathrm{M}(\mathrm{I})$ reduction wave [40].

Inspection of Figure 17 shows that our synthetic [Mg(TClPP)(DMAP)] (I) complex exhibits three oneelectron reversible oxidation waves with half-potential $\left(\mathrm{E}_{1 / 2}\right)$ values of $0.61(\mathrm{O} 1, \mathrm{R} 1), 0.91(\mathrm{O} 2, \mathrm{R} 2)$ and $1.22(\mathrm{O} 3, \mathrm{R} 3) \mathrm{V}$, respectively. Complex (I) presents also a one-electron reversible reduction wave with $\mathrm{E}_{1 / 2}$ value of $-1.42 \mathrm{~V}$. The main results deduced from this study are as follows: (i) the half-potential values of the oxidation waves of the free bases porphyrins are shifted toward the positive potential 
compared to those of the metalloporphyrins indicating that the former species are more difficult to oxidized than the porphyrins complexes (Table 9), (ii) the magnesium(II) meso-arylporphyrins present $E_{1 / 2}$ potential values of the first and the second oxidation waves slightly shifted toward the negative potentials compared to those of the zinc(II) metalloporphyrins while the $\mathrm{E}_{1 / 2}$ value of the first reduction wave of the $\mathrm{Mg}(\mathrm{II})$ and $\mathrm{Zn}$ (II) meso-arylporphyrines are very close and (iii) for the electroactive metal porphyrins such as cobaltous metalloporphyrins, the $E_{1 / 2}$ values of the first and second ring oxidations are higher than those of the non-electroactive $\mathrm{Mg}$ (II) and $\mathrm{Zn}$ (II) meso-arylporphyrin species while the half-potential value of the first cyclic reduction wave for electroactive and non-electroactive metal meso-arylporphyrines are quite the same.

\subsection{Antifungal activity}

The antifungal activities of the free base porphyrin $\mathrm{H}_{2} \mathrm{TClPP}$, the $[\mathrm{Mg}(\mathrm{TClPP})]$ and $[\mathrm{Mg}(\mathrm{TClPP})(\mathrm{DMAP})]$ complexes were quantitatively assessed by the presence, or absence of inhibition zones against three yeasts strains (C. krusei ATCC6258, $C$. albicans ATCC90028 and $C$. neoformans ATCC14116) and two fungal strains (A. brasiliensis ATCC16404 and A. fumigatus ATCC204305). The diameters of inhibition zones observed with the well diff fusion method are shown in Figure 18.

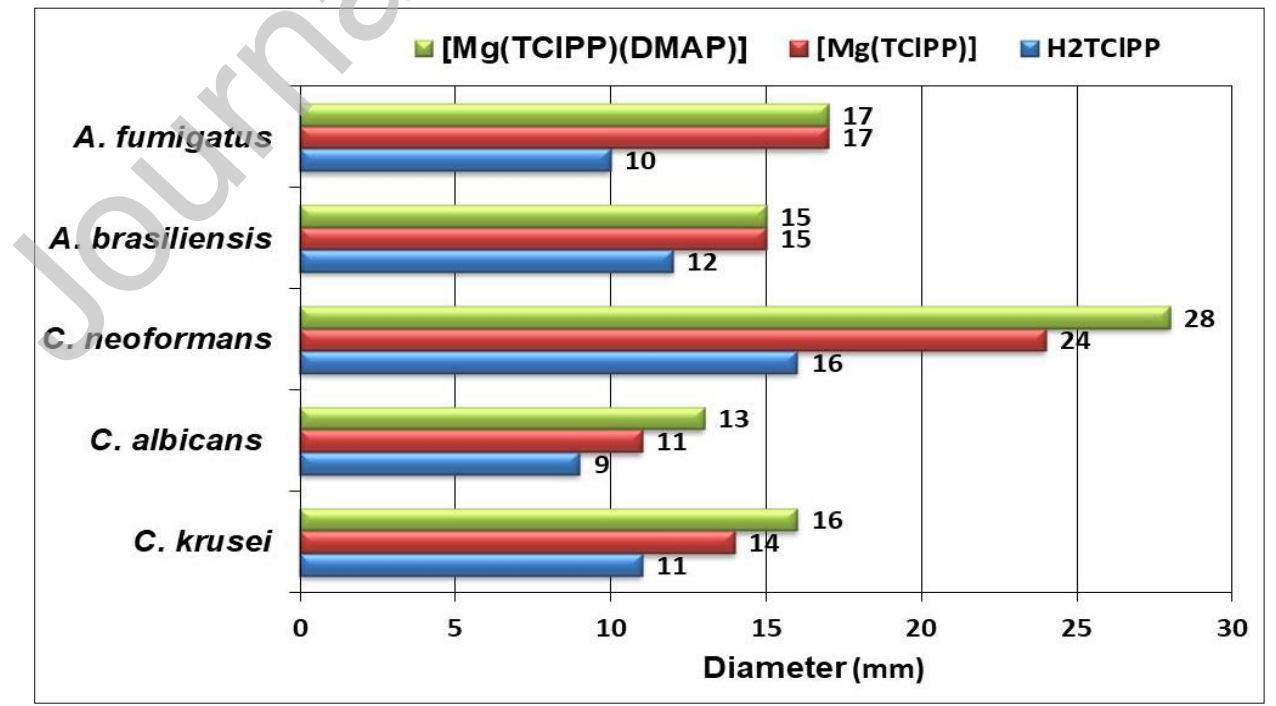

Figure 18. In vitro antifungal activity of $\mathrm{H}_{2} \mathrm{TClPP},[\mathrm{Mg}(\mathrm{TClPP})]$ and $[\mathrm{Mg}(\mathrm{TClPP})(\mathrm{DMAP})]$. 
Overall, the solvent used to prepare the compound solutions (DMSO) did not show inhibition against the tested organisms (negative control) and the yeasts strain $C$. neoformans was the most sensitive. All the synthesized compounds showed overall good activity against this antifungal strain up to $28 \mathrm{~mm}$. It is concluded that the antifungal activity of the free base porphyrin increased upon coordination to the magnesium metal. They inhibited the growth of fungi more than the free base porphyrin under identical experimental conditions (Figure 18). The magnesium derivatives show $17 \mathrm{~mm}$ in diameter of zone inhibition against A. fumigatus and $15 \mathrm{~mm}$ in diameter of zone inhibition against A. brasiliensis. They also produced $14 \mathrm{~mm}$ and 16 in diameter of zone inhibition against $C$. krusei. These compounds exhibit less antifungal activity than the standard drug Nystatin [21], who owns 29 and $19 \mathrm{~mm}$ in diameter of zone inhibition against $C$. albicans and A. fumigatus, respectively. The increase in biological activity of the magnesium compounds compared to that of free base $\mathrm{H}_{2}$ TCIPP porphyrin is due to faster diffusion of metal compounds through the cell membrane. Such increased activity of the metal compounds can be explained on the basis of Overtone's concept $[\mathbf{8 4 , 8 5}]$ and Tweedy's chelation theory $[86,87]$.

\subsection{Antioxidant activity by DPPH radical scavenging method}

Numerous antioxidant methods and modifications have been proposed to evaluate antioxidant activity and to explain how antioxidant agents work. Among them, the 1,1-diphenyl-2 picrylhydrazyl (DPPH) radical assay is the most common method used to determine the radical scavenging ability of various samples. The quite stable DPPH nitrogen centred radical possesses a characteristic absorption which decreases when exposed to antioxidants [88]. It reacts with hydrogen donating functions resulting in a colour change from purple to yellow. The intensity of this phenomena is related to the number of electrons captured [89], i.e., the greater the free radical scavenging capacity of an antioxidant compounds, the more reduction of DPPH and the less purple colour of the sample. The ability $\mathrm{H}_{2}$ TCIPP, $[\mathrm{Mg}(\mathrm{TClPP})]$ and $[\mathrm{Mg}(\mathrm{TClPP})(\mathrm{DMAP})]$ to scavenge in vitro DPPH as evaluated in comparison to the vitamin $\mathrm{C}$ reference compound [90]. The percentage antioxidant activity results (\%RSA: percentage of radical scavenging activity) were given in Figure 19. 


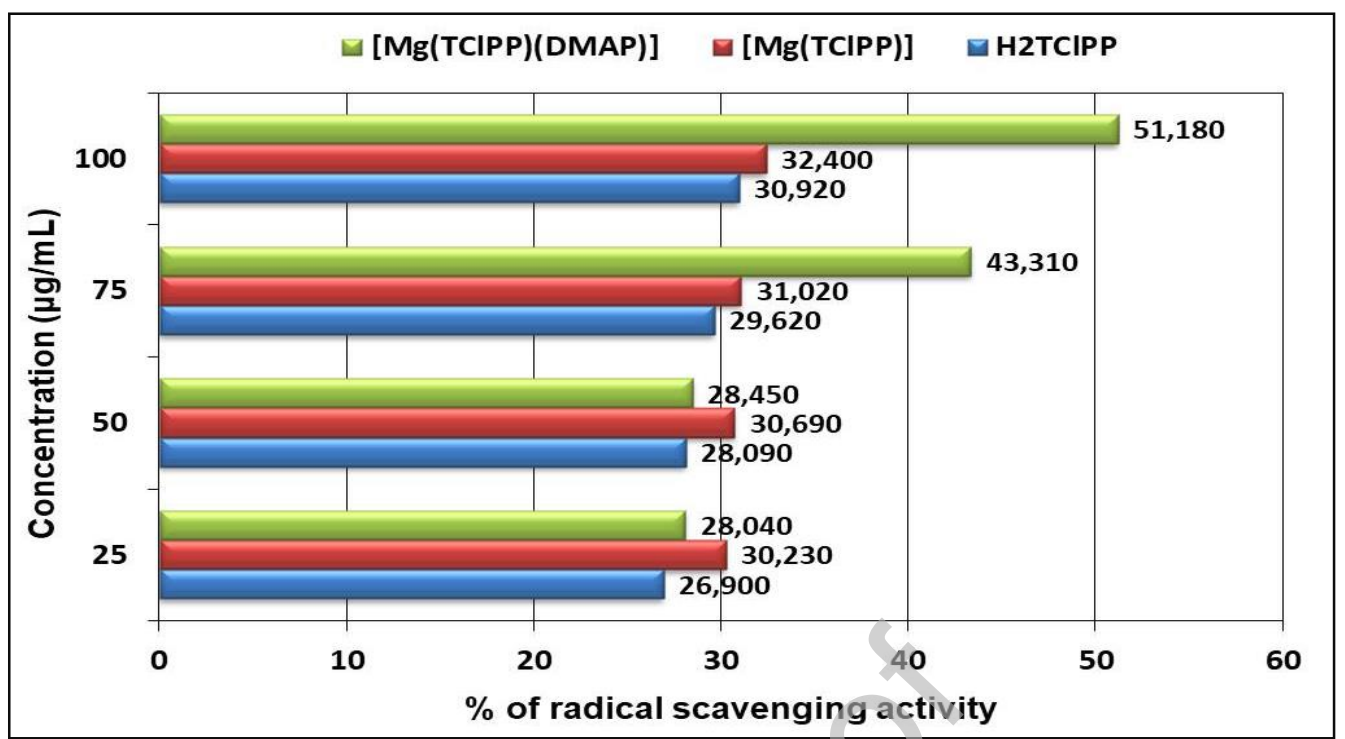

Figure 19. Emission DPPH radical scavenging activity of $\mathrm{H}_{2} \mathrm{TClPP},[\mathrm{Mg}(\mathrm{TClPP})]$ and $[\mathrm{Mg}(\mathrm{TClPP})(\mathrm{DMAP})]$ at different concentrations.

As shown in Figure 19, the free radical scavenging activity of complex (I) depend on the concentration of this species. Hence, with the increasing concentration of our $\mathrm{Mg}$ (II)-DMAP complex, the free radicals of DPPH decrease and then they stabilize. At high concentrations, the highest antioxidant activity was obtained for complex (I) compared to the free base porphyrin $\mathrm{H}_{2}$ TClPP and the starting material $[\mathrm{Mg}$ (TClPP]. For example, for a concentration of $100 \mu \mathrm{g} / \mathrm{mL}$, the DPPH scavenging activity of complex (I) reaches $51 \%$ which is significantly higher than those of $\mathrm{H}_{2}$ TClPP and $[\mathrm{Mg}(\mathrm{TClPP})]$ $(\sim 30 \%)$. It should be noted that our three porphyrin species show lower DPPH activity compared to the standard vitamin C [90]. On the other hand, our three porphyrin derivatives, exhibit weaker antioxidant activity comparted to the well-known EGCG and BHT antioxidant species (EGCG $=$ Epigallocatechin gallate plant, $\mathrm{BTH}=$ Butylated hydroxytoluene) which present strong DPPH radical scavenging activity $(\sim 80 \%)[91,92]$. 


\section{Conclusion}

In conclusion, we have reported the syntheses of the DMAP-meso-tetra(parachlorophenyl)porphyrinato]magnesium(II) complex (I) with the formula [Mg(TClPP)(DMAP)]. The IR, UV-visible, photoluminescence and the ${ }^{1} \mathrm{H}$ NMR data are consistent with a DMAP-manganese(II) meso-arylporphyrin coordination compound. The cyclic voltammetry of (I) in dichloromethane solution is characteristic of a meso-arylporphyrin complex with a non-electroactive metal. The single crystal X-ray investigation shows that the magnesium central metal of the title compound is fivefold coordinated by the four nitrogen atoms of the TCIPP macrocycle and the nitrogen atom of the pyridyl group of the DMAP axial ligand in a slightly distorted square pyramidal polyhedral. The supramolecular structure of (I) is made by layers perpendicular to the [010] direction and the crystal packing is stabilized by $\mathrm{C}-\mathrm{H} \cdots \mathrm{Cl}$ and by $\mathrm{C}-\mathrm{H} \cdots \pi$ intermolecular interactions. Hirshfeld surface analyses and two-dimensional fingerprint plots were used to quantify the intermolecular interactions present in the crystal, indicating that the most important contributions for the crystal packing are from $\mathrm{H} \cdots \mathrm{H}(49 \%), \mathrm{C}^{\cdots} \mathrm{H}(12.7 \%), \mathrm{H}^{\cdots} \mathrm{Cl}(11 \%)$ and $\mathrm{H}^{\cdots} \mathrm{N}(2.9 \%)$. A DFT study in conjunction with a DOS calculation has been performed on our synthesis compound whose aim is to calculate the energies of the HOMO and LUMO orbitals from which several important parameters have been calculated. This is notably the case for the Gap energy, the electronegativity, the global hardness, and the softness. These parameters inform us, inter alia, about the reactivity of the complex (I). Furthermore, the MEP maps show that acidic strength is important around the magnesium atom and the DMAP axial ligand. This indicates that nucleophile $\mathrm{N}$-donor type molecules can easily substitute the DMAP axial ligand in complex (I). By the other hand, the antifungal and the antioxidant activities of the $\mathrm{H}_{2}$ TClPP free base porphyrin, the $[\mathrm{Mg}(\mathrm{TClPP})]$ starting materials and $[\mathrm{Mg}(\mathrm{TClPP})(\mathrm{DMAP})]$ (I) species were examined. All three porphyrinic species showed overall good activity against yeasts strain C. neoformans. The highest antioxidant activity was obtained for complex (I) compared to the free base porphyrin $\mathrm{H}_{2}$ TCIPP and the starting material [Mg(TClPP]. Nevertheless, our three porphyrin derivatives, exhibit weaker antioxidant activity comparted to the well-known EGCG and BHT antioxidants. 


\section{Declaration of Competing Interest}

The authors declare that they have no known competing financial interests or personal relationships that could have appeared to influence the work reported in this paper.

\section{Acknowledgments}

The authors gratefully acknowledge the Ministry of Higher Education and Scientific Research of Tunisia for financial support. The author would like to express their gratitude to King Khalid University, Saudi Arabia for providing administrative and technical support.

\section{Supplementary materials}

Supplementary material associated with this article can be found, in the online version, at doi: $\operatorname{xxxxxxxxxxxxxxxxxx.}$

\section{References}

[1] A.D. Adler, F.R. Longo, J.D. Finarelli, J. Goldmacher, J. Assour, L. Korsakoff, A simplified synthesis for meso-tetraphenylporphine, J. Org. Chem. 32 (1967) 476-476. https://doi.org/10.1021/jo01288a053.

[2] J.P. Collman, R.R. Gagne, C. Reed, T.R. Halbert, G. Lang, W.T. Robinson, Picket fence porphyrins. Synthetic models for oxygen binding hemoproteins, J. Am. Chem. Soc. 97 (1975) 1427-1439. https://doi.org/10.1021/ja00839a026.

[3] J.S. Lindsey, H.C. Hsu, I.C. Schreiman, Synthesis of tetraphenylporphyrins under very mild conditions, Tetrahedron Lett. 27 (1986) 4969-4970. https://doi.org/10.1016/S0040-4039(00)85109-6.

[4] W.Robert. Scheidt, J.L. Hoard, Stereochemistry of low-spin cobalt porphyrins. I. Structure and bonding in a nitrosylcobalt porphyrin and their bearing on one rational model for the oxygenated protoheme, J. Am. Chem. Soc. 95 (1973) 8281-8288. https://doi.org/10.1021/ja00806a013.

[5] G.N. La Mar, F.A. Walker, Dynamics of axial ligation in metalloporphyrins. I. Imidazole exchange in low-spin ferric porphyrins, J. Am. Chem. Soc. 94 (1972) 8607-8608. https://doi.org/10.1021/ja00779a068. 
[6] J.P. Collman, R.R. Gagne, T.R. Halbert, J.C. Marchon, C.A. Reed, Reversible oxygen adduct formation in ferrous complexes derived from a picket fence porphyrin. Model for oxymyoglobin, J. Am. Chem. Soc. 95 (1973) 7868-7870. https://doi.org/10.1021/ja00804a054.

[7] B.M. Hoffman, J.C. Swartz, M.A. Stanford, G.H. Gibson, Evidence Regarding Mechanisms for Protein Control of Heme Reactivity, in: Biomimetic Chemistry, J. Am. Chem. Soc. 1980: pp. 235-252. https://doi.org/10.1021/ba-1980-0191.ch013.

[8] J.T. Groves, T.E. Nemo, R.S. Myers, Hydroxylation and epoxidation catalyzed by iron-porphine complexes. Oxygen transfer from iodosylbenzene, J. Am. Chem. Soc. 101 (1979) 1032-1033. https://doi.org/10.1021/ja00498a040.

[9] N. Kobayashi, P. Janda, A.B.P. Lever, Cathodic reduction of oxygen and hydrogen peroxide at cobalt and iron crowned phthalocyanines adsorbed on highly oriented pyrolytic graphite electrodes, Inorg. Chem. 31 (1992) 5172-5177.

https://doi.org/10.1021/ic00051a006.

[10] C.-T. Chen, Evolution of Red Organic Light-Emitting Diodes: Materials and Devices, Chem. Mater. 16 (2004) 4389-4400. https://doi.org/10.1021/cm049679m.

[11] V.K. Gupta, D.K. Chauhan, V.K. Saini, S. Agarwal, M.M. Antonijevic, H. Lang, A Porphyrin Based Potentiometric Sensor for $\mathrm{Zn}^{2+}$ Determination, Sensors. 3 (2003) 223-235. https://doi.org/10.3390/s30700223.

[12] C.M. Drain, A. Varotto, I. Radivojevic, Self-Organized Porphyrinic Materials, Chem. Rev. 109 (2009) 1630-1658. https://doi.org/10.1021/cr8002483.

[13] A.E. O'Connor, W.M. Gallagher, A.T. Byrne, Porphyrin and Nonporphyrin Photosensitizers in Oncology: Preclinical and Clinical Advances in Photodynamic Therapy, Photochem. Photobiol. 85 (2009) 1053-1074.

https://doi.org/10.1111/j.1751-1097.2009.00585.x.

[14] E.G. Girichev, M.I. Bazanov, N.Z. Mamardashvili, A. Gjeyzak, Electrochemical and Electrocatalytical Properties of 3,7,13,17-Tetramethyl-2,8,12,18-Tetrabutylporphyrin in Alkaline Solution, Molecules. 5 (2000) 767-774. https://doi.org/10.3390/50600767.

[15] W.A. Nevin, G.A. Chamberlain, Photovoltaic properties of iodine-doped magnesium tetraphenylporphyrin sandwich cells. II. Properties of illuminated cells, J. Appl. Phys. 69 (1991) 4324-4332. https://doi.org/10.1063/1.348407.

[16] R.A. Norwood, J.R. Sounik, Third-order nonlinear optical response in polymer thin films incorporating porphyrin derivatives, Appl. Phys. Lett. 60 (1992) 295-297. https://doi.org/10.1063/1.106690.

[17] B.B. Beyene, A.M. Mihirteu, M.T. Ayana, A.W. Yibeltal, Synthesis, characterization and antibacterial activity of metalloporphyrins: Role of central metal ion, Results Phys. 2 (2020) 100073. https://doi.org/10.1016/j.rechem.2020.100073.

[18] R. Elashnikov, M. Radocha, I. Panov, S. Rimpelova, P. Ulbrich, A. Michalcova, V. Svorcik, O. Lyutakov, Porphyrin-silver nanoparticles hybrids: Synthesis, characterization and antibacterial activity,Mater. Sci. Eng. C. 102 (2019) 192-199.

https://doi.org/10.1016/j.msec.2019.04.029. 
[19] M.V. Tesakova, V.I. Parfenyuk, The Electrochemical Evaluation of the Antioxidant Activity of Substituted Tetraphenylporphyrins, Russ J Electrochem. 53 (2017) 1281-1285. https://doi.org/10.1134/S1023193517110155.

[20] C. Cui, Q. Wang, Q. Liu, X. Deng, T. Liu, D. Li, X. Zhang, Porphyrin-based porous organic framework: An efficient and stable peroxidase-mimicking nanozyme for detection of $\mathrm{H}_{2} \mathrm{O}_{2}$ and evaluation of antioxidant,Sens. Actuators B Chem.277 (2018) 86-94. https://doi.org/10.1016/j.snb.2018.08.097.

[21] U. Singh, A.M. Malla, I.A. Bhat, A. Ahmad, M.N. Bukhari, S. Bhat, S. Anayutullah, A.A. Hashmi, Synthesis, molecular docking and evaluation of antifungal activity of $\mathrm{Ni}(\mathrm{II}), \mathrm{Co}(\mathrm{II})$ and $\mathrm{Cu}$ (II) complexes of porphyrin core macromolecular ligand, Microb. Pathog. 93 (2016) 172-179. https://doi.org/10.1016/j.micpath.2016.02.011.

[22] S. Moghnie, A. Tovmasyan, J. Craik, I. Batinic-Haberle, L. Benov, Cationic amphiphilic Znporphyrin with high antifungal photodynamic potency, Photochem. Photobiol. Sci. 16 (2017) 1709-1716. https://doi.org/10.1039/C7PP00143F.

[23] N. Amiri, F.B. Taheur, S. Chevreux, E. Wenger, G. Lemercier, H. Nasri, Synthesis, crystal structure and spectroscopic characterizations of porphyrin-based $\mathrm{Mg}$ (II) complexes - Potential application as antibacterial agent, Tetrahedron. 73 (2017) 7011-7016. https://doi.org/10.1016/j.tet.2017.10.029.

[24] N. Amiri, M. Hajji, F.B. Taheur, S. Chevreux, T. Roisnel, G. Lemercier, H. Nasri, Two novel magnesium(II) meso-tetraphenylporphyrin-based coordination complexes: Syntheses, combined experimental and theoretical structures elucidation, spectroscopy, photophysical properties and antibacterial activity,J. Solid State Chem. 258 (2018) 477-484. https://doi.org/10.1016/j.jssc.2017.11.018.

[25] E.J. Shin, D. Kim, Substituent effect on the fluorescence quenching of various tetraphenylporphyrins by ruthenium tris(2,2'-bipyridine) complex, J. Photochem. Photobiol. A 152 (2002) 25-31. https://doi.org/10.1016/S1010-6030(02)00189-2.

[26] K. Ezzayani, A. Ben Khelifa, E. Saint-Aman, F. Loiseau, H. Nasri, Complex of hexamethylenetetramine with magnesium-tetraphenylporphyrin: Synthesis, structure, spectroscopic characterizations and electrochemical properties, J. Mol. Struct. 1137 (2017) 412 418. https://doi.org/10.1016/j.molstruc.2017.02.054.

[27] F.L. Hirshfeld, Bonded-atom fragments for describing molecular charge densities, Theoret. Chim. Acta. 44 (1977) 129-138. https://doi.org/10.1007/BF00549096.

[28] S.K. Wolff, D.J. Grimwood, J.J. McKinnon, M.J. Turner, D. Jayatilaka, M.A. Spackman, CrystalExplorer 3.1 (2013), University of Western Australia, Crawley, Western Australia., (n.d.). http://hirshfeldsurface.net/CrystalExplorer.

[29] M. A. Spackman, D. Jayatilaka, Hirshfeld surface analysis, CrystEngComm. 11 (2009) 19-32. https://doi.org/10.1039/B818330A.

[30] M.A. Spackman, J.J. McKinnon, Fingerprinting intermolecular interactions in molecular crystals, CrystEngComm. 4 (2002) 378-392. https://doi.org/10.1039/B203191B.

[31] R. Timkovich, A. Tulinsky, Structure of aquomagnesium tetraphenylporphyrin, J. Am. Chem. Soc. 91 (1969) 4430-4432. https://doi.org/10.1021/ja01044a018.

[32] SMART, SAINT, and SADABS, Bruker AXS Inc., Madison, WI, (2008), (n.d.).

[33] A. Altomare, G. Cascarano, C. Giacovazzo, A. Guagliardi, M.C. Burla, G. Polidori, M. Camalli, SIRPOW.92 - a program for automatic solution of crystal structures by direct methods optimized 
for powder data, Journal of Applied Crystallography. 27 (1994) 435-436. https://doi.org/10.1107/S0021889894000221.

[34] G.M. Sheldrick, Crystal structure refinement with SHELXL, Acta Cryst C. 71 (2015) 3-8. https://doi.org/10.1107/S2053229614024218.

[35] P. McArdle, SORTX - a program for on-screen stick-model editing and autosorting of SHELX files for use on a PC, Journal of Applied Crystallography. 28 (1995) 65-65. https://doi.org/10.1107/S0021889894010642.

[36] A.L. Spek, PLATON, An Integrated Tool for the Analysis of the Results of a Single Crystal Structure Determination, Acta. Cryst. A. $46 \quad$ (1990) 34. https://doi.org/10.1107/S0108767390099780.

[37] A.L. Spek, PLATON SQUEEZE: a tool for the calculation of the disordered solvent contribution to the calculated structure factors, Acta Crystallogr C Struct Chem. 71 (2015) 9-18. https://doi.org/10.1107/S2053229614024929.

[38] C.F. Macrae, I.J. Bruno, J.A. Chisholm, P.R. Edgington, P. McCabe, E. Pidcock, L. RodriguezMonge, R. Taylor, J. van de Streek, P.A. Wood, Mercury CSD 2.0 - new features for the visualization and investigation of crystal structures, J Appl Cryst. 41 (2008) 466-470. https://doi.org/10.1107/S0021889807067908.

[39] A. Mansour, Y. Belghith, M.S. Belkhiria, A. Bujacz, V. Guérineau, H. Nasri, Synthesis, crystal structures and spectroscopic characterization of $\operatorname{Co}$ (II) bis(4,4'-bipyridine) with meso-porphyrins $\alpha, \beta, \alpha, \beta$-tetrakis(o-pivalamidophenyl) porphyrin $(\alpha, \beta, \alpha, \beta$-TpivPP) and tetraphenylporphyrin (TPP), J. $\quad$ Porphyrins $\quad$ Phthalocyanines. $17 \quad$ (2013) 1094-1103. https://doi.org/10.1142/S1088424613500843.

[40] M. Guergueb, S. Nasri, J. Brahmi, F. Loiseau, F. Molton, T. Roisnel, V. Guerineau, I. TurowskaTyrk, K. Aouadi, H. Nasri, Effect of the coordination of $\pi$-acceptor 4-cyanopyridine ligand on the structural and electronic properties of meso -tetra( para -methoxy) and meso -tetra( para chlorophenyl) porphyrin cobalt( ii ) coordination compounds. Application in the catalytic degradation of methylene blue dye, RSC Adv. 10 (2020) 6900-6918. https://doi.org/10.1039/C9RA08504A.

[41] N. Amiri, M. Hajji, F.B. Taheur, S. Chevreux, T. Roisnel, G. Lemercier, H. Nasri, Two novel magnesium(II) meso-tetraphenylporphyrin-based coordination complexes: Syntheses, combined experimental and theoretical structures elucidation, spectroscopy, photophysical properties and antibacterial activity, J. Solid State Chem. 258 (2018) 477-484. https://doi.org/10.1016/j.jssc.2017.11.018.

[42] K. Ezzayani, Z. Denden, S. Najmudin, C. Bonifácio, E. Saint-Aman, F. Loiseau, H. Nasri, Exploring the Effects of Axial Pseudohalide Ligands on the Photophysical and Cyclic Voltammetry Properties and Molecular Structures of MgII Tetraphenyl/porphyrin Complexes, Eur. J. Inorg. Chem. 2014 (2014) 5348-5361. https://doi.org/10.1002/ejic.201402546.

[43] V. Balasanthiran, M.H. Chisholm, K. Choojun, C.B. Durr, Ethyl 2-hydroxy-2-methylpropanoate derivatives of magnesium and zinc. The effect of chelation on the homo- and copolymerization of lactide and E-caprolactone, Dalton Trans. 43 (2014) 2781-2788. https://doi.org/10.1039/C3DT52553H.

[44] L. Fohlmeister, A. Stasch, Ring-shaped phosphinoamido-magnesium-hydride complexes: syntheses, structures, reactivity, and catalysis,Chem. Eur. J. 22 (2016) 1-13. https://doi.org/10.1002/chem.201601623/suppinfo.

[45] K. Ezzayani, A. Ben Khelifa, E. Saint-Aman, F. Loiseau, H. Nasri, Synthesis, spectroscopic characterizations, cyclic voltammetry investigation and molecular structure of the di- $\mu$-cyanatoN-bis $(\mu-1,4,7,10,13,16$-hexaoxacyclooctadecane)bis $(5,10,15,20$ - 
tetraphenylporphyrinato)dimagnesiumdipotassium complex, Polyhedron. 117 (2016) 817-825. https://doi.org/10.1016/j.poly.2016.06.045.

[46] L. Jiang, R.A. Zaenglein, J.T. Engle, C. Mittal, C.S. Hartley, C.J. Ziegler, H. Wang, Watersoluble ionic benzoporphyrins, Chem. Commun. 48 (2012) 6927-6929. https://doi.org/10.1039/C2CC31057K.

[47] N. Amiri, M. Hajji, T. Roisnel, G. Simonneaux, H. Nasri, Synthesis, molecular structure, photophysical properties and spectroscopic characterization of new 1D-magnesium(II) porphyrinbased coordination polymer, Res Chem Intermed. 44 (2018) 5583-5595. https://doi.org/10.1007/s11164-018-3442-9.

[48] J.W. Owens, R. Smith, R. Robinson, M. Robins, Photophysical properties of porphyrins, phthalocyanines, and benzochlorins, Inorg. Chim. Acta 279 (1998) 226-231. https://doi.org/10.1016/S0020-1693(98)00137-6.

[49] J. Zhang, P. Zhang, Z. Zhang, X. Wei, Spectroscopic and Kinetic Studies of Photochemical Reaction of Magnesium Tetraphenylporphyrin with Oxygen, J. Phys. Chem. A. 113 (2009) 53675374. https://doi.org/10.1021/jp811209k.

[50] A. Ghosh, S.M. Mobin, R. Fröhlich, R.J. Butcher, D.K. Maity, M. Ravikanth, Effect of Five Membered Versus Six Membered Meso-Substituents on Structure and Electronic Properties of Mg(II) Porphyrins: A Combined Experimental and Theoretical Study, Inorg. Chem. 49 (2010) 8287-8297. https://doi.org/10.1021/ic1008522.

[51] N. Amiri, M. Hajji, T. Roisnel, G. Simonneaux, H. Nasri, Synthesis, molecular structure, photophysical properties and spectroscopic characterization of new 1D-magnesium(II) porphyrinbased coordination polymer, Res Chem Intermed. 44 (2018) 5583-5595. https://doi.org/10.1007/s11164-018-3442-9

[52] Z. Denden, K. Ezzayani, E. Saint-Aman, F. Loiseau, S. Najmudin, C. Bonifácio, J.-C. Daran, H. Nasri, Insights on the UV/Vis, Fluorescence, and Cyclic Voltammetry Properties and the Molecular Structures of ZnII Tetraphenylporphyrin Complexes with Pseudohalide Axial Azido, Cyanato-N, Thiocyanato-N, and Cyanido Ligands, Eur. J. Inorg. Chem. (2015) 2596-2610. https://doi.org/10.1002/ejic.201403214.

[53] S. Nasri, I. Zahou, I. Turowska-Tyrk, T. Roisnel, F. Loiseau, E. Saint-Amant, H. Nasri, Synthesis, Electronic Spectroscopy, Cyclic Voltammetry, Photophysics, Electrical Properties and X-ray Molecular Structures of meso-Tetrakis[4-(benzoyloxy)phenyl]porphyrinatozinc(II) Complexes with Aza Ligands, Eur. J. Inorg. Chem. (2016) 5004-5019. https://doi.org/10.1002/ejic.201600575.

[54] C.C. Ong, V. McKee, G.A. Rodley, The crystal and molecular structure of a monohydrated dipicoline magnesium tetraphenylporphyrin complex, Inorg. Chim. Acta 123 (1986) L11-L14. https://doi.org/10.1016/S0020-1693(00)84300-5.

[55] K. Ezzayani, M.S. Belkhiria, S. Najmudin, C. Bonifácioc and Habib Nasri, Aqua-(4-cyanopyridine- $\kappa \mathrm{N}(4))(5,10,15,20$-tetra-phenyl-porphyrinato- $\kappa(4) \mathrm{N})$ magnesium., Acta Crystallogr Sect E Struct Rep Online. 69 (2012) m17-8. https://doi.org/10.1107/s1600536812049434.

[56] W.R. Scheidt, Y.J. Lee, Recent advances in the stereochemistry of metallotetrapyrroles, in: J.W. Buchler (Ed.), Metal Complexes with Tetrapyrrole Ligands I, Springer, Berlin, Heidelberg, 1987: pp. $1-70$. https://doi.org/10.1007/BFb0036789.

[57] W.R. Scheidt, D.K. Geiger, R.G. Hayes, G. Lang, Control of spin state in (porphinato)iron(III) complexes. An axial ligand orientation effect leading to an intermediate-spin complex. Molecular structure and physical characterization of the monoclinic form of bis(3- 
chloropyridine)(octaethylporphinato)iron(III) perchlorate, J. Am. Chem. Soc. 105 (1983) 26252632. https://doi.org/10.1021/ja00347a018.

[58] J. Bhuyan, R. Sarkar, S. Sarkar, A Magnesium Porphyrin Bicarbonate Complex with $\mathrm{CO}_{2^{-}}$ Modulated Photosystem I Action, Angew. Chem. Int. 123 (2011) 10791-10795. https://doi.org/10.1002/ange.201103876.

[59] N. Amiri, S. Nasri, T. Roisnel, G. Simonneaux, H. Nasri, Crystal structure of di-aqua-[5,10,15,20-tetra-kis-(4-bromo-phen-yl)porphyrinato- $\kappa 4 \mathrm{~N}]$ magnesium, Acta Cryst E. 71 (2015) m73-m74. https://doi.org/10.1107/S2056989015003722.

[60] K. Ezzayani, A. Ben Khelifa, E. Saint-Aman, F. Loiseau, H. Nasri, Complex of hexamethylenetetramine with magnesium-tetraphenylporphyrin: Synthesis, structure, spectroscopic characterizations and electrochemical properties, J. Mol. Struct.. 1137 (2017) 412 418. https://doi.org/10.1016/j.molstruc.2017.02.054.

[61] V. McKee, O.C. Choon, G.A. Rodley, X-ray crystal and molecular structures of related octahedral magnesium tetraphenylporphyrin complexes, Inorg. Chem. 23 (1984) 4242-4248. https://doi.org/10.1021/ic00193a029.

[62] M.P. Byrn, C.J. Curtis, Y. Hsiou, S.I. Khan, P.A. Sawin, S.K. Tendick, A. Terzis, C.E. Strouse, Porphyrin sponges: conservative of host structure in over 200 porphyrin-based lattice clathrates, J. Am. Chem. Soc. 115 (1993) 9480-9497. https://doi.org/10.1021/ja00074a013.

[63] N. Amiri, M. Hajji, F.B. Taheur, S. Chevreux, T. Roisnel, G. Lemercier, H. Nasri, Two novel magnesium(II) meso-tetraphenylporphyrin-based coordination complexes: Syntheses, combined experimental and theoretical structures elucidation, spectroscopy, photophysical properties and antibacterial activity, J. Solid State Chem. 258 (2018) 477-484. https://doi.org/10.1016/j.jssc.2017.11.018.

[64] Y. Tang, L.N. Zakharov, A.L. Rheingold, R.A. Kemp, Synthesis and Structural Characterization of Magnesium Amide Complexes Containing -N[(R)(SiMe 3$)]$ Ligands, Organometallics. 24 (2005) 836-841. https://doi.org/10.1021/om049203c.

[65] S.J. Bonyhady, C. Jones, S. Nembenna, A. Stasch, A.J. Edwards, G.J. McIntyre, $\beta$-DiketiminateStabilized Magnesium(I) Dimers and Magnesium(II) Hydride Complexes: Synthesis, Characterization, Adduct Formation, and Reactivity Studies, Chem. Eur. J.16 (2010) 938-955. https://doi.org/10.1002/chem.200902425.

[66] C. Jones, L. McDyre, D.M. Murphy, A. Stasch, Magnesium(I) reduction of benzophenone and anthracene: first structural characterisation of a magnesium ketyl, Chem. Commun. 46 (2010) $1511-1513$. https://doi.org/10.1039/B922002J.

[67] P.E. Werner, Structure of 4-Acetoamido-3-(1-acetyl-2-(2, 6-dichlorobenzylidene)-1, 2, 4triazole., Cryst. Struct. Commun. 5 (1976) 873.

[68] M.A. Spackman, P.G. Byrom, A novel definition of a molecule in a crystal, Chem. Phys. Lett. 267 (1997) 215-220. https://doi.org/10.1016/S0009-2614(97)00100-0.

[69] J.J. McKinnon, M.A. Spackman, A.S. Mitchell, Novel tools for visualizing and exploring intermolecular interactions in molecular crystals, Acta Cryst B. 60 (2004) 627-668. https://doi.org/10.1107/S0108768104020300.

[70] M.J. Turner, J.J. McKinnon, S.K. Wolff, D.J. Grimwood, P.R. Spackman, D. Jayatilaka, M.A. Spackman, CrystalExplorer17. University of Western Australia., (2017). 
[71] C.D.A. León, G.A. Echeverría, O.E. Piro, S.E. Ulic, J.L. Jios, J.A. Pereañez, I.C.H. Castañeda, H. Pérez, The role of non-covalent interactions in some 2-trifluoromethylchromones in the solid state, New J. Chem. 41 (2017) 14659-14674.

https://doi.org/10.1039/C7NJ00481H.

[72] Gaussian 09 Citation | Gaussian.com, (n.d.). https://gaussian.com/g09citation/ (accessed December 19, 2020).

[73] GaussView, Guassian. "Inc.(Carnergie Office Parck-Building6 Pittsburgh PA 151064 USA), Copyright@ 2000-2003 Semichem.," (200AD).

[74] A.D. Becke, Becke's three parameter hybrid method using the LYP correlation functional., J. Chem. Phys,. 98 (1993) 5648-5652.

[75] C. Lee, W. Yang, R.G. Parr, Development of the Colle-Salvetti correlation-energy formula into a functional of the electron density, Phys. Rev. B. 37 (1988) 785-789. https://doi.org/10.1103/PhysRevB.37.785.

[76] J.G. Małecki, Synthesis, crystal, molecular and electronic structures of thiocyanate ruthenium complexes with pyridine and its derivatives as ligands, Polyhedron. 29 (2010) 1973-1979. https://doi.org/10.1016/j.poly.2010.03.015.

[77] H. Bougherara, R. Kadri, M. Kadri, M. Yekhlef, A. Boumaza, Complex of 4-(2aminophenyl)-1,2,3- thiadiazole with 2,3-dichloro- 5,6-dicyano-1,4-benzoquinone: Experimental study and investigation at different exchange-correlation functionals. DOS, NBO, QTAIM and RDG analyses, J. Mol. Struct. $1223 \quad$ (2021) 12885. https://doi.org/10.1016/j.molstruc.2020.128855.

[78] N. Okulik, A. Jubert, Theoretical Analysis of the Reactive Sites of Non-steroidal Antiinflammatory Drugs, Internet Electronic Internet Electron. J. Mol. Des. 4 (2005) 17-30.

[79] K.M. Kadish, M.M. Morrison, Solvent and substituent effects on the redox reactions of parasubstituted tetraphenylporphyrin, J. Am. Chem. Soc. 98 (1976) 3326-3328. https://doi.org/10.1021/ja00427a046.

[80] A. Ghosh, S.M. Mobin, R. Fröhlich, R.J. Butcher, D.K. Maity, M. Ravikanth, Effect of Five Membered Versus Six Membered Meso-Substituents on Structure and Electronic Properties of Mg(II) Porphyrins: A Combined Experimental and Theoretical Study, Inorg. Chem. 49 (2010) 8287-8297. https://doi.org/10.1021/ic1008522.

[81] A.B. Khelifa, K. Ezzayani, M. Guergueb, F. Loiseau, E. Saint-Aman, H. Nasri, Synthesis, molecular structure, spectroscopic characterization and antibacterial activity of the pyrazine magnesium porphyrin coordination polymer, J. Mol. Struct. (2020) 129508. https://doi.org/10.1016/j.molstruc.2020.129508.

[82] S. Nasri, M. Hajji, M. Guergueb, S. Dhifaoui, V. Marvaud, F. Loiseau, F. Molton, T. Roisnel, T. Guerfel, H. Nasri, Spectroscopic, Electrochemical, Magnetic and Structural Characterization of an Hexamethylenetetramine Co(II) Porphyrin Complex - Application in the Catalytic Degradation of Vat Yellow 1 dye, J. Mol. Struct. (2020) 129676. https://doi.org/10.1016/j.molstruc.2020.129676.

[83] F. D’Souza, M.E. Zandler, P. Tagliatesta, Z. Ou, J. Shao, E. Van Caemelbecke, K.M. Kadish, Electronic, Spectral, and Electrochemical Properties of (TPPBrx)Zn Where TPPBrx Is the Dianion of $\beta$-Brominated-Pyrrole Tetraphenylporphyrin and $\mathrm{x}$ Varies from 0 to 8, Inorg. Chem. 37 (1998) 4567-4572. https://doi.org/10.1021/ic980336y.

[84] C.E. Overton, Overton, C. E. (1901). Studien über die Narkose: zugleich ein Beitrag zur allgemeinen Pharmakologie. G. Fischer., (n.d.). 
[85] N. Dharmaraj, P. Viswanathamurthi, K. Natarajan, Ruthenium(II) complexes containing bidentate Schiff bases and their antifungal activity, Transit. Met. Chem. 26 (2001) 105-109. https://doi.org/10.1023/A:1007132408648.

[86] B.G. Tweedy, Plant extracts with metal ions as potential antimicrobial agents. Phytopathology, 1964, vol. 55, p. 910-914., Phytopathology. 55 (1964) 910-914.

[87] L. Mishra, V.K. Singh, Synthesis, structural and antifungal studies of $\mathrm{Co}(\mathrm{II}), \mathrm{Ni}(\mathrm{II}), \mathrm{Cu}(\mathrm{II})$ and $\mathrm{Zn}$ (II) complexes with new Schiff bases bearing benzimidazoles, IJC-A Vol.32A(05). (1993). http://nopr.niscair.res.in/handle/123456789/43838

[88] R. Thangam, V. Suresh, S. Kannan, Optimized extraction of polysaccharides from Cymbopogon citratus and its biological activities,Int. J. Biol. Macromol. 65 (2014) 415-423. https://doi.org/10.1016/j.ijbiomac.2014.01.033.

[89] Y. Carmona-Jiménez, M.V. García-Moreno, J.M. Igartuburu, C. Garcia Barroso, Simplification of the DPPH assay for estimating the antioxidant activity of wine and wine by-products, Food Chem. 165 (2014) 198-204. https://doi.org/10.1016/j.foodchem.2014.05.106.

[90] N. Amiri, S. Nouir, M. Hajji, T. Roisnel, T. Guerfel, G. Simonneaux, H. Nasri, Synthesis, structure, photophysical properties and biological activity of a cobalt(II) coordination complex with 4,4'-bipyridine and porphyrin chelating ligands, J. Saudi Chem. Soc. 23 (2019) 781-794. https://doi.org/10.1016/j.jscs.2019.03.003.

[91] C. Hu, D.D. Kitts, Evaluation of antioxidant activity of epigallocatechin gallate in biphasic model systems in vitro, Mol Cell Biochem. 218 (2001) 147-155. https://doi.org/10.1023/A:1007220928446.

[92] H.-H. Housam, K. Warid, A.-A. Zaid, Estimating the antioxidant activity for natural antioxidants (tocochromanol) and synthetic one by DPPH, Int J Pharm Pharm Sci. 6 (2014) 441-444. 


\section{Figures:}

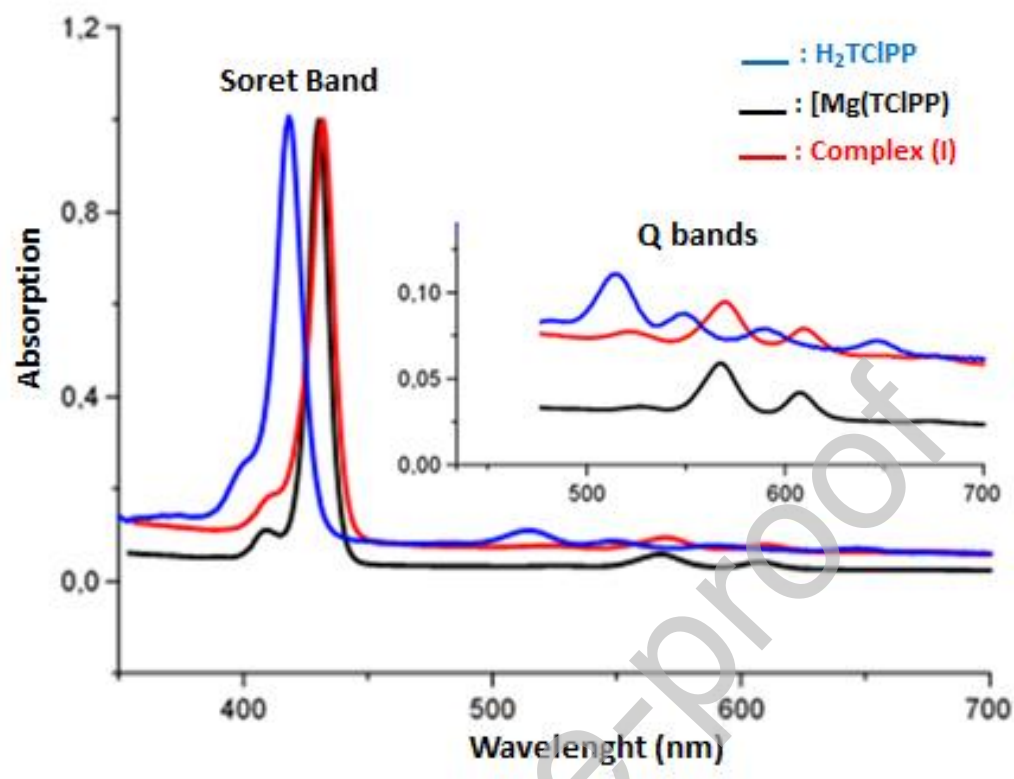

Figure 1. Electronic absorption spectra of free base $\mathrm{H}_{2} \mathrm{TClPP}$, the starting material $[\mathrm{Mg}(\mathrm{TClPP})]$ and complex (I) at ca. $10^{-6} \mathrm{M}$ in dichloromethane. The inset shows enlarged views.

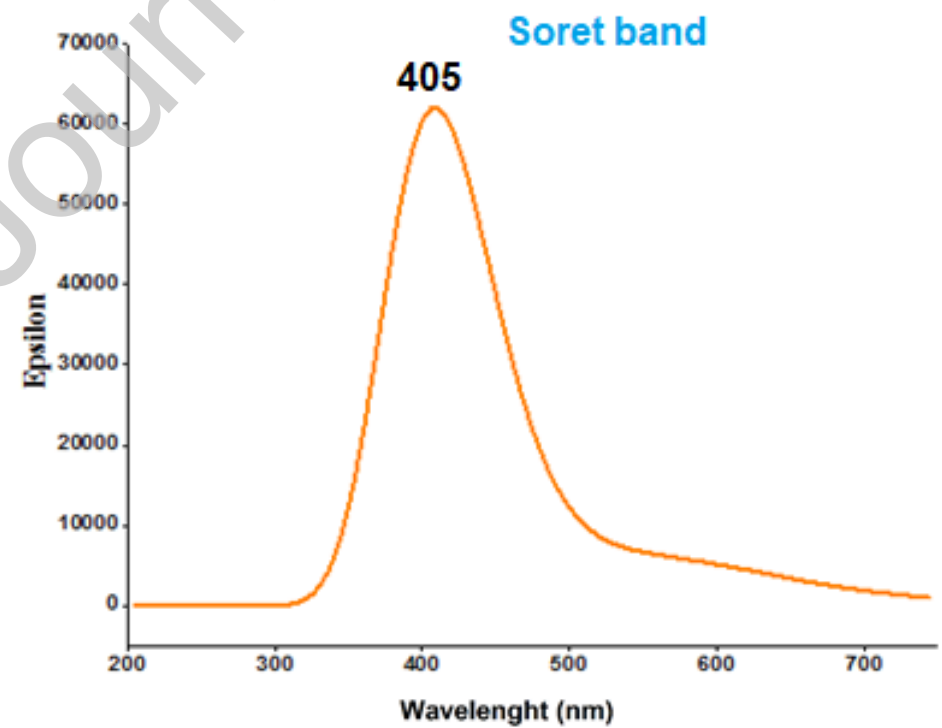


Figure 2. Theoretical UV-visible spectrum of [Mg(TCPP)(DMAP)] (I) TD/DFT method in chloroform solvent.

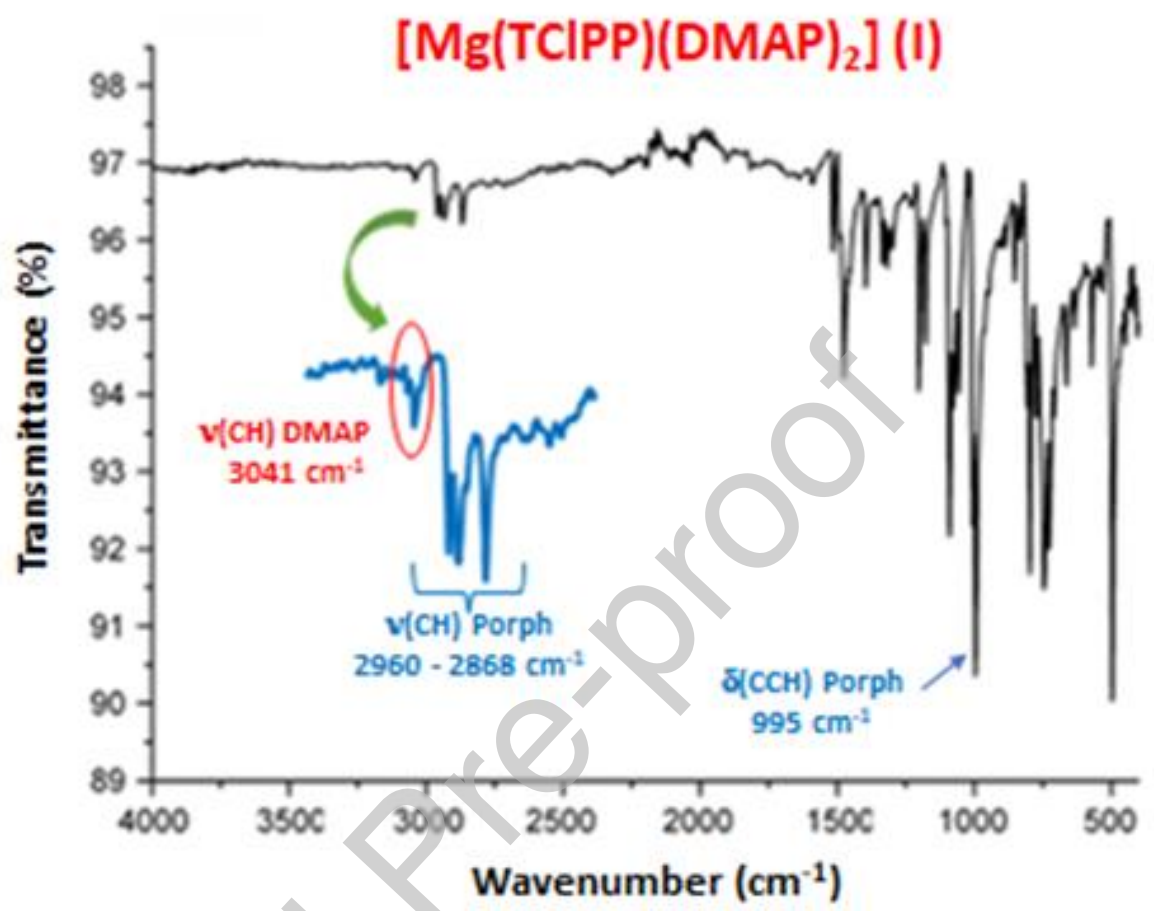

Figure 3. Solid IR spectrum of [Mg(TC1PP)(DMAP)] (I).

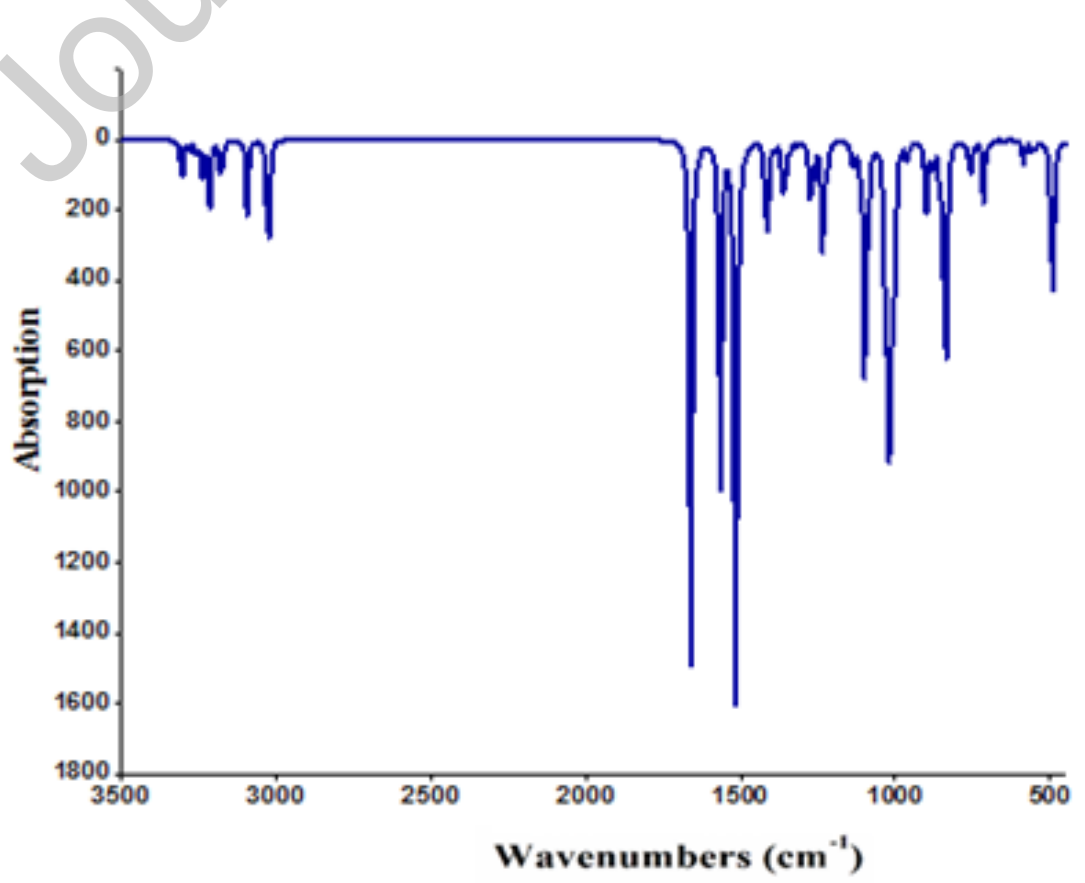


Figure 4. Calculated IR spectra (gas phase) of [Mg (TCPP)(DMAP)] (I) using the B3LYP/LanL2DZ method.

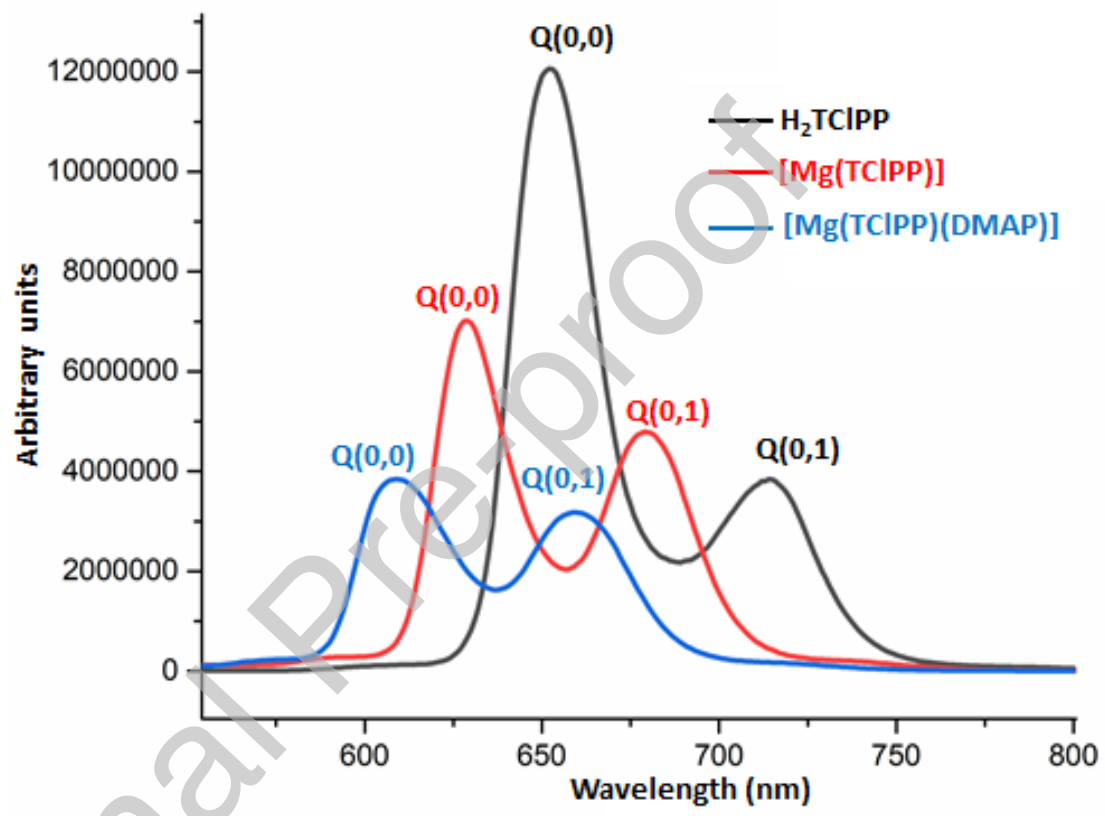

Figure 5. Emission spectrum of $\mathrm{H}_{2} \mathrm{TClPP},[\mathrm{Mg}(\mathrm{TClPP})]$ and $[\mathrm{Mg}(\mathrm{TClPP})(\mathrm{DMAP})]$ (I). Concentrations $\sim 10^{-6} \mathrm{M}$ in dichloromethane solutions.

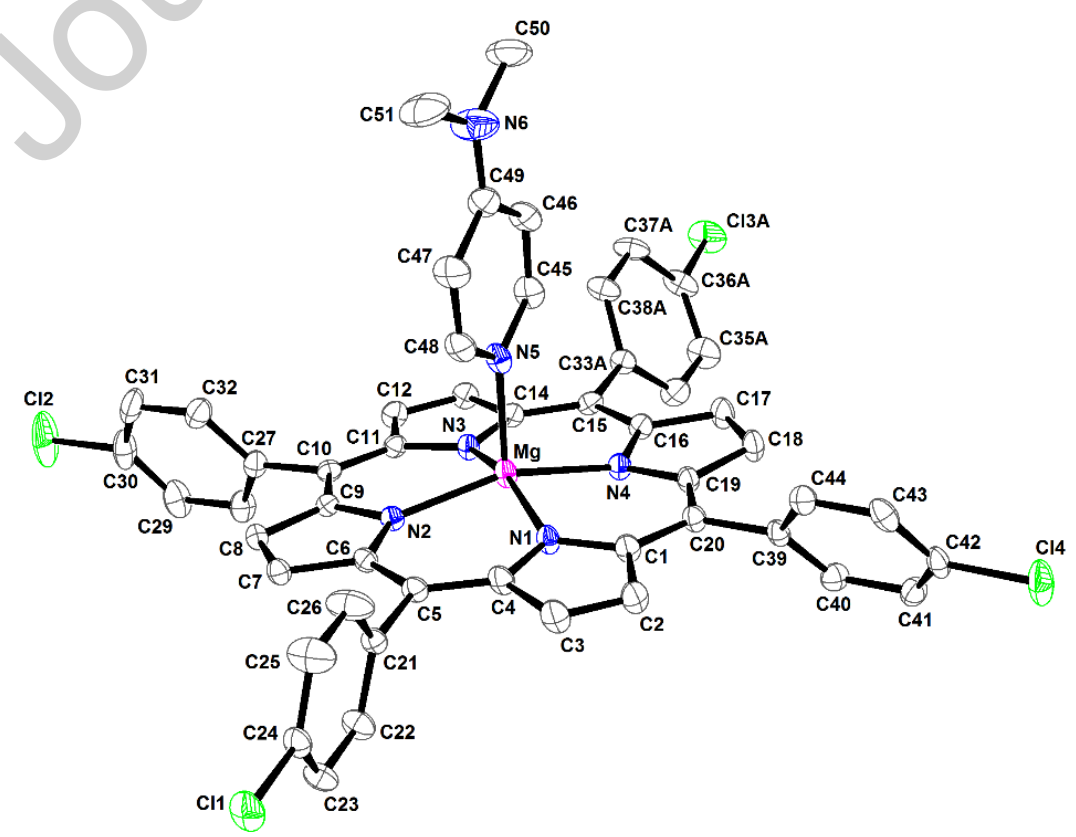


Figure 6. Ortep drawing of $[\mathrm{Mg}(\mathrm{TClPP})(\mathrm{DMAP})]$ (I) with thermal ellipsoids drawn at $30 \%$ probability. The hydrogen atoms are removed for clarity. Only the major positions of (i) the disordered phenyl group of the porphyrin is shown and (ii) the $\mathrm{N}\left(\mathrm{CH}_{2}\right)$ - group of the DMAP axial ligand are represented.

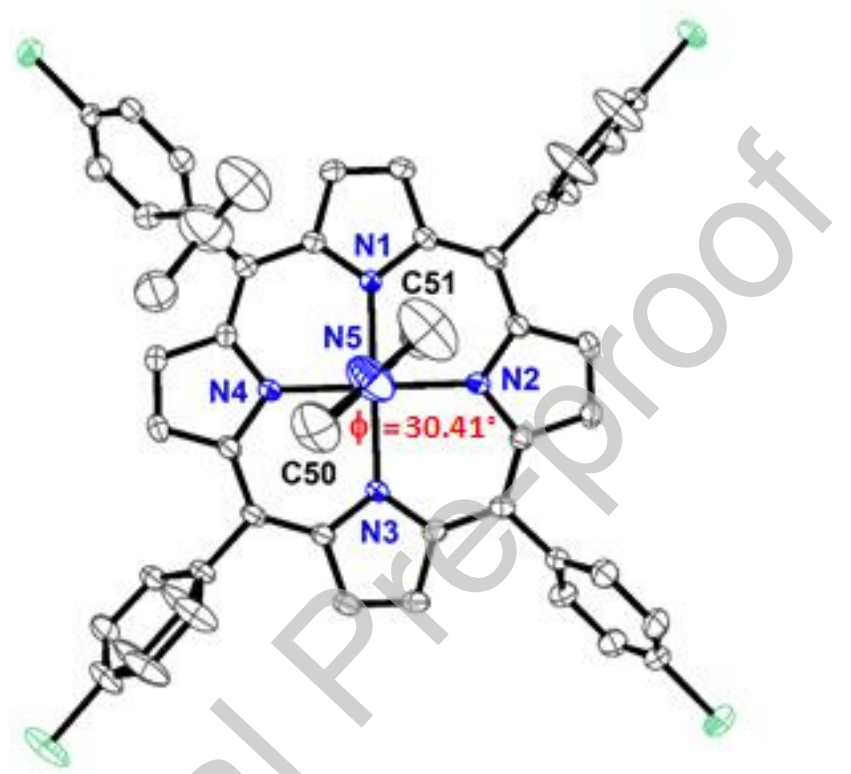

Figure 7. Ortep diagram of $[\mathrm{Mg}(\mathrm{TClPP})(\mathrm{DMAP})]$ viewed perpendicular to the mean plane of the porphyrinato core showing the $\phi$ dihedral angle. The hydrogen atoms are removed for clarity and only the major positions of the disordered fragments are represented.

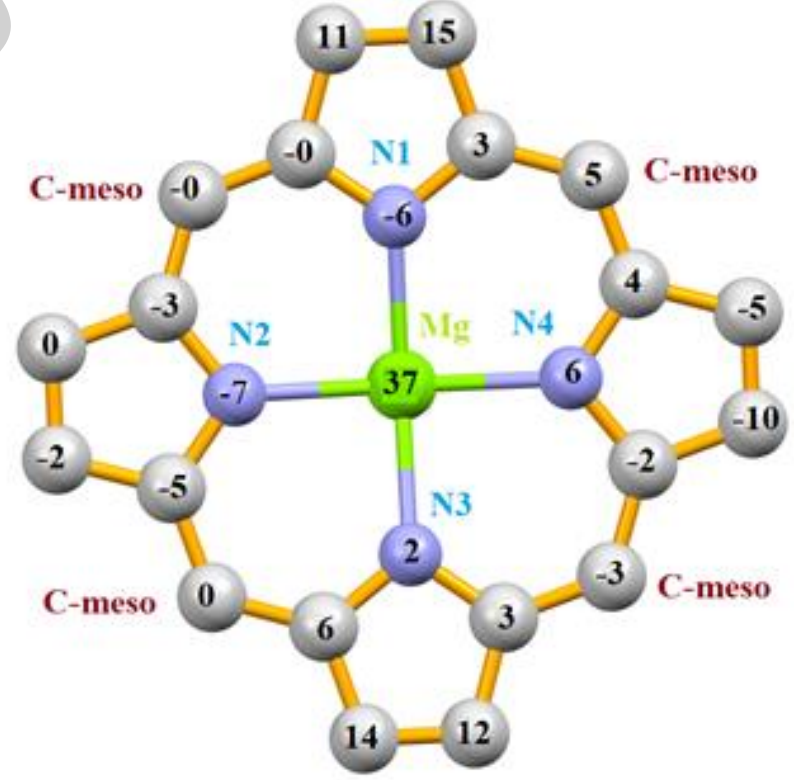


Figure 8. Formal diagram of the mean plane of the 24-atom porphyrin core. Positive values of the displacements are toward the axial DMAP ligand.

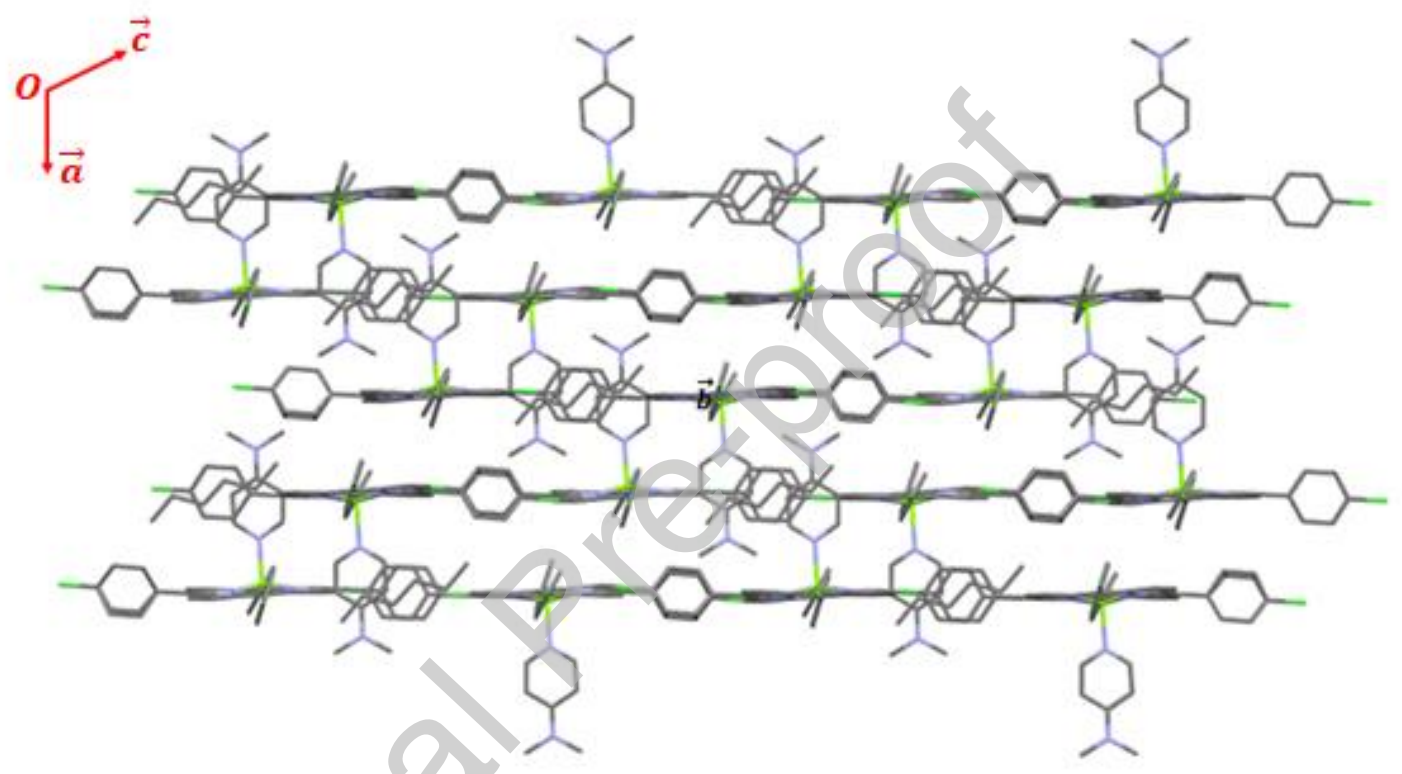

Figure

down

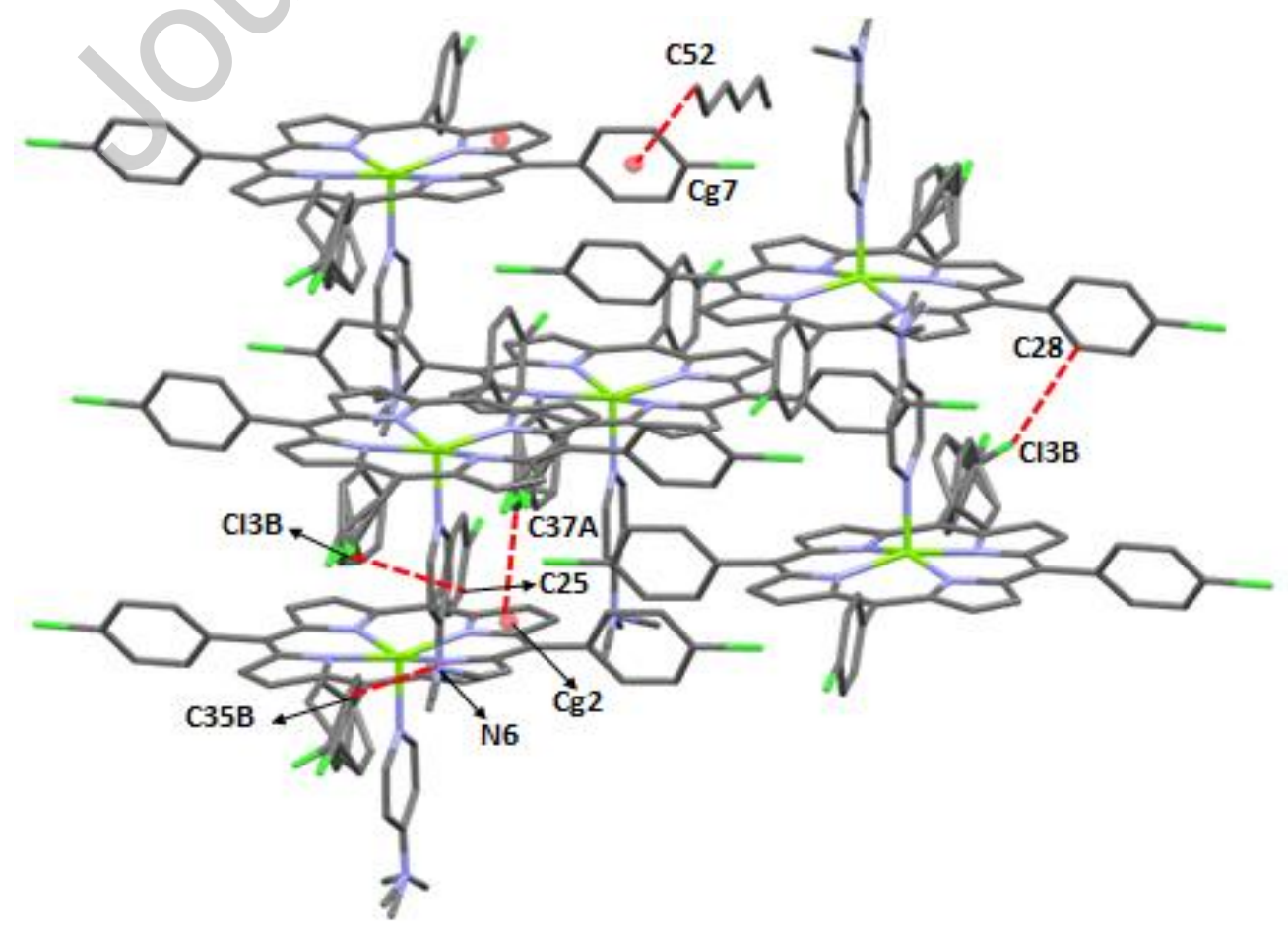

9. Projection the [010] direction showing the parallel layers. 
Figure 10. Packing diagram of (I) showing the three dimensional arrangement of the $[\mathrm{Mg}(\mathrm{TClPP})(\mathrm{DMAP})]$ and the n-hexane molecules.
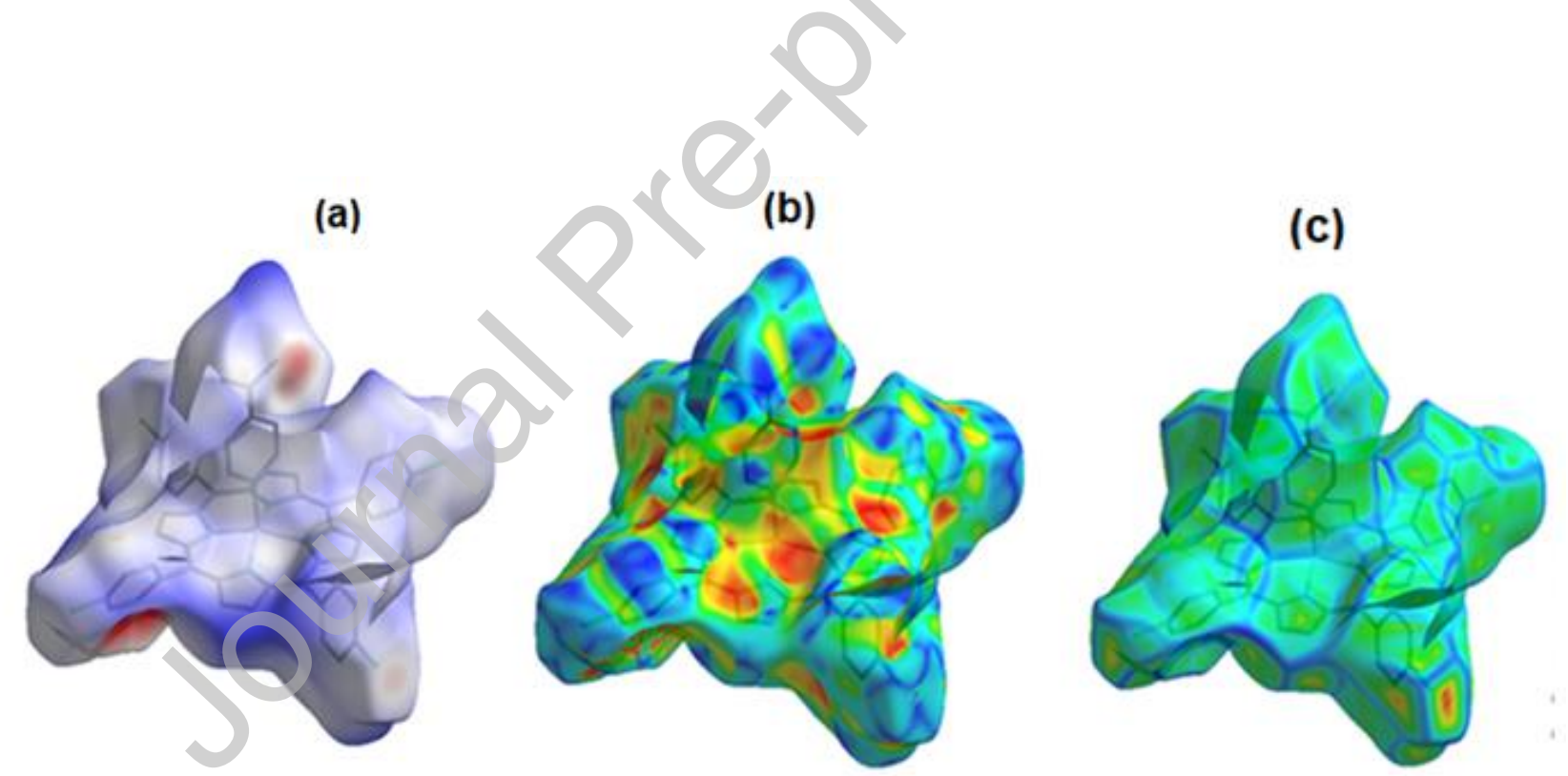

Figure 11. Hirshfeld surfaces mapped with $\mathrm{d}_{\text {norm }}(\mathbf{a})$, shape Index surface (b) and curvedness surfaces(c) for (I).
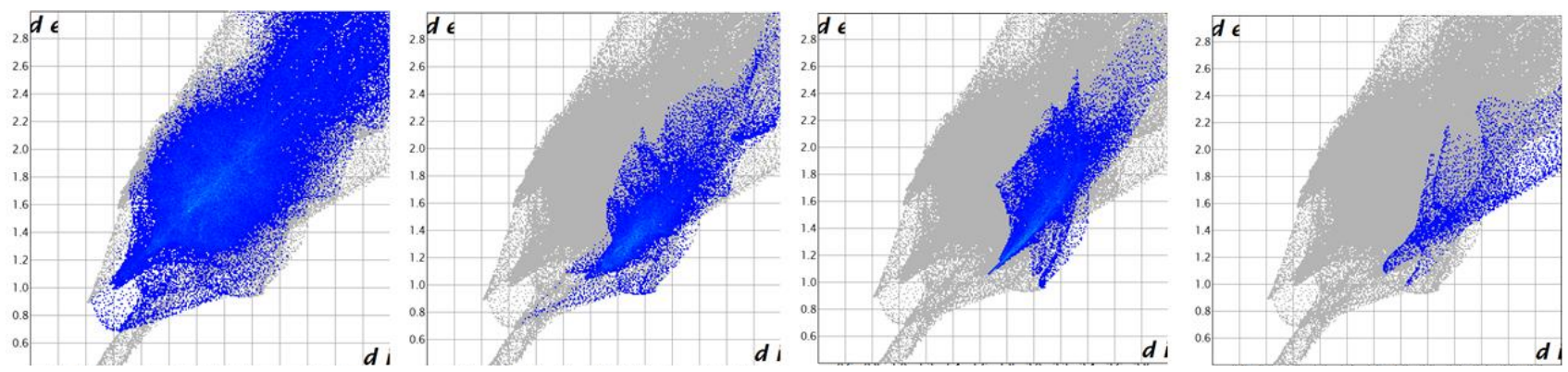
Figure 12. Two-dimensional fingerprint plots for (I).

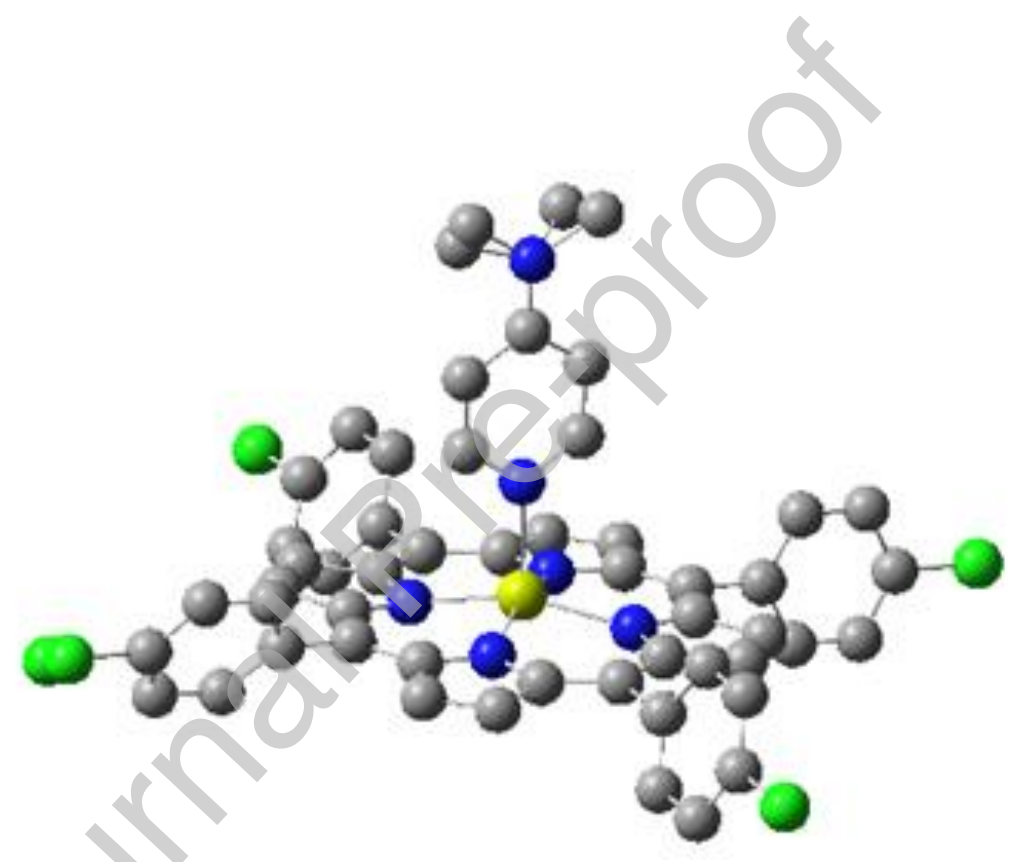

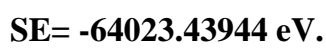

Figure 13. Optimized molecular structure of [Mg(TCPP)(DMAP)] using DFT/B3LYP/LanL2DZ method in gas phase. 


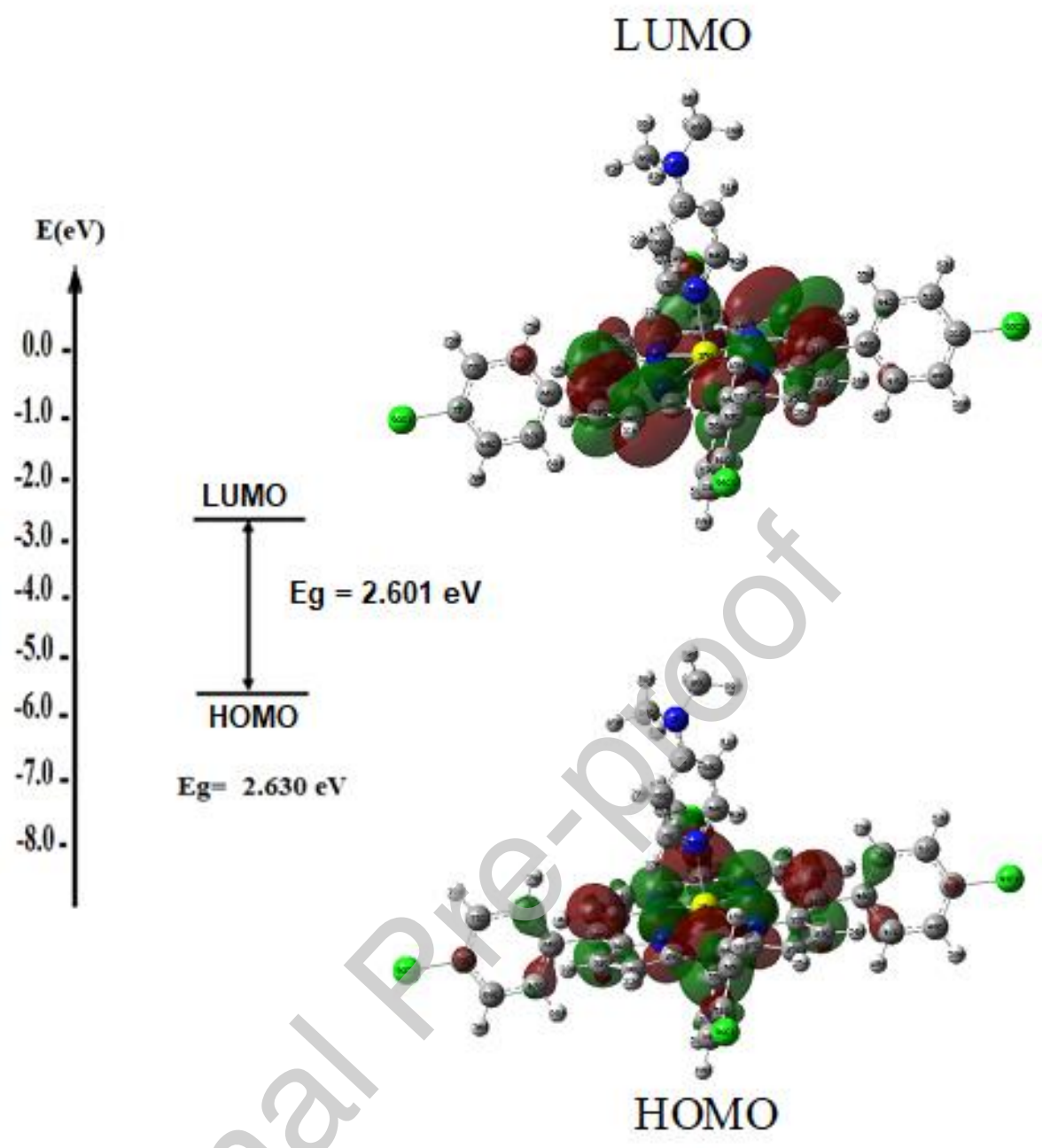

Figure 14. Plot of the frontier molecular orbitals of $[\mathrm{Mg}(\mathrm{TCPP})(\mathrm{DMAP}]$ in gas phase by using TD-DFT calculations. 


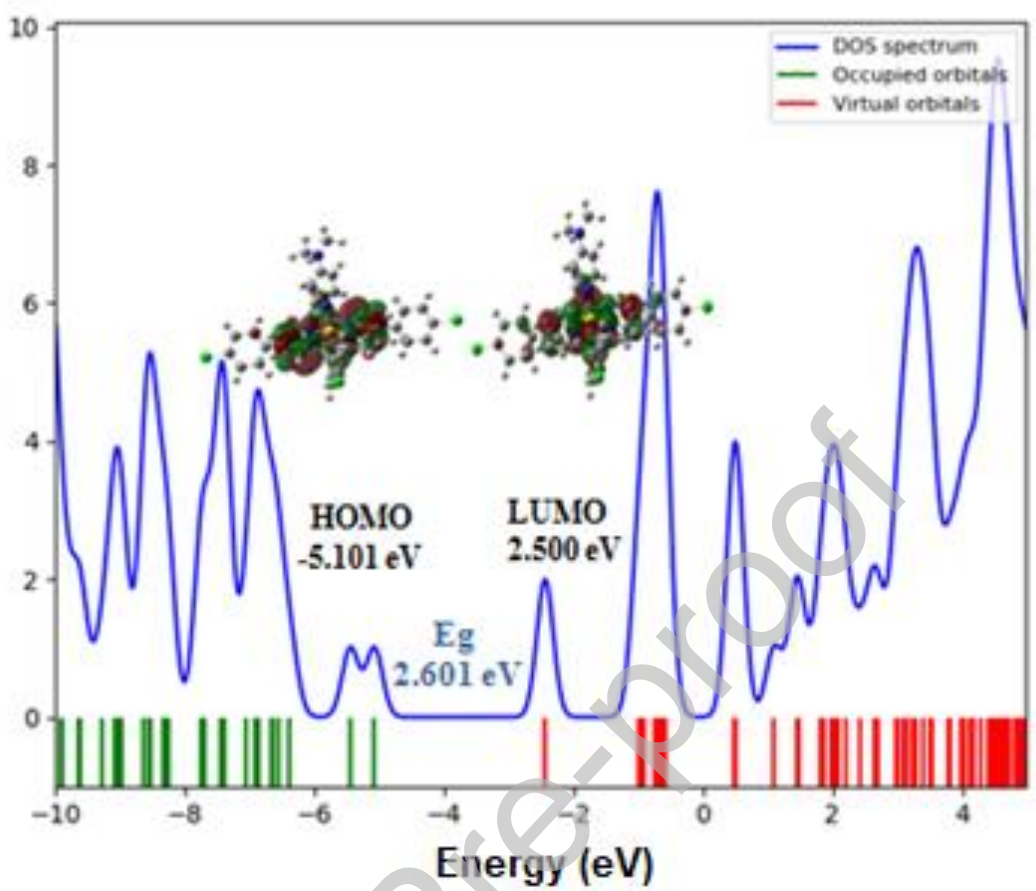

Figure 15. The density of states plots (DOS) of $[\mathrm{Mg}(\mathrm{TCPP})(\mathrm{DMAP})]$ using Gauss Sum program.
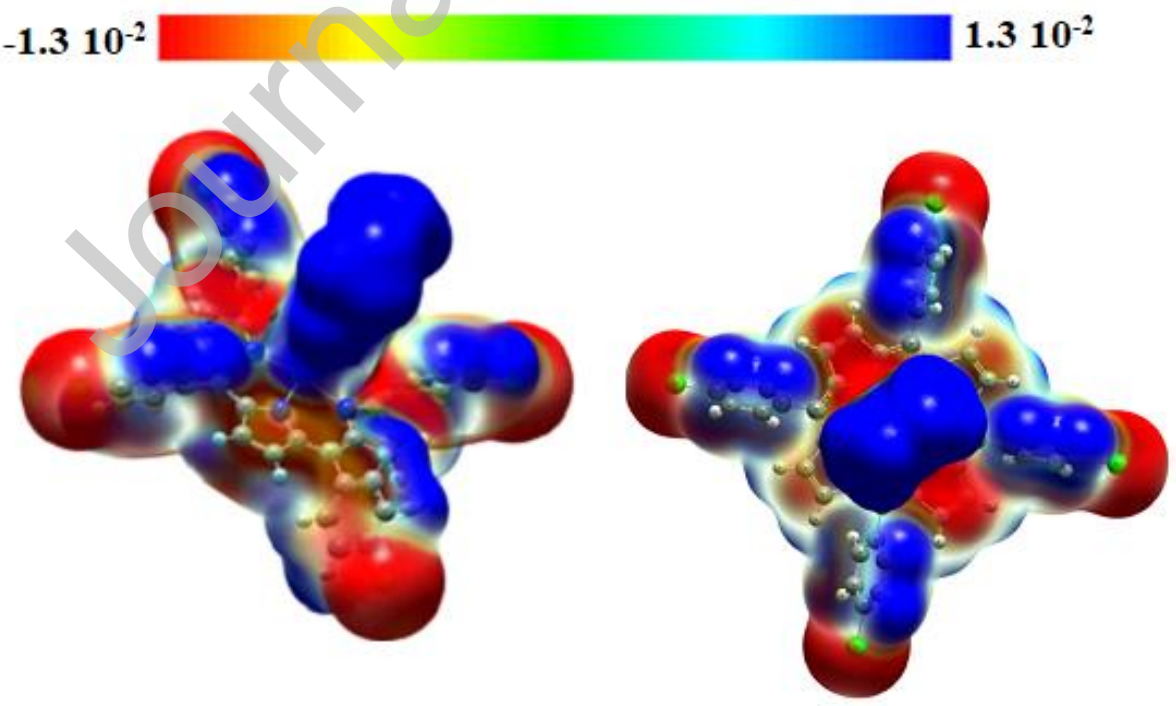

Figure 16. Molecular Electrostatic Potential (MEP) maps of the [Mg(TClPP)(DMAP)] molecule. 


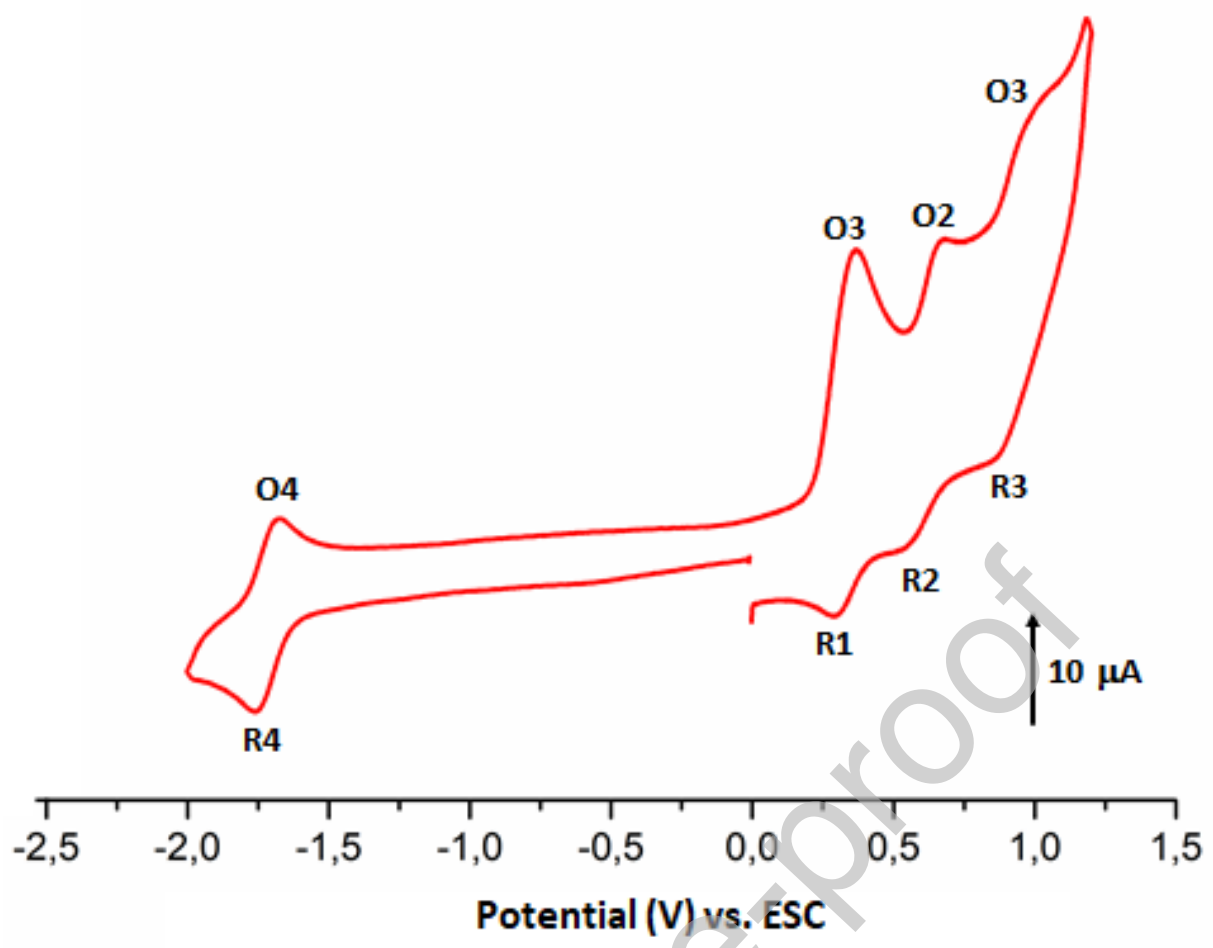

Figure 17. Cyclic voltammogram of (I). The solvent is $\mathrm{CH}_{2} \mathrm{Cl}_{2}$, and the concentration is ca. $10^{-3} \mathrm{M}$ in $0.2 \mathrm{M}$ TBAP, $50 \mathrm{mV} / \mathrm{s}$, vitreous carbon working electrode $(\varnothing=3 \mathrm{~mm})$.

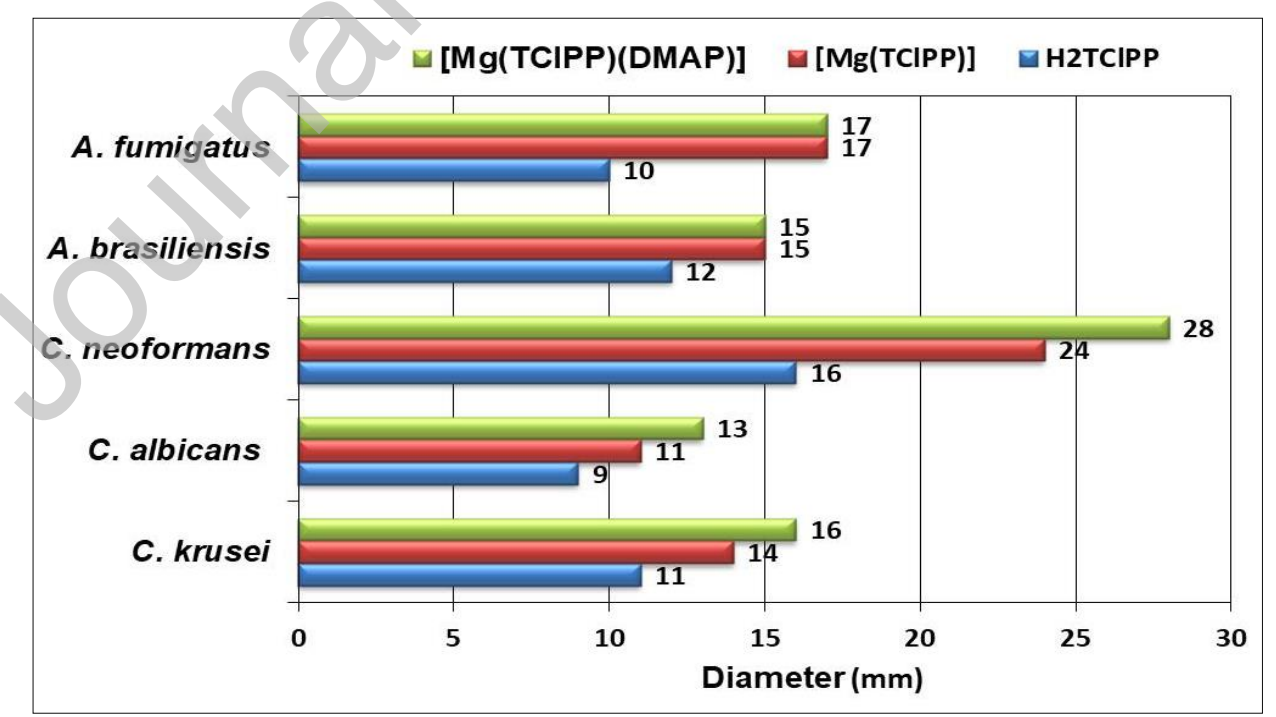

Figure 18. In vitro antifungal activity of $\mathrm{H}_{2} \mathrm{TClPP},[\mathrm{Mg}(\mathrm{TClPP})]$ and $[\mathrm{Mg}(\mathrm{TClPP})(\mathrm{DMAP})]$. 


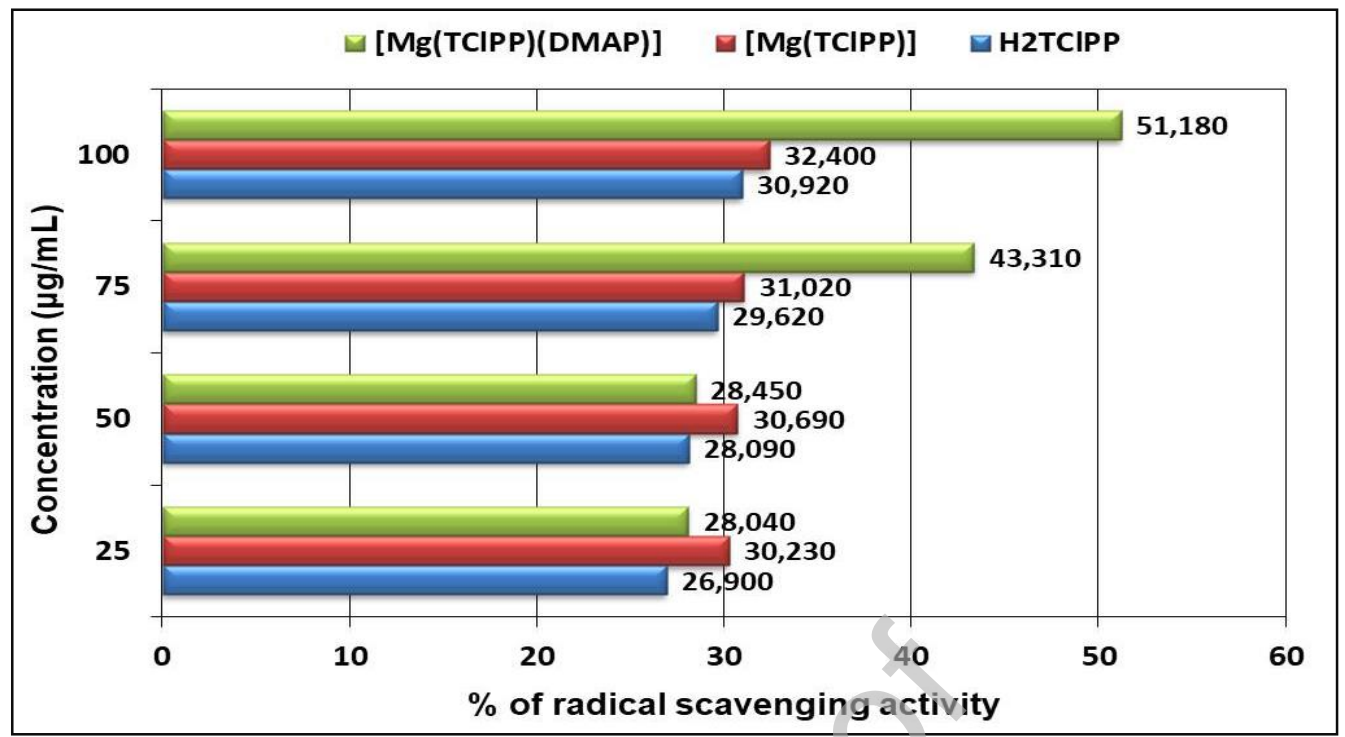

Figure 19. Emission DPPH radical scavenging activity of $\mathrm{H}_{2} \mathrm{TClPP},[\mathrm{Mg}(\mathrm{TClPP})]$ and [Mg(TClPP)(DMAP)] at different concentrations. 
Tables :

Table 1. Crystal data and structural refinement for $[\mathrm{Mg}(\mathrm{TClPP})(\mathrm{DMAP})] \cdot 1 / 2 \mathrm{C}_{6} \mathrm{H}_{14}{ }^{*}$ (I).

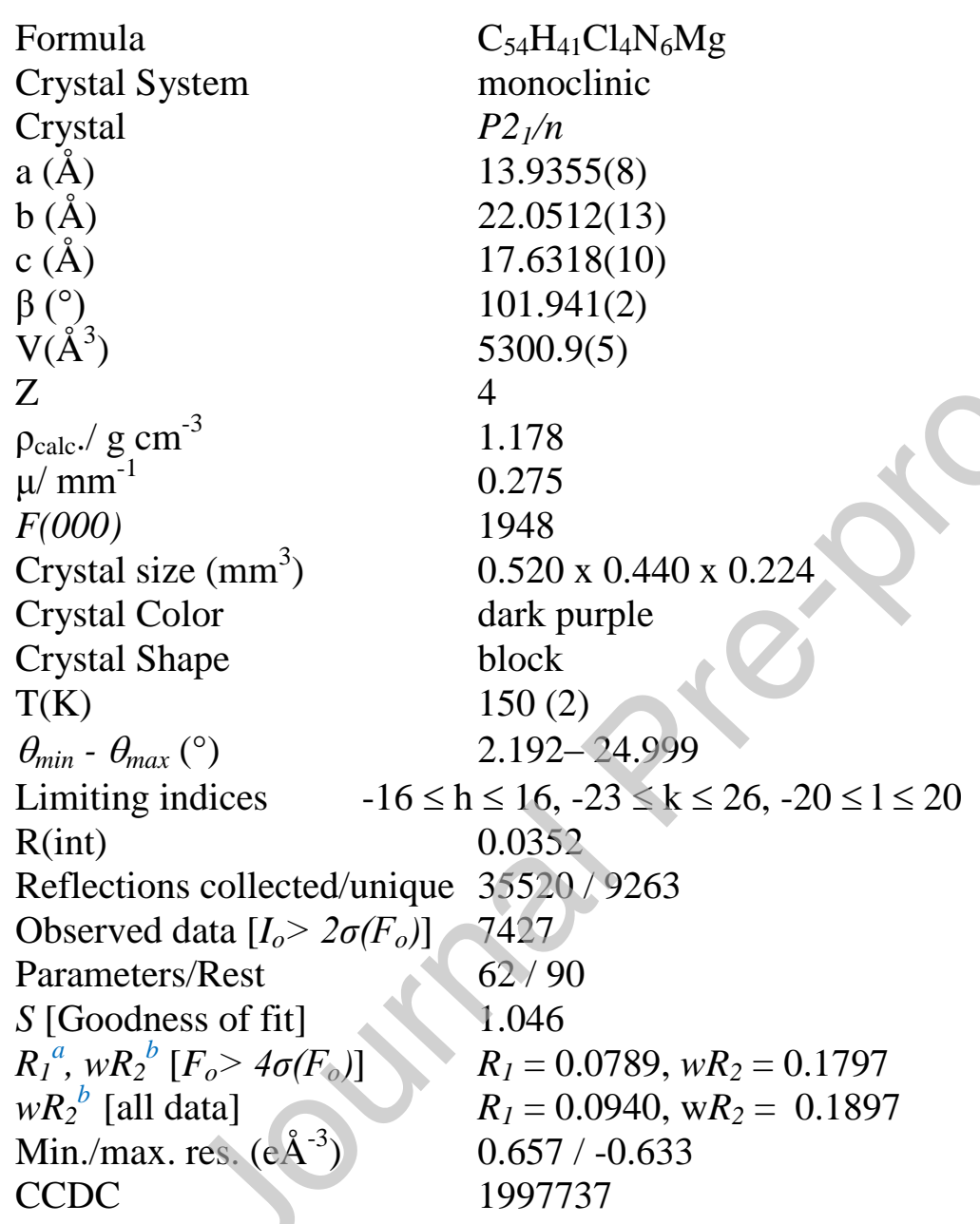

*: The given chemical formula of (I) and other crystal data of this complex do not take into account the removed n-hexane solvent molecule, using PLATON-Squeeze procedure (see details in the text).

${ }^{\mathrm{a}}: R_{1}=\left.\Sigma|| F_{\mathrm{O}}|-| F_{\mathrm{C}}|/ \Sigma| F_{\mathrm{O}}\right|^{\mathrm{b}}, w R_{2}=\left\{\Sigma\left[w\left(\left|F_{\mathrm{O}}\right|^{2}-\left|F_{\mathrm{C}}\right|^{2}\right)^{2}\right] / \Sigma\left[w\left(\left|F_{\mathrm{O}}\right|^{2}\right)^{2}\right]\right\}^{1 / 2}$. 
Table 2. Selected bond lengths $(\AA)$ and angles $\left(^{\circ}\right)$ of $(\mathbf{I})$.

Magnesium coordination polyhedron

$\begin{array}{llllll}\mathrm{Mg}-\mathrm{N} 1 & 2.084(3) & \mathrm{N} 1-\mathrm{Mg}-\mathrm{N} 2 & 88.53(11) & \mathrm{N} 3-\mathrm{Mg}-\mathrm{N} 4 & 88.27(11) \\ \mathrm{Mg}-\mathrm{N} 2 & 2.083(3) & \mathrm{N} 1-\mathrm{Mg}-\mathrm{N} 3 & 160.58(14) & \mathrm{N} 1-\mathrm{Mg}-\mathrm{N} 5 & 98.34(12) \\ \mathrm{Mg}-\mathrm{N} 3 & 2.08(3) & \mathrm{N} 1-\mathrm{Mg}-\mathrm{N} 4 & 88.59(11) & \mathrm{N} 2-\mathrm{Mg}-\mathrm{N} 5 & 101.45(12) \\ \mathrm{Mg}-\mathrm{N} 4 & 2.079(3) & \mathrm{N} 2-\mathrm{Mg}-\mathrm{N} 3 & 87.88(11) & \mathrm{N} 3-\mathrm{Mg}-\mathrm{N} 5 & 101.08(12) \\ \mathrm{Mg}-\mathrm{N} 5 & 2.130(4) & \mathrm{N} 2-\mathrm{Mg}-\mathrm{N} 4 & 159.92(13) & \mathrm{N} 4-\mathrm{Mg}-\mathrm{N} 5 & 98.64(12)\end{array}$

DMAP Axial ligand

$\begin{array}{ll}\mathrm{N} 5-\mathrm{C} 45 & 1.345(5) \\ \mathrm{C} 45-\mathrm{C} 46 & 1.359(6) \\ \mathrm{C} 46-\mathrm{C} 49 & 1.397(6) \\ \mathrm{C} 49-\mathrm{C} 47 & 1.397(5) \\ \mathrm{C} 47-\mathrm{C} 48 & 1.363(6) \\ \mathrm{C} 48-\mathrm{N} 5 & 1.337(5) \\ \mathrm{C} 49-\mathrm{N} 6 & 1.357(6) \\ \mathrm{N} 6-\mathrm{C} 50 & 1.463(4) \\ \mathrm{N} 6-\mathrm{C} 51 & 1.466(4) \\ \mathrm{N} 6-\mathrm{C} 50 \mathrm{~A} & 1.460(2) \\ \mathrm{N} 6-\mathrm{C} 51 \mathrm{~A} & 1.462(5) \\ \mathrm{Mg}-\mathrm{N} 5-\mathrm{C} 45 & 124.6(3)\end{array}$

Mg-N5-C48

C45-N5-C48

$\mathrm{N} 5-\mathrm{C} 45-\mathrm{C} 46$

$\mathrm{C} 45-\mathrm{C} 46-\mathrm{C} 49$

$\mathrm{C} 47-\mathrm{C} 49-\mathrm{C} 46$

C48-C47-C49

$\mathrm{C} 47-\mathrm{C} 48-\mathrm{N} 5$

C47-C49-N6

C46-C49-N6

C50-N6-C51

C50A-N6-C51A
120.9(3)

$114.5(3)$

125.1(4)

119.8(3)

115.7(4)

119.9(4)

125.0(4)

121.8(4)

122.6(4)

118.0(5)

121(5) 
Table 3. Chemical shift values for selected free base meso-arylporphyrins and magnesium(II) meso-arylporphyrin complexes and several non-porphyrinic DMAP complexes from ${ }^{1} \mathrm{H}$ NMR spectra. Spectra recorded in $\mathrm{CDCl}_{3}$, exception is indicated*.

\begin{tabular}{|c|c|c|c|c|c|}
\hline Compound & $\mathrm{H} \beta$-pyrrolic & H-phenyl & H-pyrrole & $\mathrm{H}_{\mathrm{L}, \mathrm{o}} ; \mathrm{H}_{\mathrm{L}, \mathrm{m}} ; \mathrm{H}_{\mathrm{a}}{ }^{\mathrm{a}}$ & Ref. \\
\hline
\end{tabular}

Meso-arylporphyrins

$\begin{array}{llllll}\mathrm{H}_{2} \mathrm{TPP}^{\mathrm{b}} & 8.84 & 8.23 ; 7.91 ; 7.67 ; 7.26 & -2.87 & - & \text { [39] } \\ \mathrm{H}_{2} \mathrm{TpivPP}^{\mathrm{c}} & 8.82 & 8.70 ; 7.88 ; 7.50 & -2.86 & - & {[39]} \\ \mathrm{H}_{2} \mathrm{TMPP}^{\mathrm{d}} & 8.86 & 8.08 ; 7.27 ; & -2.89 & - & {[40]} \\ \mathrm{H}_{2} \mathrm{TBrPP}^{\mathrm{e}} & 8.85 & 8.05 ; 7.91 & -2.86 & - & {[23]} \\ \mathrm{H}_{2} \mathrm{TClPP}^{\mathrm{f}} & 8.89 & 8.18 ; 7.74 & -2.83 & - & {[40]} \\ \mathrm{H}_{2} \mathrm{TPBP}^{\mathrm{f}} & 8.94 & 8.42 ; 8.33 ; 7.60 & -2.80 & - & {[41]}\end{array}$

Tetracoordinated Mg(II)-meso-arylporphyrins

$\begin{array}{lllllr}{[\mathrm{Mg}(\mathrm{TBrPP})]^{\mathrm{e}}} & 8.88 & 8.35 ; 8.08 ; 7.94 & - & - & {[23]} \\ {\left[_{\mathrm{Mg}(\mathrm{TPBP})]^{\mathrm{f}}}\right.} & 8.96 & 8.67 ; 8.36 ; 7.62 & - & - & {[41]} \\ {[\mathrm{Mg}(\mathrm{TClPP})]} & 8.85 & 8.14 ; 7.72 & - & - & \text { this work }\end{array}$

Mg(II)-meso-arylporphyrins

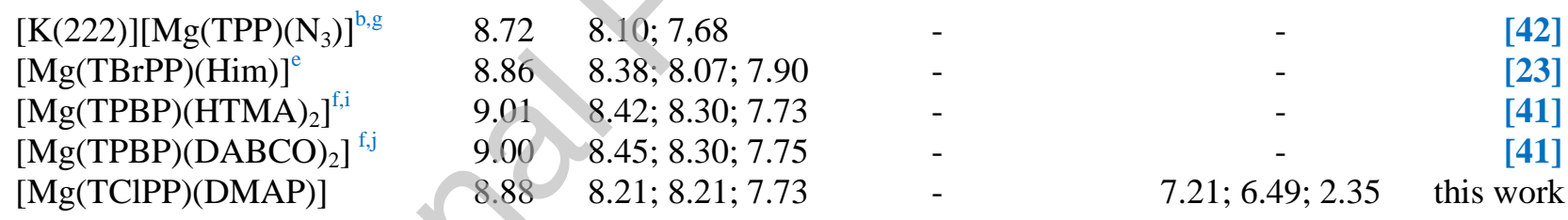

Non-porphyrinic DMAP complexes

\begin{tabular}{|c|c|c|c|}
\hline $\begin{array}{l}(\mathrm{BDI}) \\
{\left[\mathrm{Mg}\left(\mathrm{OCMe}{ }_{2} \mathrm{COOEt}\right)(\mathrm{DMAP})\right]^{\mathrm{k}, *}}\end{array}$ & - & - & $8.76 ; 5.99 ; 2.22$ \\
\hline$\left[\mathrm{Mg}(\mathrm{L})(\mathrm{DMAP})_{2}(1,2-\text { dadhp })\right]^{1, \mathrm{~m}}$ & - & - & $7.71 ; 4.75 ; 2.93$ \\
\hline
\end{tabular}

\footnotetext{
${ }^{a}$ : $\mathrm{H}_{\mathrm{L}, 0} ; \mathrm{H}_{\mathrm{L}, \mathrm{m}} ; \mathrm{H}_{\mathrm{a}}=$ otho, meta and the $\mathrm{CH}_{2}$ protons of the $\mathrm{N}\left(\mathrm{CH}_{2}\right)_{2}$ - protons of the DMAP axial ligand (see Figure $\mathrm{S} 4$ ),

${ }^{\mathrm{b}}: \mathrm{H}_{2} \mathrm{TPP}=$ meso-tetraphenylporphyrin, ${ }^{c}: \mathrm{H}_{2} \mathrm{TpivPP}=$ meso-[ $\alpha, \alpha, \alpha, \alpha$-tetrakis $(o$-pivalamidophenyl $\left.)\right]$ porphyrin,

${ }^{\mathrm{d}}: \mathrm{H}_{2} \mathrm{TMPP}=$ meso-tetra(para-methoxyphenyl)porphyrin, ${ }^{\mathrm{e}}: \mathrm{H}_{2} \mathrm{TBrPP}=$ meso-tetrakis(4-bromophenyl)porphyrin,

f: $\mathrm{H}_{2}$ TPBP $=$ meso-tetrakis[4(benzoyloxy)phenyl]porphinato, ${ }^{\mathrm{g}}:[\mathrm{K}(222)]^{+}=($cryptand-222)potassium $(+)$cation,

${ }^{\mathrm{i}}:$ HTMA $=$ Hexamethylenetetramine, ${ }^{\mathrm{j}}:$ DABCO $=$,4-diazabicyclo[2.2.2]octane, ${ }^{\mathrm{k}}:$ (BDI) $=2-[(2,6-$ diisopropylphenyl)amino]-4-[(2,6-diisopropylphenyl)imino]pent-2-ene, ${ }^{1}: \mathrm{L}=(\mathrm{Ph} 2 \mathrm{PNDip})-$ and $\mathrm{Dip}=2,6$ $\left.{ }_{i P_{2}} \mathrm{C}_{6} \mathrm{H}_{3}\right),{ }^{\mathrm{m}}:$ 1,2-dadhp $=$ 4-dimethylamino-1,2-dihydropyridide, $*$ : spectrum recorded in toluene.
} 
Table 4. UV-visible ${ }^{\mathrm{a}}$. data of complex (I) and a selection of meso-arylporphyrin compounds.

\begin{tabular}{llc}
\hline Compound & Soret band & Q bands \\
& $-\lambda_{\max }(\mathrm{nm})(\log \varepsilon)$ & Ref.
\end{tabular}

Meso-arylporphyrins

$\begin{array}{llll}\mathrm{H}_{2} \mathrm{TPP}^{\mathrm{b}} & 418(7.96) & 515(6.60) 549(6.30) 591(6.27) 647(6.27) & {[45]} \\ \mathrm{H}_{2} \mathrm{TBrPP}^{\mathrm{c}} & 419(6.58) & 515(5.24) 549(4.93) 590(4.77) 648(4.68) & {[23]} \\ \mathrm{H}_{2} \mathrm{TPBP}^{\mathrm{d}} & 419(5.90) & 514(4.46) 551(4.13) 590(3.94) 646(3.84) & {[41]} \\ \mathrm{H}_{2} \mathrm{TClPP} & 418(5.49) & 515(4.20) 550(4.27) 549(3.78) 647(3.45) & \text { this work }\end{array}$

Manganese(II) tetracoordinated meso-arylporphyrins

$\begin{array}{lllll}{[\mathrm{Mg}(\mathrm{TPP})]^{\mathrm{b}}} & 424(5.87) & 563(4.52) & 603(4.39) & {[46]} \\ {[\mathrm{Mg}(\mathrm{TBrPP})]^{\mathrm{c}}} & 426(6.63) & 563(5.23) & 603(5.06) & {[23]} \\ {[\mathrm{Mg}(\mathrm{TPBP})]^{\mathrm{d}}} & 427(5.86) & 565(4.42) & 605(4.16) & {[41]} \\ {[\mathrm{Mg}(\mathrm{TClPP})]} & 429(5.77) & 567(4.60) & 607(4.52) & \text { this work }\end{array}$

Manganese(II) hexacoordinate meso-arylporphyrins

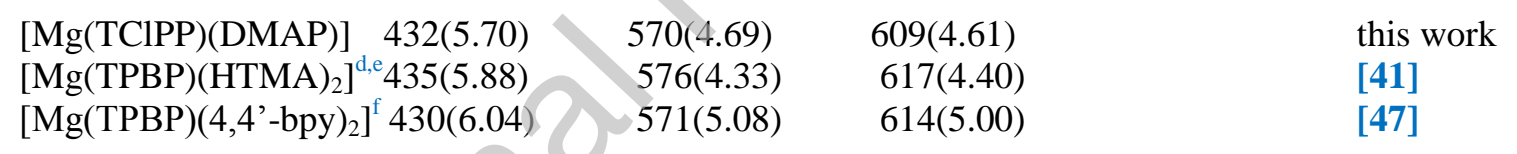

${ }^{\mathrm{a}}$ : All data are from spectra recorded in dichloromethane, ${ }^{\mathrm{b}}: \mathrm{H}_{2} \mathrm{TPP}=$ meso-tetraphenylporphyrin, $,{ }^{\mathrm{c}}: \mathrm{H}_{2} \mathrm{TBrPP}=$ meso-tetrakis(4-bromophenyl)porphyrin, ${ }^{\mathrm{d}}: \mathrm{H}_{2} \mathrm{TPBP}=$ meso-tetrakis[4(benzoyloxy)phenyl]porphinato, ${ }^{\mathrm{e}}$ : HTMA = Hexamethylenetetramine, ${ }^{\mathrm{f}}:$ 4,4'-bpy = 4,4'-bipyridine. 
Table 5. Emission parameter values of several meso-porphyrins and a selection of Magnesium(II) mesometalloporphyrins.

\begin{tabular}{lllllll}
\hline Compound & $\lambda_{\text {exci }}$ & $Q(0,0)$ & $Q(0,1)$ & $\Phi_{\mathrm{f}}$ & $\tau_{\mathrm{f}}^{\mathrm{c}}$ (in ns) & Ref.
\end{tabular}

Free base meso-arylporphyrin

$\begin{array}{lllllll}\mathrm{H}_{2} \text { TClPP } & 418 & 651 & 714 & 0.089 & 7.42 & {[40]} \\ \mathrm{H}_{2} \text { TClPP } & 420 & 652 & 714 & 0.082 & 7.20 & \text { this work } \\ \mathrm{H}_{2} \mathrm{TMPP}^{\mathrm{a}} & 424 & 656 & 719 & 0.082 & 7.20 & {[40]} \\ \mathrm{H}_{2} \mathrm{TPP}^{\mathrm{b}} & - & 653 & 722 & 0.12 & 9.60 & {[48]} \\ \mathrm{H}_{2} \mathrm{TBrPP}^{\mathrm{c}} & 420 & 654 & 720 & 0.055 & - & {[23]} \\ \mathrm{H}_{2} \mathrm{TPBP}^{\mathrm{d}} & - & 652 & 719 & - & - & {[41]}\end{array}$

Tetracoordinated Magnesium(II) meso-arylmetalloporhyrins

$\begin{array}{lllllll}{[\mathrm{Mg}(\mathrm{TClPP})]} & 420 & 628 & 679 & 0.18 & 6.3 & \text { this work } \\ {[\mathrm{Mg}(\mathrm{TPP})]^{\mathrm{b}}} & - & 608 & 665 & 0.15 & 9.2 & {[49]} \\ {[\mathrm{Mg}(\mathrm{TPBP})]^{\mathrm{d}}} & - & 611 & 665 & - & - & {[23]} \\ {[\mathrm{Mg}(\mathrm{TClPP})]} & 420 & 615 & 670 & 0.18 & 6.3 & \text { this work }\end{array}$

Pentacoordinated and hexacoordinated Magnesium(II)meso-arylporphyrins

\begin{tabular}{|c|c|c|c|c|c|c|}
\hline$[\mathrm{Mg}(\mathrm{TClPP})(\mathrm{DMAP})]$ & 420 & 608 & 659 & 0.16 & 5.0 & this work \\
\hline$\left[\mathrm{Mg}(\mathrm{TPP})(\mathrm{THF})_{2}\right]^{\mathrm{b}}$ & - & & 660 & 0.16 & - & {$[50]$} \\
\hline$[\mathrm{Mg}(\mathrm{TPP})(\mathrm{NCO})]^{-\mathrm{b}}$ & 560 & 609 & 664 & 0.18 & 3.8 & [42] \\
\hline$[\mathrm{Mg}(\mathrm{TPP})(\mathrm{NCS})]^{-\mathrm{b}}$ & 560 & 608 & 662 & 0.19 & 6.1 & {$[42]$} \\
\hline$\left[\mathrm{Mg}(\mathrm{TPBP})(\mathrm{HTMA})_{2}\right]^{\mathrm{d}}$ & & 611 & 666 & 0.055 & - & [41] \\
\hline$[\mathrm{Mg}(\mathrm{TPBP})(\mathrm{DABCO})$ & & 612 & 666 & 0.065 & - & [41] \\
\hline$\left[\mathrm{Mg}(\mathrm{TPBP})\left(4,4^{\prime}-\mathrm{bpy}\right)_{2}\right]$ & & 611 & 665 & 0.060 & - & {$[51]$} \\
\hline
\end{tabular}

Pentacoordinated and hexacoordinated Zinc(II)meso-arylporphyrins

$\begin{array}{lllllll}{\left[\mathrm{Zn}(\mathrm{TPP})\left(\mathrm{N}_{3}\right)\right]^{-\mathrm{b}}} & 560 & 594 & 643 & 0.036 & 1.7 & {[\mathbf{5 2}]} \\ {[\mathrm{Zn}(\mathrm{TPP})(\mathrm{CN})]^{-\mathrm{b}}} & 560 & 594 & 643 & 0.055 & 1.7 & {[\mathbf{5 2}]} \\ {[\mathrm{Zn}(\mathrm{TPBP})(\mathrm{DABCO})]^{\mathrm{d}}} & 540 & 612 & 660 & 0.039 & 1.3 & {[\mathbf{5 3}]} \\ {\left[\mathrm{Zn}(\mathrm{TPBP})(\mathrm{pyz})_{2}\right]^{\mathrm{d}, \mathrm{i}}} & 540 & 596 & 644 & 0.049 & 1.6 & {[\mathbf{5 3}]} \\ {[\mathrm{Zn}(\mathrm{TPBP})(4-\mathrm{CNpy})]^{\mathrm{d}, \mathrm{j}}} & 540 & 596 & 645 & 0.041 & 1.5 & {[\mathbf{5 3}]}\end{array}$

\footnotetext{
${ }^{\mathrm{a}}: \mathrm{H}_{2} \mathrm{TMPP}=$ meso-tetra(para-methoxyphenyl)porphyrin, ${ }^{\mathrm{b}}: \mathrm{H}_{2} \mathrm{TPP}=$ meso-tetraphenylporphyrin, ${ }^{\mathrm{c}}: \mathrm{H}_{2} \mathrm{TBrPP}=$ mesotetrakis(4-bromophenyl)porphyrin, ${ }^{\mathrm{d}}: \mathrm{H}_{2} \mathrm{TPBP}=$ meso-tetrakis[4(benzoyloxy)phenyl]porphinato, ${ }^{\mathrm{e}}$ : HTMA = Hexamethylenetetramine, ${ }^{\mathrm{f}}:$ DABCO $=, 4$-diazabicyclo[2.2.2] octane, ${ }^{\mathrm{g}}:{ }^{\prime}$ 4,4'-bpy $=4,4^{\prime}$ '-bipyridine. ${ }^{\mathrm{i}}:$ pyz $=$ pyrazine, ${ }^{\mathrm{j}}$ : 4-CNpy = 4-cyanopyridine.
} 
Table 6. Selected bond lengths $[\AA]$ and angles $\left[{ }^{\circ}\right]$ for $[\mathrm{Mg}(\mathrm{TClPP})(\mathrm{DMAP})] \cdot 1 / 2 \mathrm{C}_{6} \mathrm{H}_{14}(\mathbf{I})$ and several related complexes.

Complex $\quad \mathrm{M}^{-} \mathrm{N}_{\mathrm{p}}{ }^{\mathrm{a}} \quad \mathrm{M}-\mathrm{X}_{\mathrm{L}}{ }^{\mathrm{b}} \quad \mathrm{M}-\mathrm{P}_{\mathrm{C}}{ }^{\mathrm{c}} \quad$ Ref.

\section{Pentacoodinayed Magnesium(II) Metalloporphyrins}

$\begin{array}{lllll}{[\mathrm{Mg}(\mathrm{TBrPP})(\mathrm{HIm})]^{\mathrm{d}, \mathrm{e}}} & 2.094(2) & 2.120(3) & 0.52 & {[\mathbf{2 3}]} \\ {\left[\mathrm{Bu} \mathrm{N}_{4} \mathrm{~N}\right]\left[\mathrm{Mg}(\mathrm{TPP})\left(\mathrm{HCO}_{3}\right)\right]^{\mathrm{f}}} & 2.101(3) & 1.959(2) & 0.478 & {[\mathbf{5 8}]} \\ {[\mathrm{K}(222)]\left[\mathrm{Mg}(\mathrm{TPP})\left(\mathrm{N}_{3}\right)\right]^{\mathrm{fg}}} & 2.1187(16) & 1.997(2) & 0.6629(7) & {[42]} \\ {[\mathrm{K}(222)][\mathrm{Mg}(\mathrm{TPP})(\mathrm{NCS})]^{\mathrm{f}, \mathrm{g}}} & 2.0962(13) & 2.0817(15) & 0.5797(6) & {[42]} \\ {\left[\mathrm{Mg}(\mathrm{TPP})\left(\mathrm{H}_{2} \mathrm{O}\right)\right]^{\mathrm{f}}} & 2.092(7) & 2.012(6) & 0.460 & {[\mathbf{5 4}]} \\ {[\mathrm{Mg}(\mathrm{TClPP})(\mathrm{DMAP})]} & 2.082(3) & 2.130(4) & 0.3709(14) & \text { this work }\end{array}$

Hexacoordinnated Magnesium(II) Metalloporphyrins

$\begin{array}{lllll}{\left[\mathrm{Mg}(\mathrm{TPP})(4-\text { picoline}-\mathrm{N})_{2}\right]^{\mathrm{f}, \mathrm{i}}} & 2.070 & 2.385 & 0.000 & 0.000 \\ \left\{\left[\mathrm{Mg}(\mathrm{TPBP})\left(4,4^{\prime}-\text {-bpy }\right)_{2}\right]\right\}_{\mathrm{n}}^{\mathrm{j}, \mathrm{k}} & 2.066 & 2.320 & 0.000 & {[51]} \\ {\left[\mathrm{Mg}(\mathrm{TBrPP})\left(\mathrm{H}_{2} \mathrm{O}\right)_{2}\right]^{\mathrm{j}}} & 2.069 & 2.221 & 0.000 & {[59]} \\ {\left[\mathrm{Mg}(\mathrm{TPP})\left(\mathrm{H}_{2} \mathrm{O}\right)_{2}\right]^{\mathrm{f}}} & 2.071 & 2.213 & 0.000 & {[55]} \\ {\left[\mathrm{Mg}(\mathrm{TPP})(\mathrm{HTMA})_{2}\right]^{\mathrm{f}, \mathrm{m}}} & 2.067(5) & 2.473(2) & 0.000 & {[60]} \\ {\left[\mathrm{Mg}(\mathrm{TPP})(1-\mathrm{MeIm})_{2}\right]^{\mathrm{f}, \mathrm{n}}} & 2.079 & 2.297 & 0.000 & {[61]} \\ {\left[\mathrm{Mg}(\mathrm{TPP})(\text { pipz })_{2}\right]^{\mathrm{f}, \mathrm{o}}} & 2.073 & 2.423 & 0.000 & {[61]} \\ {\left[\mathrm{Mg}(\mathrm{TPP})(\mathrm{py})_{2}\right]^{\mathrm{f}, \mathrm{p}}} & 2.072 & 2.376 & 0.000 & {[62]} \\ {\left[\mathrm{Mg}(\mathrm{TPBP})(\mathrm{HTMA})_{2}\right]^{\mathrm{j}, \mathrm{m}}} & 2.074 & 2.439 & 0.000 & {[24]} \\ {\left[\mathrm{Mg}(\mathrm{TPBP})(\mathrm{DABCO})_{2}\right]^{\mathrm{j}, \mathrm{r}}} & 2.066 & 2.487 & {[63]}\end{array}$

DMAP-Mg(II) non-porphyrinic complexes

\begin{tabular}{|c|c|c|c|}
\hline$\left[\mathrm{Mg}(\mathrm{DMAP})_{2}\left(\mathrm{~L}_{1}\right)_{2}\right]^{\mathrm{s}}$ & $2.156(1) / 2.154(2)$ & - & [64] \\
\hline $\left.\operatorname{Mg}(\mathrm{I})(\mathrm{DMAP})\left(\mathrm{L}_{2}\right)\right]^{\mathrm{t}}$ & $2.112(3)$ & - & [65] \\
\hline$\left[\mathrm{Mg}(\mathrm{DMAP})\left(\mathrm{L}_{3}\right)\left(\mathrm{L}_{4}\right)\right]^{\mathrm{u}, \mathrm{V}}$ & 2.096 & - & [66] \\
\hline$\left[\operatorname{Mg}(\mathrm{DMAP})\left(\mathrm{L}_{5}\right)\left(\mathrm{L}_{6}\right)\right]^{x, y}$ & 2.142 & - & [67] \\
\hline
\end{tabular}

\footnotetext{
${ }^{\mathrm{a}}: \mathrm{M}-\mathrm{Np}=$ average equatorial cobalt-nitrogen pyrrole distance, ${ }^{\mathrm{b}}: \mathrm{M}-\mathrm{X}_{\mathrm{L}}=$ metal-axial ligand distance, ${ }^{c}: \mathrm{M}-\mathrm{P}_{\mathrm{C}}=$ distance between the metal atom and the mean plane made by the 24 -atom core of the porphyrin $\left(\mathrm{P}_{\mathrm{C}}\right)$. . $: \mathrm{TBrPP}=$ meso-tetrakis(4-bromophenyl)porphyrinato, e: Him = imidazole, ${ }^{\mathrm{f}}:$ meso-tetraphenylporphyrin, ${ }^{\mathrm{g}}$ : $[\mathrm{K}(222)]^{+}=$ (cryptand-222)potassium $(+)$ cation, ${ }^{\mathrm{i}}:$ 4-picoline $=4$-Methylpyridine, ${ }^{\mathrm{j}}:$ TPBP $=$ meso-\{tetrakis-[4(benzoyloxy)phenyl]porphyrinato, ${ }^{\mathrm{m}}:$ HTMA $=$ hexamethylenetetramine, ${ }^{\mathrm{n}}: 1$-MeIm $=1$-methylimidazole, ${ }^{\circ}:$ pipz $=$ piperazine, ${ }^{\mathrm{p}}:$ py $=$ pyridine, ${ }^{\mathrm{r}}: \mathrm{DABCO}=4$-diazabicyclo[2.2.2] octane $^{\mathrm{s}}: \mathrm{L}_{1}=$ Isopropyl(trimethylsilyl)amido, ${ }^{\mathrm{t}}: \mathrm{L}_{2}=$ N,N'-bis(2,6-Di-isopropylphenyl)-2,2,6,6-tetramethylheptane-3,5-di-iminato- $\mathrm{N}, \mathrm{N}^{\prime},{ }^{\prime}: \mathrm{L}_{3}=$ Benzophenone radical-O, ${ }^{\mathrm{v}}$ : $\mathrm{L}_{4}=\mathrm{N}, \mathrm{N}$-bis(2,6-di-isopropylphenyl)-2,4-diiminopropane, ${ }^{\mathrm{x}}: \mathrm{L}_{5}=$ (4,4,5,5-tetramethyl-1,3,2-dioxborolan-2yl)diphenylmethoxy, ${ }^{\mathrm{y}}: \mathrm{L}_{6}=\mathrm{N}, \mathrm{N}^{\prime}$-bis(2,6-di-isopropylphenyl)pentane-2,4-di-iminato.
} 
Table 7. Maximum force, RMS force, RMS Gradient Norm and point group of [Mg(TCPP)(DMAP)] calculated at B3LYP/ LanL2DZ levels of theory.

B3LYP / LanL2DZ

Parameters

Gaz Chloroform

$\begin{array}{lll}\text { Energy (a.u.) } & -2353.9201 & -2353.9355 \\ \text { Dipole moment (Debye) } & 9.0341 & 10.7891 \\ \text { Maximum force } & 0.1680 & 0.1680 \\ \text { RMS force } & 0.0734 & 0.0733 \\ \text { RMS Gradient Norm (a.u.) } & 3.01 .10^{-6} & 1.75 .10^{-6} \\ \text { Point group } & \mathrm{C}_{1} & \mathrm{C}_{1}\end{array}$

Table 8. Difference of energies between the frontier molecular orbital, the chemical potential, the global hardness, the softness and the electrophilicity in the gas phase of complex (I).

\begin{tabular}{ll}
\hline DET / B3LYP / Lan2DZ & Gas phase \\
\hline $\mathrm{E}_{\mathrm{HOMO}}(\mathrm{eV})$ & -5.101 \\
$\mathrm{E}_{\mathrm{LUMO}}(\mathrm{eV})$ & -2.500 \\
$\left.\Delta \mathrm{E}\left[\mathrm{E}_{\mathrm{HOMO}}-\mathrm{E}_{\mathrm{LUMO}}\right)\right]:$ E-Gap $(\mathrm{eV})$ & 2.601 \\
$I$ (ionization potential) $(\mathrm{eV})$ & 5.101 \\
$A$ (electron affinity) $(\mathrm{eV})$ & 2.500 \\
Chemical potential $\mu(\mathrm{eV})$ & -3.800 \\
Global hardness $\eta(\mathrm{eV})$ & 1.300 \\
Softness $S(\mathrm{eV})^{-1}$ & 0.384 \\
Electrophilicity $\psi(\mathrm{eV})$ & 5.553 \\
\hline
\end{tabular}


Table 9. Cyclic voltammetry data ${ }^{a}$ for complex (I) and a selection of meso-arylphenylporphyrin species.

\begin{tabular}{|c|c|c|c|c|c|}
\hline \multirow[t]{3}{*}{ Compound } & \multicolumn{3}{|c|}{ Ring oxidation } & \multirow{2}{*}{$\begin{array}{l}\text { Ring reduction } \\
- \text { First Red. } \\
(\mathrm{R} 4, \mathrm{O} 4)\end{array}$} & Ref. \\
\hline & $\begin{array}{l}\text { First Oxid. } \\
(\mathrm{O} 1, \mathrm{R} 1)\end{array}$ & $\begin{array}{l}\text { Second Oxid. } \\
(\mathrm{O} 2, \mathrm{R} 2)\end{array}$ & $\begin{array}{l}\text { Third oxid. } \\
(\mathrm{O} 3, \mathrm{R} 3)\end{array}$ & & \\
\hline & $\mathrm{E}_{1 / 2}^{\mathrm{b}}$ & $E_{1 / 2}$ & $\mathrm{E}_{1 / 2}$ & $\mathrm{E}_{1 / 2}$ & \\
\hline
\end{tabular}

Meso-arylporphyrins

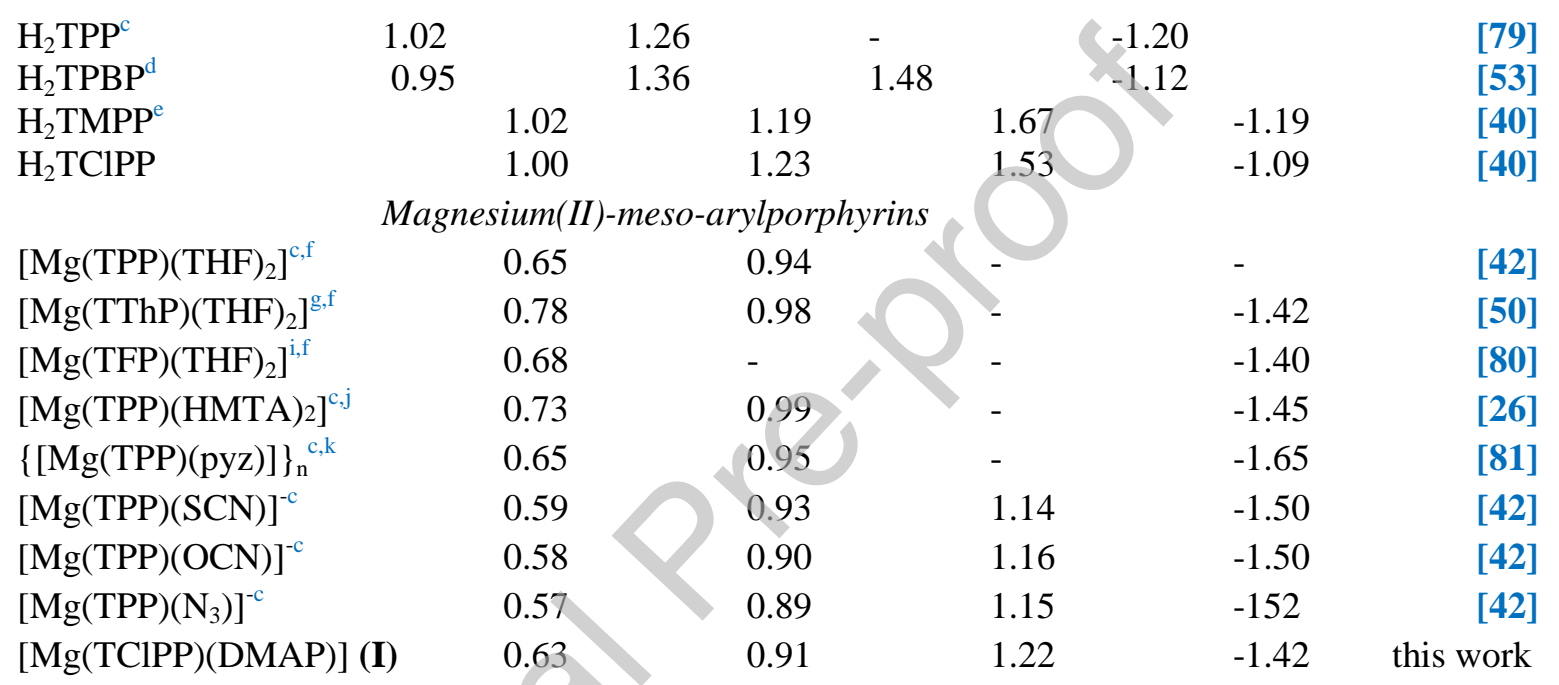

Zinc(II)-meso-arylporphyrins

\begin{tabular}{|c|c|c|c|c|c|}
\hline$\left[\mathrm{Zn}(\mathrm{TPP})\left(\mathrm{N}_{3}\right)\right]^{-\mathrm{c}}$ & 0.71 & 1.15 & 1.40 & -1.53 & [52] \\
\hline$[\mathrm{Zn}(\mathrm{TPBP})(\mathrm{DABCO})]^{\mathrm{d}, \mathrm{l}}$ & 0.84 & 1.12 & - & -1.33 & [53] \\
\hline$[\mathrm{Zn}(\mathrm{TPBP})(\mathrm{pyz})]^{\mathrm{d}, \mathrm{k}}$ & 0.82 & 1.12 & 1.38 & -1.34 & [53] \\
\hline$\left[\mathrm{Zn}(\mathrm{TPBP})\left(4,4{ }^{\prime} \text {-diam }\right)\right]^{\mathrm{d}}$ & 0.81 & 1.28 & - & -1.31 & [53] \\
\hline$[\mathrm{Zn}(\mathrm{TPBP})(4-\mathrm{CNpy})]^{\mathrm{d}, \mathrm{n}}$ & 0.81 & 1.10 & 1.36 & -1.52 & [53] \\
\hline & II)-me & rphyri & & & \\
\hline$\left[\mathrm{Co}^{\mathrm{II}}(\mathrm{TMPP})(4-\mathrm{CNpy}]^{\mathrm{e}, \mathrm{n}}\right.$ & 0.89 & 1.25 & - & -1.43 & [40] \\
\hline$\left[\mathrm{Co}^{\mathrm{II}}(\mathrm{TClPP})(4-\mathrm{CNpy})\right]^{\mathrm{n}}$ & 1.13 & 1.31 & - & -1.32 & [40] \\
\hline$\left[\mathrm{Co}^{\mathrm{II}}(\mathrm{TMPP})(\mathrm{HMTA})\right]^{\mathrm{e}, \mathrm{j}}$ & 0.91 & 1.21 & - & -1.44 & [82] \\
\hline
\end{tabular}

${ }^{\mathrm{a}}$ : Potentials reported versus SCE, ${ }^{\mathrm{b}}: \mathrm{E}_{1 / 2}=$ half wave potential, ${ }^{\mathrm{c}}: \mathrm{H}_{2} \mathrm{TPP}=$ meso-tetraphenylporphyrin, ${ }^{\mathrm{d}}$ : $\mathrm{H}_{2} \mathrm{TPBP}=$ meso-tetrakis[4(benzoyloxy)phenyl]porphyrin, ${ }^{\mathrm{e}}: \mathrm{H}_{2} \mathrm{TMPP}=$ meso-tetra $($ para -

methoxyphenyl)porphyrin, ${ }^{\mathrm{f}}: \mathrm{THF}=$ tetrahydrofuran, ${ }_{\mathrm{g}}^{\mathrm{g}}: \mathrm{TThP}=$ meso-thienylporphyrin, ${ }^{\mathrm{i}}: \mathrm{TFP}=$ mesofurylporphyrin, ${ }^{\mathrm{j}}:$ HTMA $=$ Hexamethylenetetramine, ${ }^{\mathrm{k}}:$ pyz $=$ pyrazine, ${ }^{1}:$ DABCO $=, 4-$ diazabicyclo[2.2.2] octane, ${ }^{\mathrm{m}}: 4,4^{\prime}$-mda $=4,4^{\prime}$-diaminodiphenylmethane, ${ }^{\mathrm{n}}:$ 4-CNpy $=4$-cyanopyridine. 